\title{
Hydrographic, Biological, and Nutrient Properties of Tomales Bay, California, March 1985 to May 1986
}

By Brian E. Cole, and Stephen W. Hager

U.S. Geological Survey

and

James T. Hollibaugh

California State University at San Francisco

U.S. GEOLOGICAL SURVEY

Open-File Report 90-178

Menlo Park, California

1990 


\section{DEPARTMENT OF THE INTERIOR \\ MANUEL LUJAN, JR., Secretary \\ U.S. GEOLOGICAL SURVEY}

Dallas L. Peck, Director

For additional information write to: Copies of this report can be purchased from:

James P. Bennett

Chief, Branch of Regional Research

U.S. Geological Survey

345 Middlefield Rd.

Menlo Park, CA 94025
U.S. Geological Survey Books and Open-File Reports Section Federal Center, Bldg. 810

Box 25425

Denver, Colorado 80225 
CONTENTS

Abstract

Introduction

2

Methods

References cited

\section{FIGURES}

Figure 1. Map of Tomales Bay showing station locations......

\section{TABLES}

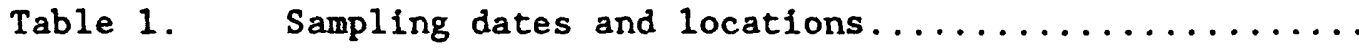

Table 2. Salinometer calibration parameters............ 14

\section{APPENDIXES}

Appendix A. Hydrographic and Nutrient Data for Tomales Bay....

Appendix B. Hydrographic and Nutrient Data for Walker and

Lagunitas Creeks..................... 40

Appendix C. Phytoplankton Productivity Data............. 43

Appendix D. Phytoplankton Identifications and Enumerations.... 72

Appendix E. Bacterioplankton Abundance and Productivity...... 86 
Conversion Factors.

The following conversion factors may be used to convert from International System (SI) units used in this report to inch-pound terms:

Multiply

kilometer $(\mathrm{km})$

meter (m)

liter (L)

microgram $(\mu g)$

milligram (mg)

degree Celsius $\left({ }^{\circ} \mathrm{C}\right)$
By

0.6214

3.281

1.057

$2.2 \times 10^{9}$

$2.2 \times 10^{-6}$

$\left(1.8 \times{ }^{\circ} \mathrm{C}\right)+32$
To obtain

mile (mi)

feet $(f t)$

quart (qt)

pound, avolrdupois (lb)

pound, avoirdupois (1b)

degree Fahrenheit $\left({ }^{\circ} \mathrm{F}\right)$ 
HYDROGRAPHIC, BIOLOGICAL, AND NUTRIENT PROPERTIES OF

TOMALES BAY, CALIFORNIA - MARCH 1985 TO MAY 1986

By Brian E. Cole, Stephen W. Hager, and James T. Hollibaugh

\section{ABSTRACT}

This report summarizes hydrographic, biological, and nutrient data collected from Tomales Bay, California, between March 1985 and May 1986. Spatial distributions are given for salinity, temperature, chlorophyll-ä, phaeopigments, light attenuation coefficients, suspended particulate matter, dissolved nutrients, (nitrite, nitrate + nitrite, dissolved reactive phosphate, dissolved silica, ammonium), total dissolved nitrogen and phosphorus, and particulate nitrogen and carbon. The data were typically collected at monthly intervals at 10 stations located along the longitudinal axis of Tomales Bay. Also reported are: (1) nutrient data for Walker and Lagunitas Creeks; (2) the results of 28 experiments measuring rates of carbon uptake at selected sites in Tomales Bay; (3) enumeration data for phytoplankton samples collected concurrently with samples for carbon uptake; (4) bacteria and blue-green algae densities; and (5) rates of bacterial uptake of thymidine at selected sites and times over the course of the study. 


\section{INTRODUCTION}

This report is a compilation of data collected from Tomales Bay, a coastal embayment in California, during 20 sampling cruises between March 1985 and May 1986. Specific sampling sites and dates are listed in table 1. Data were collected to (1) document temporal and spatial changes in the physical, biological, and nutrient conditions of Tomales Bay and its major sources of freshwater; (2) measure spatial and seasonal variations in the rate of carbon uptake by phytoplankton; (3) determine the composition of the phytoplankton community at the time of carbon uptake experiments; and (4) determine the abundance of bacteria and blue-green algae and the rates of thymidine uptake as a measure of bacteria growth rates.

Salinity and temperature were measured at one meter intervals at each sampling site to estimate variations in water column stability.

Chlorophyll-ä, phaeopigment, and nutrient $\left(\mathrm{NO}_{2}^{-}, \mathrm{NO}_{3}^{-}+\mathrm{NO}_{2}^{-}, \mathrm{NH}_{4}^{+}, \mathrm{PO}_{4}^{-3}\right.$, and $\mathrm{SiO}_{2}$ ) data were collected at 2 kilometer intervals to characterize spatial variations within the system. Measurements of carbon uptake were made periodically on samples collected at a site in each of the three major hydrographic regions (E.H. Smith and others, 1971; S.V. Smith and others, 1987) of Tomales Bay to determine the seasonal and temporal range of primary productivity by phytoplankton. Phytoplankton samples were collected and preserved at each site where carbon uptake experiments were conducted to characterize the composition of the phytoplankton community at the time of the incubation experiments. 
Samples also were collected at selected stations to characterize the abundance and growth rate of bacterioplankton. Autofluorescing cells (cyanobacteria) were enumerated in a few samples at stations selected to represent each of the three major hydrographic regions of Tomales Bay (fig. 1). Most of the bacteria samples were from surface waters, but near-bottom samples were collected regularly at stations representative of the deeper, central parts of the bay.

Nutrient samples were routinely collected on Walker and Lagunitas Creeks to determine nutrient levels in the principal sources of freshwater flowing into Tomales Bay.

METHODS

Sampling positions are shown in figure 1. Stations are identified by numbers that are equal to their distance (in kilometers) from the mouth of Tomales Bay. The data were collected from a drifting boat at sites located in the deeper regions along the longitudinal axis of the bay. Occasionally samples were collected near the shore at sites east and west of the channel stations. These lateral stations are identified in the data tables by an $E$ (east) or $W$ (west) following the station number. Sampling locations were based on land sitings.

Salinity and temperature were measured with a Beckman ${ }^{1}$ portable conductivity-temperature meter. The salinity calibration of the

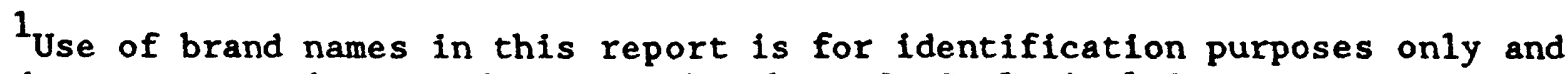
does not constitute endorsement by the U.S. Geological Survey. 
instrument was frequently checked with discrete salinity samples collected at the water's surface coincidental to surface readings with the portable conductivity-temperature meter. These bottled salinity samples were returned to the laboratory for analysis with a high precision $( \pm 0.003)$ Beckman salinometer. The salinities reported in Appendix $A$ and $B$ were calculated from linear regressions of the discrete salinity samples against the readings of the field instrument. Calibration coefficients for the field salinometer are given in table 2. Light attenuation (water clarity) was measured at each station with a Secchi disk. The depth of disappearance of the Secchi disk was related to the light extinction coefficient by the equation:

extinction coefficient $\left(\mathrm{m}^{-1}\right)=0.4+109 / \operatorname{Secchi} \operatorname{depth}(\mathrm{cm})$

derived from light attenuation and Secchi depth data collected in San Francisco Bay (unpublished data).

Samples for all other properties were collected with handheld bottles dipped into the surface water or with a Kemmerer water sampling bottle lowered to depth. Samples for chlorophyll-a and phaeopigments were collected at the surface and bottom depth at each station. The samples were held in the dark for 2-6 hours; filtered at less than $130 \mathrm{~mm} \mathrm{Hg}$ vacuum through a Gelman glass fiber filter; then stored frozen until analyzed. The filters were ground in 90 percent acetone. After extraction for 12 to 24 hours at $-10^{\circ} \mathrm{C}$, samples were centrifuged and absorbances read on a Varian 635D spectrophotometer. Samples were acidified (Riemann, 1979) to measure 
to measure phaeopigments. Chlorophyll-a and phaeopigment values were calculated using Lorenzen's (1967) equations.

Nutrient samples were collected from the surface water directly into doubly rinsed $2 \mathrm{~L}$ high-density polyethylene bottles cleaned with acetone. Care was taken not to sample the surface microlayer. Samples were placed immediately into an opaque cooler in contact with ice. On arrival at the laboratory ( 2 to 7 hours later), the samples were rapidly cooled to just above freezing, and held at that temperature untll processing was complete.

For dissolved nutrients, aliquots were filtered through $47 \mathrm{~mm}, 0.4 \mu \mathrm{m}$ pore size Nuclepore filters at less than $130 \mathrm{~mm} \mathrm{Hg}$ vacuum. After two rinses, filtrate was placed in $30 \mathrm{~mL}$ linear polyethylene bottles previously soaked with $2.5 \mathrm{meq} / \mathrm{L} \mathrm{NaHCO}_{3}$ solution. Samples were frozen $\left(-20^{\circ} \mathrm{C}\right)$ until analyzed. Prior to analysis, the samples were allowed to thaw for at least 15 hours, and were well shaken.

For total dissolved nutrients, sample water was filtered by gravity through $47 \mathrm{~mm}$ Gelman GF/AE filters, previously combusted for 4 hours at $450{ }^{\circ} \mathrm{C}$. Duplicate filtrations were performed, and the filtrates placed into $120 \mathrm{~mL}$ quartz irradiation tubes. They were digested with hydrogen peroxide and ultra-violet light (Hager and Harmon, 1984). Total dissolved nitrogen is called DNU and total dissolved phosphorus DPU; the ' $U$ ' indicating the ultra-violet method.

Dissolved and total dissolved nutrients were analyzed on a Technicon Autoanalyzer II system, with all manifolds maintained at $37^{\circ} \mathrm{C}$. Dissolved nitrate plus nitrite and DNU were analyzed using a modification of Technicon method AII 100-70W (Technicon, 1973). The $\mathrm{pH}$ of the ammonium chloride 
reagent was not adjusted, and $6 \mathrm{mg} / \mathrm{L} \mathrm{CuSO}{ }_{4}: 5 \mathrm{H}_{2} \mathrm{O}$ was added to it (Connors and Beland, 1976). The cadmium column preparation followed Wood and others (1967). Dissolved nitrite was measured using the same chemistry, but bypassing the cadmium reducing column.

Dissolved ammonium was measured using an automated method based on the method of Solorzano (1969). Color development was at $37^{\circ} \mathrm{C}$.

Dissolved phosphate and total dissolved phosphorus were measured with a modification of the method of Atlas and others (1971), using ascorbic acid (70 $\mathrm{g} / \mathrm{L}$ with $50 \mathrm{~mL}$ acetone/L) as reductant.

Dissolved silica was measured with an adaptation of Technicon method AII 105-71W (Technicon, 1976). The sample tube delivery rate was halved to give linear response to $320 \mu \mathrm{M}$.

For particulate carbon and nitrogen (PCC and PNC; $C$ for the combustion method), water was filtered at less than $130 \mathrm{~mm} \mathrm{Hg}$ through $13 \mathrm{~mm} \mathrm{GF} / \mathrm{AE}$ Gelman glass fiber filters, previously combusted at $450^{\circ} \mathrm{C}$ for four hours. Filters were folded and placed in nickel capsules that had previously been heated to $450^{\circ} \mathrm{C}$. These were placed into loosely capped, combusted glass vials, and into a dessicator over magnesium perchlorate for at least two weeks prior to analysis. Analysis was with a Perkin-Elmer 240C Elemental Analyzer. Acetanilide was used as a standard and unused filters as blanks. Suspended particulate material was filtered onto preweighed $47 \mathrm{~mm}, 0.4$ $\mu \mathrm{m}$ pore size Nuclepore filters. Filters were air dried and reweighed to \pm $0.1 \mathrm{mg}$. An empirical correction $(0.023 \mathrm{mg} /$ filter per ppt. salinity) was used to correct for the weight of salt crystals on the filter. 
Phytoplankton productivity samples were collected from surface waters, then held in the dark until returned to shore. To test for nitrogen limitation, some samples were amended with $\mathrm{NH}_{4} \mathrm{Cl}$ (40 $\mu \mathrm{g}$-at in a $2 \mathrm{~L}$ bottle) immediately after collection. After inoculation with carbon-14 (5 $\mu \mathrm{Ci}$ in a $150 \mathrm{~mL}$ bottle), $24 \mathrm{~h}$ incubations were done in incubation racks floating at the water's surface along the shore. Samples were exposed to natural sunlight of 8 intensities: $100,55,30,15,8,3,1$, and 0 percent of ambient irradiance. Light exposure was varied by placing the bottles in nickel screen tubes of different mesh. Following incubation, $3 \mathrm{~mL}$ subsamples were removed from each bottle and placed in a scintillation vial. After adding $0.1 \mathrm{~mL}$ of $0.2 \mathrm{~N} \mathrm{HCl}$, each aliquot was shaken for 30 minutes while ${ }^{14} \mathrm{CO}_{2}$ was stripped from the sample. The residual activity of the sample was measured using a liquid scintillation spectrometer. Actual carbon uptake rates and dark bottle corrected rates are listed in Appendix C. Assimilation number is the dark bottle corrected uptake rate normalized by the initial chlorophyll-a concentration. Estimates of photic zone and water column depth integrated production were made by trapezoidal quadrature. When the calculated photic depth exceeded the water depth (that 1s, light penetrated to the bottom sediments), estimates of integrated productivity over the photic zone exceeded estimates of carbon uptake over the water depth. None of the carbon uptake data have been adjusted to account for respiration by the phytoplankton.

Samples for phytoplankton identification and enumeration (Appendix D) were collected at selected sites and preserved with Lugol's preservative. 
Each enumeration sample was counted at $120 \mathrm{X}$ after filling a 1 -mL SedgewickRafter chamber. Identification and enumeration of samples was delayed until March 1987. The phytoplankton identifications and enumerations were done by Dr. Deneb Karentz.

Water samples for bacterioplankton (Appendix E) were collected in opaque, $500 \mathrm{~mL}$ polyethylene bottles. The samples were stored in an insulated chest until processed on shore.

Bacterial abundance was determined by epifluorescence microscopy. The sample was mixed gently, then a $100 \mathrm{~mL}$ subsample was poured into an acid cleaned, sample-rinsed bottle and preserved with 2 percent (final concentration) borate-buffered formaldehyde. This subsample was stored in a refrigerator for up to two weeks before counting. A $2.00 \mathrm{~mL}$ subsample was collected on a $0.2 \mu \mathrm{m}$ pore size Nuclepore filter, stained with Acridine Orange and counted following the protocol given by Hobbie and others (1977). Ten fields on one slide were counted for each sample (a minimum of 400 cells). Autofluorescing particles were enumerated by collecting a $10 \mathrm{~mL}$ subsample on a $0.2 \mu \mathrm{m}$ pore size Nuclepore filter, then counting the unstained sample using the FITC filter set. Ten fields were counted. However, usually fewer than 100 cells were observed.

Bacterioplankton population growth rate was estimated from the rate at which methyl- $\left[{ }^{3} \mathrm{H}\right]$-thymidine $\left({ }^{3} \mathrm{H}-\mathrm{TdR}\right)$ was incorporated into material soluble in chilled 5 percent trichloroacetic acid (TCA). The protocol used is essentially that of Fuhrman and Azam (1982). Five $5 \mathrm{~mL}$ subsamples were drawn from sample bottles and placed in polystyrene test tubes. Duplicate control samples were fixed immediately with 2 percent formaldehyde. After 
15-30 minutes, $1 \mu \mathrm{Ci}$ of a $20 \mu \mathrm{Ci} / \mathrm{nmole}^{3} \mathrm{H}$-TdR stock (New England Nuclear) was added to each tube (final concentration of added $T d R=10 \mathrm{nM}$ ). The samples were incubated in a water bath maintained in the range of temperatures encountered on a particular sampling date. The incubation was terminated after 0.5 to $1.5 \mathrm{hrs}$ either by adding $5.0 \mathrm{~mL}$ of chilled 10 percent TCA to each sample or by filtering the samples through a $0.45 \mu \mathrm{m}$ pore size membrane filter, then rinsing with chilled 5 percent TCA. Comparison revealed no difference in extraction efficiency between methods. Occasionally, a second set of samples was extracted for $1 \mathrm{hr}$ in hot 5 percent TCA $\left(95-100{ }^{\circ} \mathrm{C}\right)$ to verify that ${ }^{3} \mathrm{H}-\mathrm{TdR}$ was not being metabolized to protein by bacterioplankton. Samples extracted in test tubes were collected on $0.45 \mu \mathrm{m}$ pore size membrane filters and rinsed with chilled 5 percent TCA. Membrane filters were placed in scintillation vials, air dried, dissolved in ethyl acetate, then radioassayed by liquid scintillation spectrometry. 


\section{REFERENCES CITED}

Atlas, E.L., Hager, S.W., Gordon, L.I., and Park, P.K., 1971, A practical manual for use of the Technicon AutoAnalyzer in seawater nutrient analyses, revised: Department of Oceanography, Oregon State University, Ref. 71-22.

Connors, J.J., and Beland, J., 1976, Analytical notes: Journal American Water Works Association, v. 68, p. 55-56.

Fuhrman, J.A., and Azam, F., 1982, Thymidine incorporation as a measure of heterotrophic bacterial production in marine surface waters:

evaluation and field results: Marine Biology, v. 66, p. 109-120.

Hager, S.W., and Harmon, D.D., 1984, Chemical determination of particulate nitrogen in San Francisco Bay. A comparison of two estimates: Estuarine Coastal and Shelf Science, v. 19, p. 181-191.

Hobbie, J.E., Daley, R. J., and Jasper, S., 1977, Use of Nuclepore filters for counting bacteria by fluorescence microscopy: Applied Environmental Microbiology, v. 33, p. 1225-1228.

Lorenzen, C.J., 1967, Determination of chlorophyll and pheopigments: Spectrophotometric equations: Limnology and Oceanography, v. 12, p. 343-346.

Riemann, B., 1979, Carotenoid interference in spectrophotometric determination of chlorophyll degradation products from natural populations of phytoplankton: Limnology and Oceanography, v. 23, p. 1059-1066.

Smith, E.H., Johnson, R.G., and Obrebski, S., 1971, Physical, chemical, microbiological and hydrographic characteristics of Tomales Bay: University of the Pacific, Stockton, California, Pacific Marine Station Research Report Number 9, 70 pp.

Smith, S.V., Wiebe, W.J., Hollibaugh, J.T., Dollar, S.J., Hager, S.W., Cole, B.E., Tribble, G.W., and Wheeler, P.A., 1987, Stoichiometry of $C, N, P$, and $S i$ fluxes in a temperate-climate embayment: Journal of Marine Research, v. 5, p. 427-460.

Solorzano, L., 1969, Determination of ammonium in natural waters by the phenolhypochlorite method: Limnology Oceanography, v. 14, p. $799-801$.

Technicon Instruments Corporation, 1973, Nitrate and nitrite in water and wastewater: Technicon AutoAnalyzer II, Industrial Method No. 100-70w. 
Technicon Instruments Corporation, 1976, Silicates in water and wastewater: Technicon AutoAnalyzer II, Industrial Method No. 105-71W.

Wood, E.D., Armstrong, F.A.J., and Richards, F.A., 1967, Determination of nitrate in seawater by cadmium copper reduction to nitrite: Journal of the Marine Biological Association of the United Kingdon, v. 47, p. 23-31. 


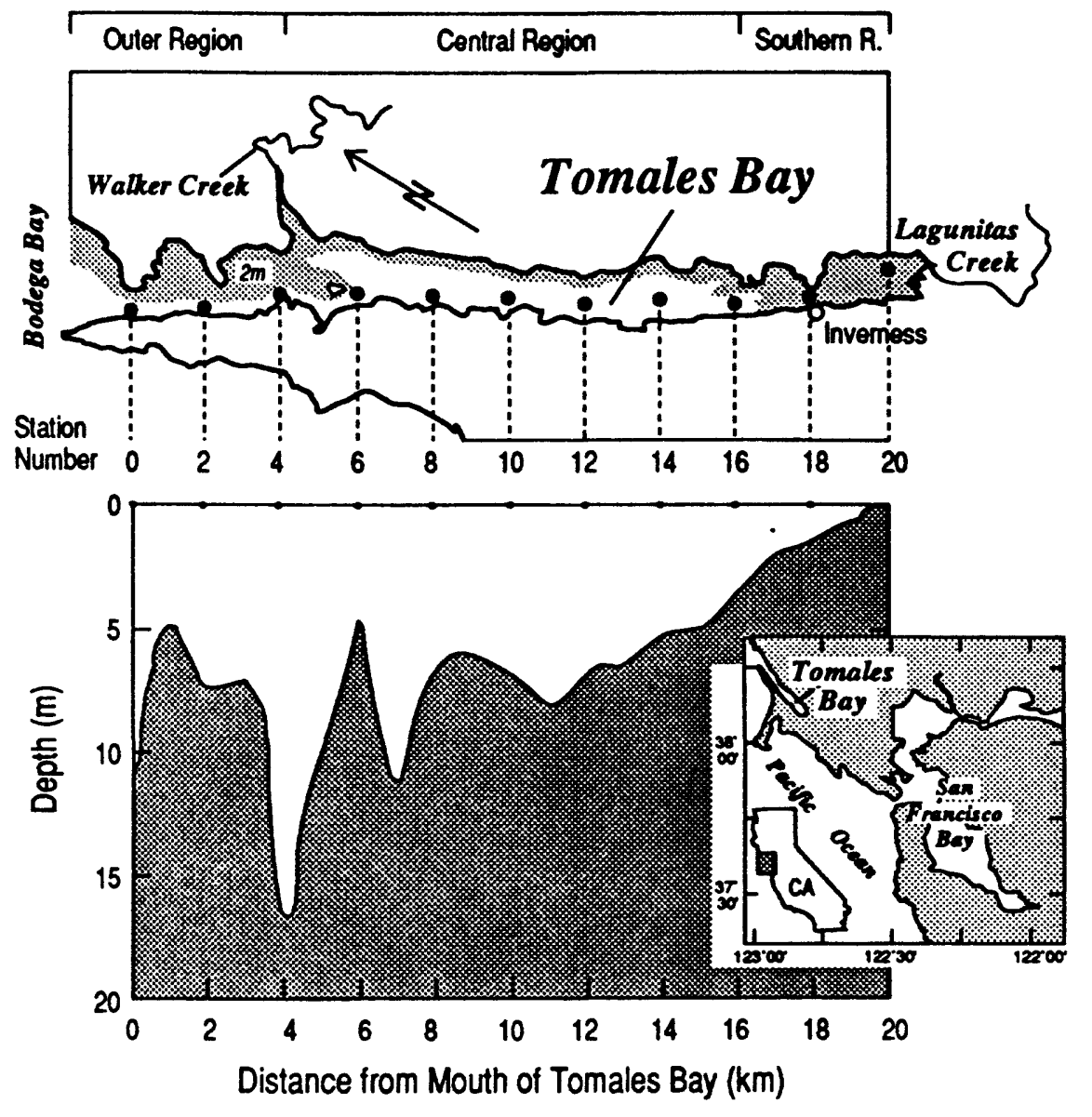

Figure 1. (a) Map of Tomales Bay, California, and environs showing locations of sampling sites. The station numbers reflect the distance, in kilometers, of the sampling site from the mouth of the bay. Shaded portions: areas where water depth (MLLW) are less than $2 \mathrm{~m}$. (b) Longitudinal cross section of the bay showing water depths at the sampling sites. 
Table 1. Sampling dates and locations for hydrographic (HYDRO) and nutrient (NUTR) data; and dates when measurements were made of phytoplankton productivity and cell density (PHYTO PROD), bacterial productivity (BACTER PROD), and bacterial abundance (BACTER ABUND).

\begin{tabular}{|c|c|c|c|c|c|c|}
\hline DATE & STATIONS & $\begin{array}{l}\text { HYDRO } \\
\text { DATA }\end{array}$ & $\begin{array}{l}\text { NUTR } \\
\text { DATA }\end{array}$ & $\begin{array}{l}\text { PHYTO } \\
\text { PROD }\end{array}$ & $\begin{array}{l}\text { BACTER } \\
\text { PROD }\end{array}$ & $\begin{array}{l}\text { BACTER } \\
\text { ABUND }\end{array}$ \\
\hline $\operatorname{Mar} 11,1985$ & $0-18$ & $\mathrm{x}$ & $\mathrm{X}$ & & $\mathrm{X}$ & $\mathrm{X}$ \\
\hline Mar 27 & $0-18$ & $\mathrm{x}$ & & & $\mathrm{x}$ & $\mathrm{x}$ \\
\hline Apr 8 & $0-18$ & $\mathrm{X}$ & $\mathrm{X}$ & & $\mathrm{X}$ & $\mathrm{X}$ \\
\hline Apr 17 & $0-20$ & $\mathrm{X}$ & $\mathrm{X}$ & $\mathrm{X}$ & $\mathrm{X}$ & \\
\hline May 17 & $0-16$ & $\mathrm{X}$ & $\mathrm{x}$ & & $\mathrm{X}$ & $\mathbf{X}$ \\
\hline June 11 & $0-18$ & $\mathrm{X}$ & $\mathrm{x}$ & $\mathrm{x}$ & $\mathrm{X}$ & \\
\hline July 16 & $0-18$ & $\mathrm{X}$ & $\mathrm{X}$ & & $\mathrm{X}$ & \\
\hline Aug 21 & $0-18$ & $\mathrm{x}$ & $\mathrm{x}$ & $\mathrm{x}$ & $\mathrm{x}$ & \\
\hline Sept 30 & $0-18$ & $\mathbf{x}$ & $\mathrm{x}$ & $\mathrm{X}$ & & \\
\hline Oct 3 & $0-18$ & $\mathbf{X}$ & $\mathrm{x}$ & & $\mathrm{x}$ & $\mathrm{X}$ \\
\hline Oct 8 & $0-18$ & $\mathrm{X}$ & $\mathrm{X}$ & & & \\
\hline Nov 6 & $0-18$ & $\mathrm{x}$ & $\mathrm{X}$ & & & \\
\hline Dec 4 & $0-18$ & $\mathrm{X}$ & $\mathbf{x}$ & $\mathrm{x}$ & $\mathrm{X}$ & \\
\hline Jan 29, 1986 & $0-6$ & $\mathrm{X}$ & & & & \\
\hline Feb 5 & $0-18$ & $\mathrm{x}$ & $\mathrm{x}$ & & & \\
\hline Mar 19 & $0-18$ & $\mathrm{x}$ & $\mathrm{x}$ & $\mathrm{X}$ & $\mathrm{x}$ & \\
\hline Apr 2 & $2-18$ & $\mathrm{X}$ & $\mathrm{x}$ & & & \\
\hline Apr 16 & $0-18$ & $\mathrm{x}$ & $\mathrm{X}$ & & $\mathrm{x}$ & \\
\hline Apr 30 & $0-17$ & $\mathrm{x}$ & $\mathrm{x}$ & & & \\
\hline May 14 & $6-18$ & $\mathrm{X}$ & $\mathrm{x}$ & & & \\
\hline
\end{tabular}


Table 2. Salinometer calibration parameters.

Least squares regression parameters for regression of discrete salinity values measured in the laboratory against field readings with the Beckman conductivity-temperature meter. In each case the regression intercept was forced through the origin.

True salinity - SLOPE $\times$ field salinity value

\begin{tabular}{cccccr}
\hline DATES & & SLOPE & r2 & n \\
\hline Mar 11, 1985 & to & Apr 17, 1985 & 1.15367 & 1.00 & 40 \\
May 17, 1985 & to & Feb 5, 1986* & 1.05665 & 0.99 & 56 \\
Aug 21, 1985 & & & 1.07218 & 0.94 & 9 \\
Mar 19, 1986 & to May 14, 1986 & 0.91988 & 1.00 & 62 \\
\hline
\end{tabular}

* excluding Aug 21, 1985 
Abbreviations and units for hydrographic and nutrient data summaries.

\begin{tabular}{|c|c|c|}
\hline Abbreviation & Parameter & Units \\
\hline STA & Station & \\
\hline TIME & Time & \\
\hline DEPTH & Depth & m \\
\hline SAL & Salinity & \\
\hline TEMP & Temperature & ${ }^{\circ} \mathrm{C}$ \\
\hline DISCR SAL & Discrete salinity & \\
\hline CHL & Chlorophyl1-a & $\mu g / L$ \\
\hline PHEO & Phaeopigment & $\mu \mathrm{g} / \mathrm{L}$ \\
\hline EXT COEF & Extinction coefficient & $m^{-1}$ \\
\hline SPM & Suspended particulate matter & $\mathrm{mg} / \mathrm{L}$ \\
\hline NO2 & Nitrite & $\mu \mathrm{M}$ \\
\hline$N+N$ & Nitrate plus nitrite & $\mu \mathrm{M}$ \\
\hline DRP & Dissolved reactive phosphate & $\mu \mathrm{M}$ \\
\hline Sio & Dissolved silica & $\mu \mathrm{M}$ \\
\hline NH4 & Ammonium & $\mu \mathrm{M}$ \\
\hline DNU & Dissolved nitrogen ( $U-V$ method) & $\mu \mathrm{M}$ \\
\hline DPU & Dissolved phosphorus (U-V method) & $\mu \mathrm{M}$ \\
\hline PNC & Particulate nitrogen (combustion method) & $\mu \mathrm{M}$ \\
\hline PCC & Particulate carbon (combustion method) & $\mu \mathrm{M}$ \\
\hline
\end{tabular}


Appendix A.

Hydrographic and Nutrient data for Tomales Bay 
Julian Date: 85070

STA TINE DEPTH SAL TEP SAL CISCR

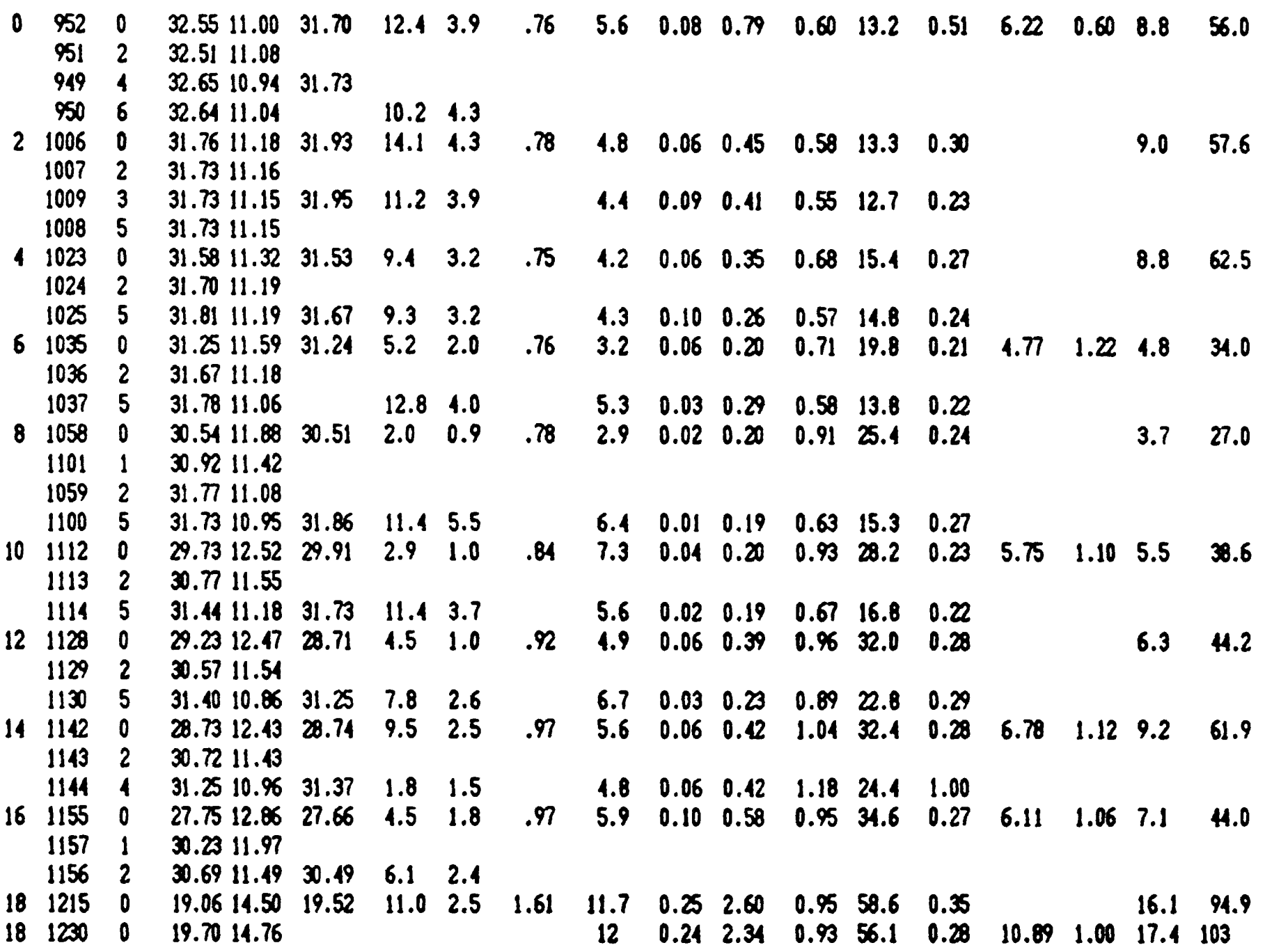




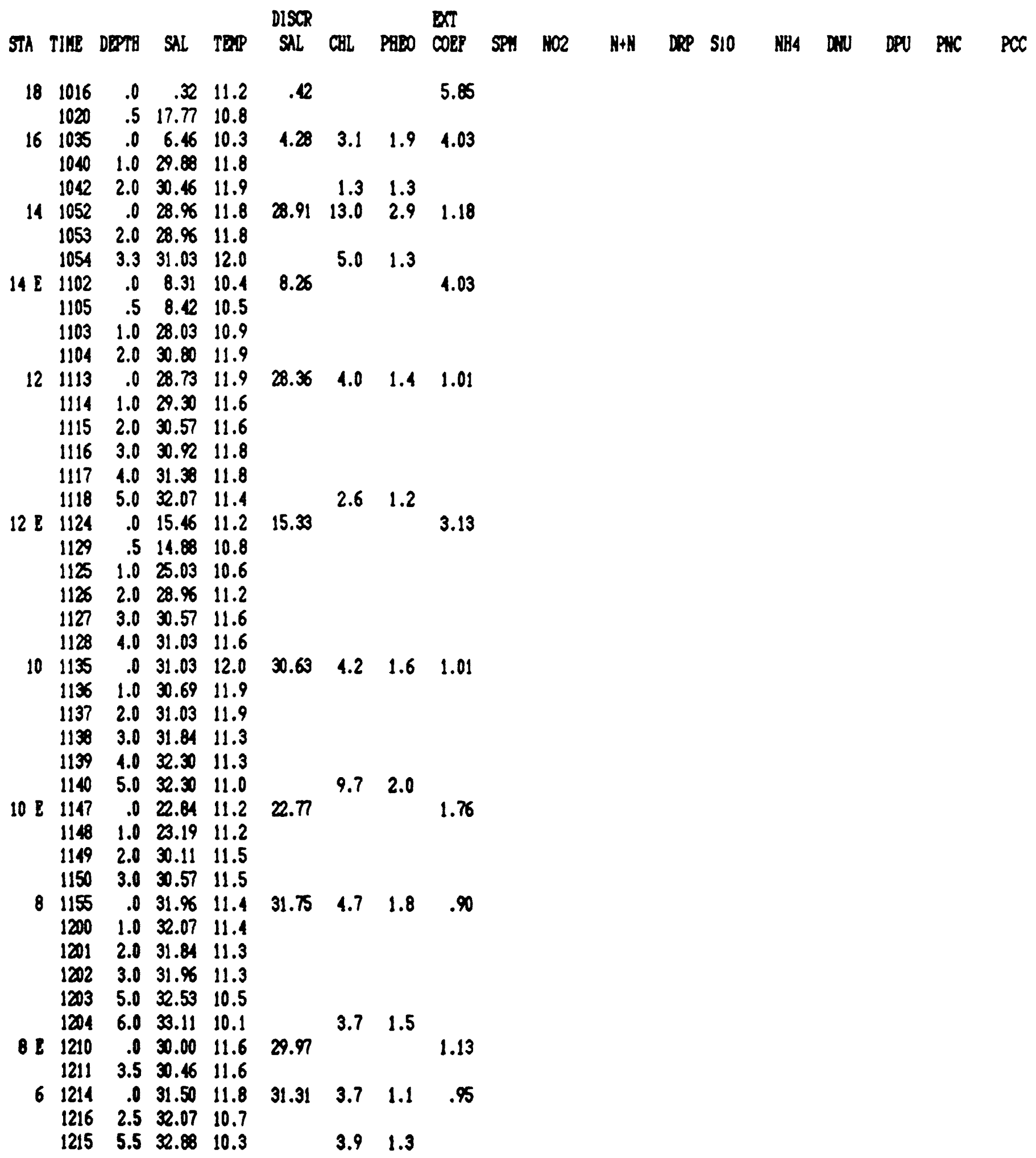




\begin{tabular}{|c|c|c|c|c|c|c|c|c|}
\hline & & & & & DISCR & & & $E X I$ \\
\hline STA & TIME & DEPIH & SAL & TQP & SAL & CAL & PHEO & \\
\hline 4 & 1225 & .0 & 31.84 & 10.9 & 31.72 & 4.9 & 2.4 & .95 \\
\hline & 1227 & 5.0 & $31 . \%$ & 10.8 & & & & \\
\hline & 1226 & 9.5 & 32.07 & 10.8 & & 4.4 & 2.5 & \\
\hline 2 & 1240 & .0 & $31 . \%$ & 10.4 & 31.95 & 4.0 & 1.8 & 1.08 \\
\hline & 1242 & 4.0 & $31 . \%$ & 10.4 & & & & \\
\hline & 1241 & 8.5 & 31.96 & 10.4 & & 2.8 & 2.5 & \\
\hline 0 & 1251 & .0 & 33.46 & 9.2 & 33.48 & 1.0 & 2.1 & .95 \\
\hline & 1253 & 4.0 & 33.46 & 9.2 & & & & \\
\hline & 1252 & 8.0 & 33.46 & 9.2 & & .9 & 1.6 & \\
\hline 68 & 1307 & .0 & 16.61 & 11.8 & 16.65 & & & \\
\hline & 1310 & .5 & 16.50 & 11.8 & & & & \\
\hline & 1309 & 1.0 & 29.30 & 11.3 & & & & \\
\hline & 1308 & 2.0 & 30.57 & 11.4 & & & & \\
\hline
\end{tabular}


DISCR DXI

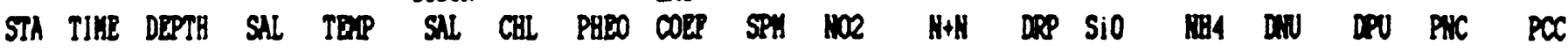

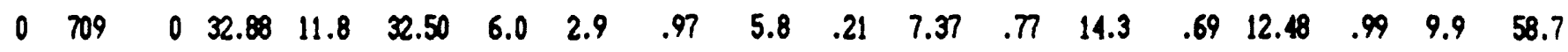

$\begin{array}{llll}710 & 1 & 32.65 & 11.8\end{array}$

$\begin{array}{llll}711 & 2 & 32.76 & 11.8\end{array}$

$\begin{array}{llll}712 & 1 & 32.65 & 11.8\end{array}$

$\begin{array}{llll}713 & 5 & 32.65 & 11.8\end{array}$

$\begin{array}{lllll}2 & 726 & 0 & 32.53 & 12.0\end{array}$

$\begin{array}{llll}727 & 3 & 32.53 & 12.0\end{array}$

$\begin{array}{lllll}4747 & 0 & 32.19 & 12.2\end{array}$

$\begin{array}{llll}746 & 1 & 32.30 & 12.2\end{array}$

$\begin{array}{llll}745 & 3 & 32.30 & 12.2\end{array}$

$\begin{array}{llll}744 & 5 & 32.30 & 12.1\end{array}$

$\begin{array}{llll}743 & 7 & 32.30 & 12.3\end{array}$

$\begin{array}{lllll}6 & 758 & 0 & 31.26 & 12.6\end{array}$

$\begin{array}{llll}757 & 1 & 31.96 & 12.7\end{array}$

$\begin{array}{llll}756 & 2.5 & 32.53 & 12.1\end{array}$

$\begin{array}{lllll}8 & 808 & 0 & 30.23 & 13.3\end{array}$

$\begin{array}{llll}007 \quad 1 & 31.15 & 13.1\end{array}$

$\begin{array}{llll}806 & 3 & 31.73 & 12.6\end{array}$

$\begin{array}{lllll}805 & 5.5 & 32.76 & 11.9\end{array}$

$\begin{array}{lllll}10 & 824 & 0 & 30.34 & 13.4\end{array}$

$\begin{array}{llll}823 & 1 & 30.69 & 13.3\end{array}$

$\begin{array}{llll}822 \quad 3 & 31.26 & 13.0\end{array}$

$\begin{array}{llll}821 & 5 & 31.50 & 12.9\end{array}$

$\begin{array}{lllll}12 & 835 & 0 & 30.23 & 13.8\end{array}$

$\begin{array}{llll}834 \quad 1 \quad 30.23 & 13.8\end{array}$

$\begin{array}{llll}833 \quad 3 & 21.26 & 13.1\end{array}$

$\begin{array}{llll}832 & 5 & 31.38 & 12.9\end{array}$

$\begin{array}{lllll}14 & 847 & 0 & 29.53 & 13.7\end{array}$

$\begin{array}{llll}846 \quad 1 & 30.00 & 13.7\end{array}$

$\begin{array}{llll}845 \quad 3 & 30.69 & 13.5\end{array}$

$\begin{array}{lllll}16 & 659 & 0 & 25.73 & 14.3\end{array}$

$\begin{array}{llll}858 & .5 & 27.11 & 14.3\end{array}$

$\begin{array}{llll}857 \quad 1 & 27.46 & 14.1\end{array}$

$\begin{array}{llll}856 & 2 & 29.19 & 13.9\end{array}$

$\begin{array}{lllll}18 & 908 & 0 & 15.00 & 13.8\end{array}$

$\begin{array}{lllllllll}8.9 & 3.6 & & 6.8 & .21 & 6.31 & .79 & 18.1 & .65\end{array}$

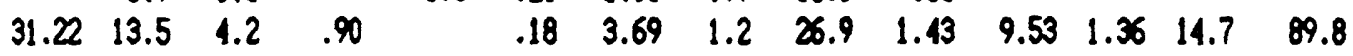

$\begin{array}{lllllllllll}8.8 & 3.9 & .84 & 6.3 & .23 & 6.99 & .76 & 15.3 & .64 & 94 & 59.3\end{array}$

7.92 .8

$\begin{array}{llllll}5.6 & .24 & 6.31 & .88 & 18.1 & .78\end{array}$

$11.3 \quad 67.1$

8.32 .9

$\begin{array}{lllllllllllll}22.0 & 5.4 & 1.01 & 6.0 & .07 & .35 & 1.23 & 29.6 & .62 & 15.38 & 1.78 & 23.5 & 154\end{array}$

$\begin{array}{llllllll}7.4 & 2.8 & 6.4 & .21 & 7.10 & .79 & 13.7 & .82\end{array}$

$\begin{array}{llllllllll}30.32 & 13.9 & 3.6 & 1.04 & 7.6 & .09 & .46 & .96 & 29.7 & 1.03\end{array}$

$18.6 \quad 119$

$\begin{array}{ll}5.0 & 2.2\end{array}$

$\begin{array}{lllllllllllll}8.1 & 2.0 & .87 & 3.9 & .07 & .40 & .88 & 30.4 & 1.2 & 8.41 & 1.17 & 12.0 & 79.7\end{array}$

\section{$\begin{array}{llllllll}3.0 & 1.8 & 4.4 & .15 & 3.15 & 1.01 & 28.8 & 1.64\end{array}$}

$\begin{array}{lllllllll}2.5 & 1.1 & .87 & 4.1 & .05 & .44 & 1.12 & 29.8 & .87\end{array}$

$2.7 \quad 1.4$

$\begin{array}{rrrr}26.10 & 1.4 & .9 & 1.13\end{array}$

\section{$1.3 \quad .5$}

$\begin{array}{lll}15.06 & 3.2 & 1.8\end{array}$ $\begin{array}{llllll}13.0 & .14 & .53 & .97 & 67.2 & .65\end{array}$
$6.5 \quad 48.7$

$5.5 \quad 40.6$

$\begin{array}{llllll}6.9 & .09 & .49 & 1.19 & 38.0 & 1.05\end{array}$

$12.19 \quad 1.17 \quad 8.8$

66.3 


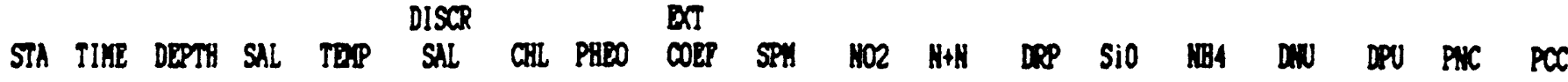

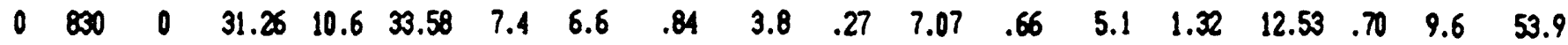

$\begin{array}{llll}829 & 2 & 31.15 \quad 10.6\end{array}$

$828 \quad 4 \quad 31.03 \quad 10.5$

$\begin{array}{llll}827 & 6 & 31.15 & 10.7\end{array}$

$\begin{array}{llll}826 & 8 & 31.15 & 10.7\end{array}$

$\begin{array}{lllll}825 & 10 & 31.26 & 10.8\end{array}$

$\begin{array}{lllll}2 & 844 & 0 & 32.65 & 10.7\end{array}$

$\begin{array}{llll}843 \quad 2 & 32.76 & 10.8\end{array}$

842432.6510 .8

$\begin{array}{llll}841 & 5 & 32.88 & 10.7\end{array}$

$\begin{array}{llll}840 & 7 & 32.76 & 10.7\end{array}$

$4859 \quad 0 \quad 32.65 \quad 11.0$

$\begin{array}{lllll}658 & 2 & 32.65 & 10.95 & 31.22\end{array}$

$857 \quad 1 \quad 32.65 \quad 10.9$

$\begin{array}{lllll}6 & 910 & 0 & 32.07 & 12.3\end{array}$

$\begin{array}{llll}909 & 2 & 32.07 & 12.1\end{array}$

$\begin{array}{llll}908 & 4 & 32.07 & 12.1\end{array}$

$\begin{array}{lllll}8 & 925 & 0 & 31.38 & 13.6\end{array}$

$\begin{array}{llll}924 & 2 & 31.38 & 13.3\end{array}$

$\begin{array}{lllll}923 & 4 & 31.96 & 12.3 & 30.32\end{array}$

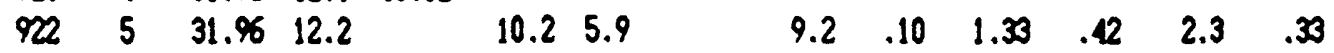

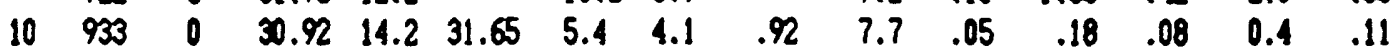

$\begin{array}{llll}932 & 2 & 31.03 & 14.1\end{array}$

$931431.84 \quad 13.0$

$\begin{array}{lllll}930 & 6 & 31.84 & 12.8\end{array}$

$\begin{array}{lllll}12 & 943 & 0 & 30.11 & 15.1\end{array}$

$\begin{array}{llll}942 & 2 & 30.11 & 15.0\end{array}$

8.15 .9

$\begin{array}{lllllllll}9.5 & 7.7 & .67 & 4.0 & .18 & 5.77 & .50 & 3.4 & .79\end{array}$

$6.9 \quad 5.5$

$\begin{array}{lllllllllllll}9.4 & 6.3 & .67 & 4.1 & .18 & 4.11 & .47 & 3.3 & .00 & 9.75 & .36 & 9.0 & 51.2\end{array}$

$9.1 \quad 6.8$

$\begin{array}{lllllllll}12.2 & 6.5 & .90 & 7.6 & .10 & .9 & .37 & 1.9 & .35\end{array}$

$9.3 \quad 5.2$

$\begin{array}{lllllllllllll}9.8 & 4.8 & .95 & 7.0 & .10 & .25 & .14 & 0.5 & .22 & 6.5 & .09 & 8.4 & 72.1\end{array}$

$\begin{array}{llll}944 & 3 & 30.23 & 14.9\end{array}$

$\begin{array}{llll}941 \quad 4 & 31.15 & 14.1\end{array}$

$\begin{array}{llll}940 & 6 & 31.50 & 13.7\end{array}$

$\begin{array}{lllll}14 & 958 & 0 & 29.76 & 15.6\end{array}$

$\begin{array}{llll}957 & 2 & 29.88 & 15.4\end{array}$

$\begin{array}{llll}956 & 3 & 30.57 & 14.4\end{array}$

$955 \quad 4 \quad 31.26 \quad 14.0$

$\begin{array}{lllll}16 & 1018 & 0 & 28 . \% & 15.8\end{array}$

$\begin{array}{llll}1017 & 1 & 29.19 & 15.7\end{array}$

$\begin{array}{llll}1016 & 2 & 29.53 & 15.6\end{array}$

$\begin{array}{llll}1015 & 3 & 29.76 & 15.6\end{array}$

$18 \quad 1029 \quad 0$

28.0316 .3

10281

20.7815 .7

$9.2 \quad 3.0$

$\begin{array}{lllllllllllll}2.5 & 3.1 & .95 & 8.2 & .09 & .13 & .12 & 0.4 & .23 & 6.38 & .08 & 6.4 & 65.0\end{array}$

$20.3 \quad 1045 \quad 0$ $\begin{array}{lllll}23.07 & 16.0 & 23.58 & 5.5 & 2.7\end{array}$

$3.5 \quad 1.2$

$\begin{array}{lllllllll}2.8 & 2.3 & 1.08 & 7.7 & .08 & .21 & .38 & 0.7 & .23\end{array}$

$4.4 \quad 1.8$

$\begin{array}{llllllllllllll}28.73 & 2.1 & 1.3 & 1.24 & 8.0 & .02 & .19 & .73 & 8.3 & .25 & 7.21 & . \% & 5.4 & 38.4\end{array}$

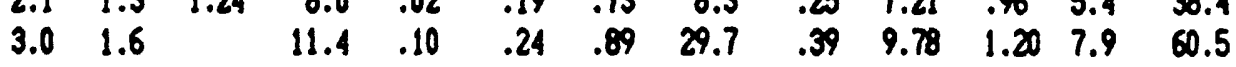

$\begin{array}{llllllll}10.4 & 4.3 & 9.0 & .10 & .30 & .12 & 0.9 & .26\end{array}$

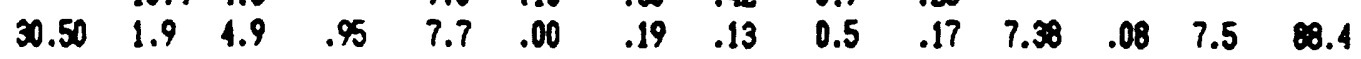

. 
TOARLES BAY DATh SUMARY 17 hay $1985 \quad$ Julian Date: 85137

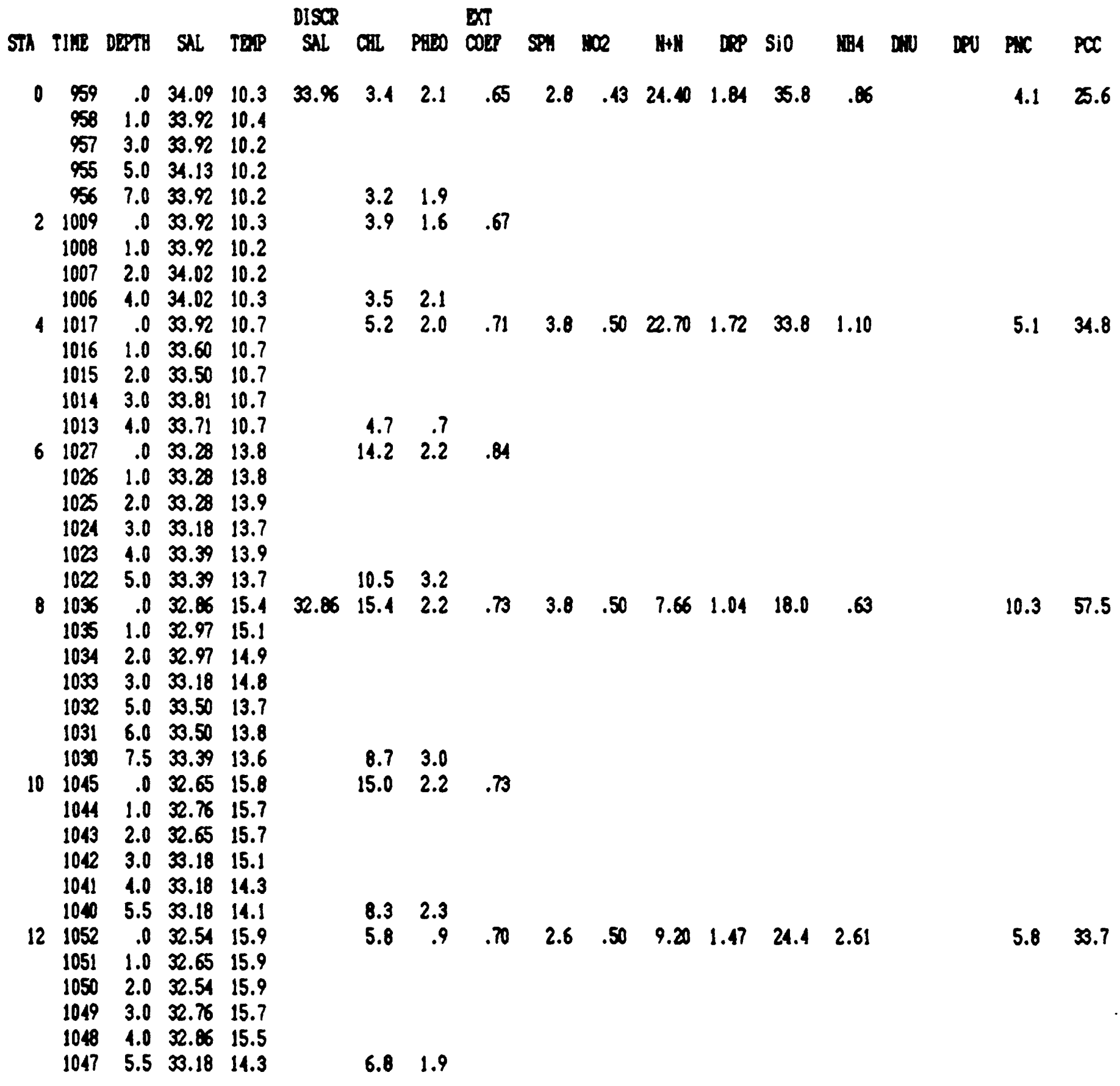




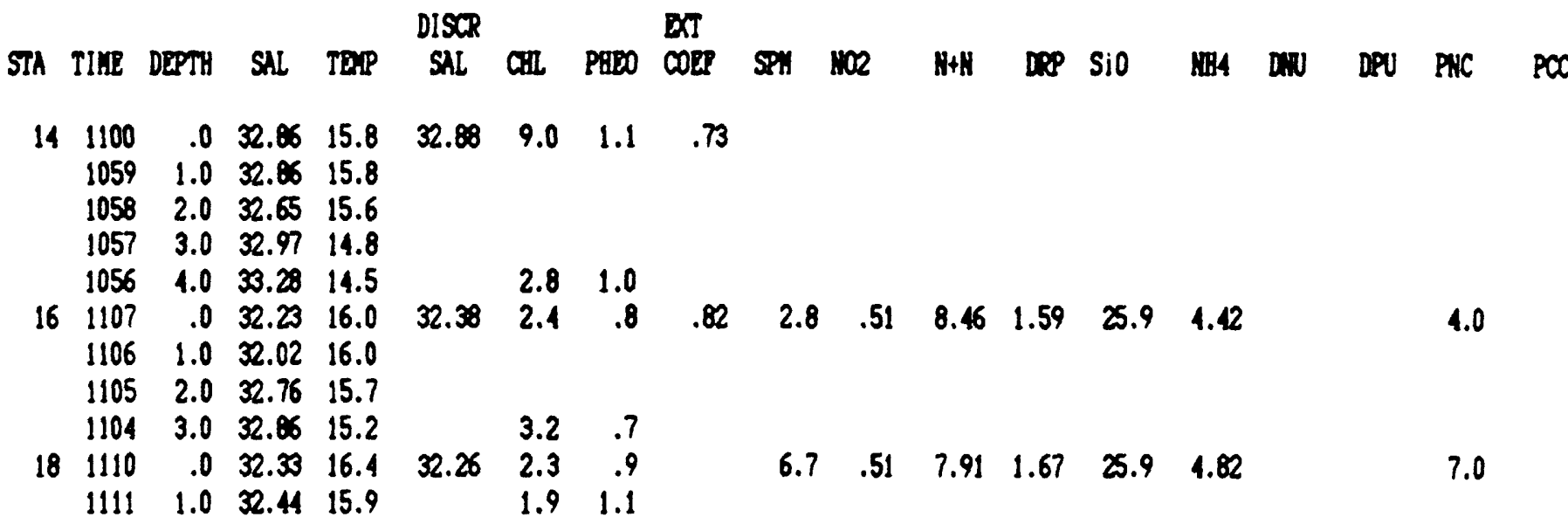


DISCR BXI

STA TIME DEPTH SAL TER SAL CAL PHED CORP

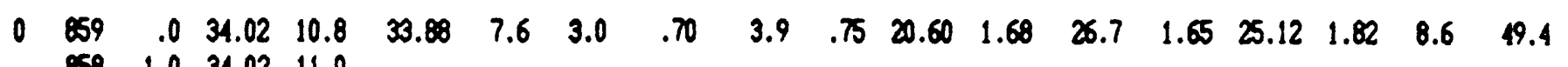

$857 \quad 2.0 \quad 33.92 \quad 11.0$

$\begin{array}{lllll}856 & 4.0 & 34.13 & 11.0\end{array}$

$\begin{array}{lllll}855 & 6.0 & 34.13 & 10.9\end{array}$

$\begin{array}{lllll}2 & 912 & .0 & 34.02 & 12.2\end{array}$

$\begin{array}{llll}911 & 2.0 & 33.92 & 12.0\end{array}$

$\begin{array}{lllll}910 & 3.0 & 33.60 & 12.1\end{array}$

$\begin{array}{lllll}909 & 5.0 & 33.92 & 11.8\end{array}$

$\begin{array}{llll}908 & 6.5 & 34.13 & 11.7\end{array}$

$\begin{array}{lllll}4 & 927 & .0 & 33.81 & 14.1\end{array}$

$\begin{array}{lllll}926 & 1.0 & 33.81 & 13.9\end{array}$

$\begin{array}{lllll}925 & 3.0 & 33.81 & 13.8\end{array}$

$\begin{array}{lllll}924 & 4.5 & 33.81 & 13.8\end{array}$

$\begin{array}{lllll}6 & 938 & .0 & 33.81 & 16.8\end{array}$

$\begin{array}{lllll}937 & 1.0 & 33.92 & 16.0\end{array}$

$\begin{array}{lllll}936 & 2.0 & 33.81 & 14.8\end{array}$

$\begin{array}{llll}935 & 3.0 & 33.81 & 14.2\end{array}$

$\begin{array}{lllll}8 & 949 & .0 & 33.81 & 18.4\end{array}$

$\begin{array}{lllll}948 & 1.0 & 33.71 & 17.5\end{array}$

$\begin{array}{lllll}947 & 2.0 & 33.60 & 15.9\end{array}$

$\begin{array}{lllll}946 & 4.0 & 33.81 & 14.6\end{array}$

$\begin{array}{lllll}945 & 6.0 & 33.81 & 14.5\end{array}$

$\begin{array}{llllll}10 & 1010 & .0 & 33.71 & 19.3\end{array}$

$\begin{array}{llll}1009 & 1.0 & 33.81 & 18.5\end{array}$

$\begin{array}{llll}1008 & 2.0 & 33.50 & 17.5\end{array}$

$\begin{array}{llll}1007 & 4.0 & 33.60 & 16.5\end{array}$

$\begin{array}{llll}1006 & 5.5 & 33.50 & 16.1\end{array}$

$\begin{array}{llllll}12 & 1022 & .0 & 33.50 & 20.0\end{array}$

$\begin{array}{lllll}1021 & 1.0 & 33.60 & 19.8\end{array}$

$\begin{array}{lllll}1020 & 2.0 & 33.50 & 19.4\end{array}$

$\begin{array}{lllll}1019 & 4.0 & 33.50 & 18.8\end{array}$

$\begin{array}{llll}1018 & 5.0 & 33.60 & 17.0\end{array}$

$\begin{array}{lllll}14 & 1032 & .0 & 33.50 & 20.4\end{array}$

$\begin{array}{lllll}1031 & 1.0 & 33.50 & 20.3\end{array}$

$\begin{array}{llll}1030 & 2.0 & 33.60 & 20.0\end{array}$

$1029 \quad 3.0 \quad 33.50 \quad 19.8$

$\begin{array}{llll}16 \quad 1042 \quad .0 & 33.07 \quad 20.6\end{array}$

$\begin{array}{llll}1041 & 1.0 & 33.07 & 20.6\end{array}$

$\begin{array}{llll}1040 & 2.0 & 33.07 & 20.2\end{array}$

$\begin{array}{lllll}18 & 1056 \quad .0 & 32.97 & 21.3\end{array}$

$\begin{array}{llll}1055 & .5 & 32.97 & 21.3\end{array}$

$\begin{array}{lllllllll}5.7 & 3.5 & .73 & 2.7 & .66 & 16.10 & 1.49 & 21.6 & 2.06\end{array}$

$6.2 \quad 3.0$

$\begin{array}{lllllllllllll}5.9 & 2.6 & .90 & 4.7 & .51 & 9.86 & 1.23 & 16.4 & 1.94 & 17.36 & 1.49 & 8.7 & 49.2\end{array}$

$\begin{array}{lll}6.3 & 3.4\end{array}$

$\begin{array}{lllllllll}5.7 & 1.3 & .87 & 3.5 & .23 & 1.56 & .88 & 8.7 & .58\end{array}$

$\begin{array}{lllllllllllll}6.5 & 3.3 & & & & & & & & & & & \\ 3.7 & 1.3 & .85 & 3.5 & .12 & .21 & .91 & 6.1 & .27 & 6.30 & 1.18 & 6.0 & 39.8\end{array}$

$\begin{array}{llllllllll}1.9 & 1.2 & .84 & 2.8 & .09 & .11 & 1.05 & 8.1 & .35\end{array}$

$\begin{array}{rrrrrrrrrrrrr}7.7 & 2.3 & & & & & & & & & & & \\ .9 & .7 & .69 & 2.2 & .09 & .11 & 1.15 & 10.3 & .26 & 7.70 & 1.16 & 2.8 & 21.5\end{array}$

$10.3 \quad 2.8$

$\begin{array}{rrrrrrrrr}1.7 & .9 & .67 & 2.2 & .15 & .14 & 1.49 & 17.3 & .44\end{array}$

$\begin{array}{llllllllllllll}5.8 & 1.3 & & & & & & & & & & & & \end{array}$

$\begin{array}{llllllllllllll}33.01 & 1.1 & 1.8 & .95 & 6.4 & .23 & .50 & 1.77 & 28.2 & .75 & 10.21 & 2.22 & 5.6 & 37.5\end{array}$

$\begin{array}{llllllllll}32.94 & 2.2 & 2.0 & 1.96 & 29.5 & .49 & 2.97 & 1.61 & 32.3 & 4.14\end{array}$ 


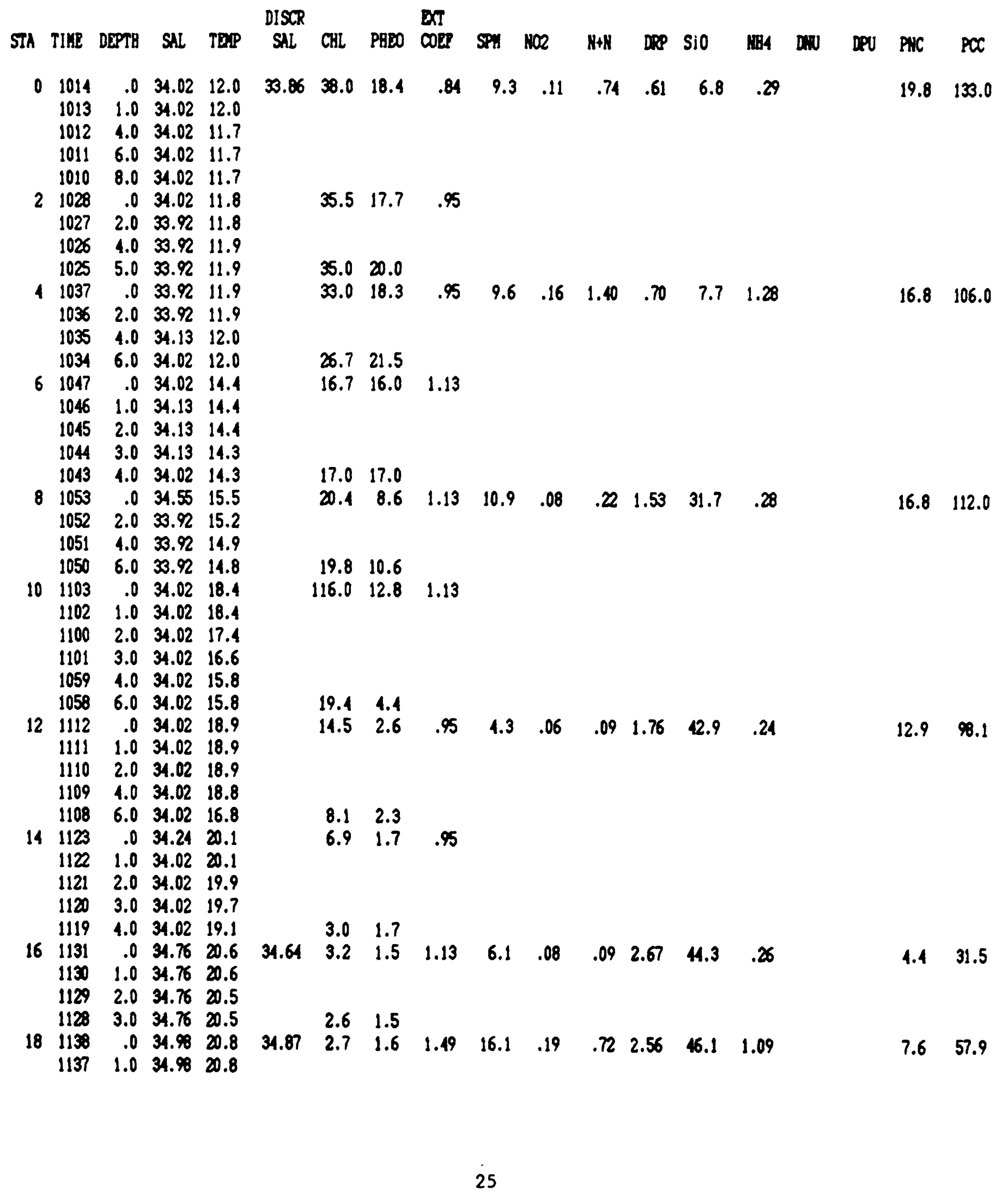


TOHALES BYY DATA SUMARY 21 Aug 1965 Julian Date: 85233

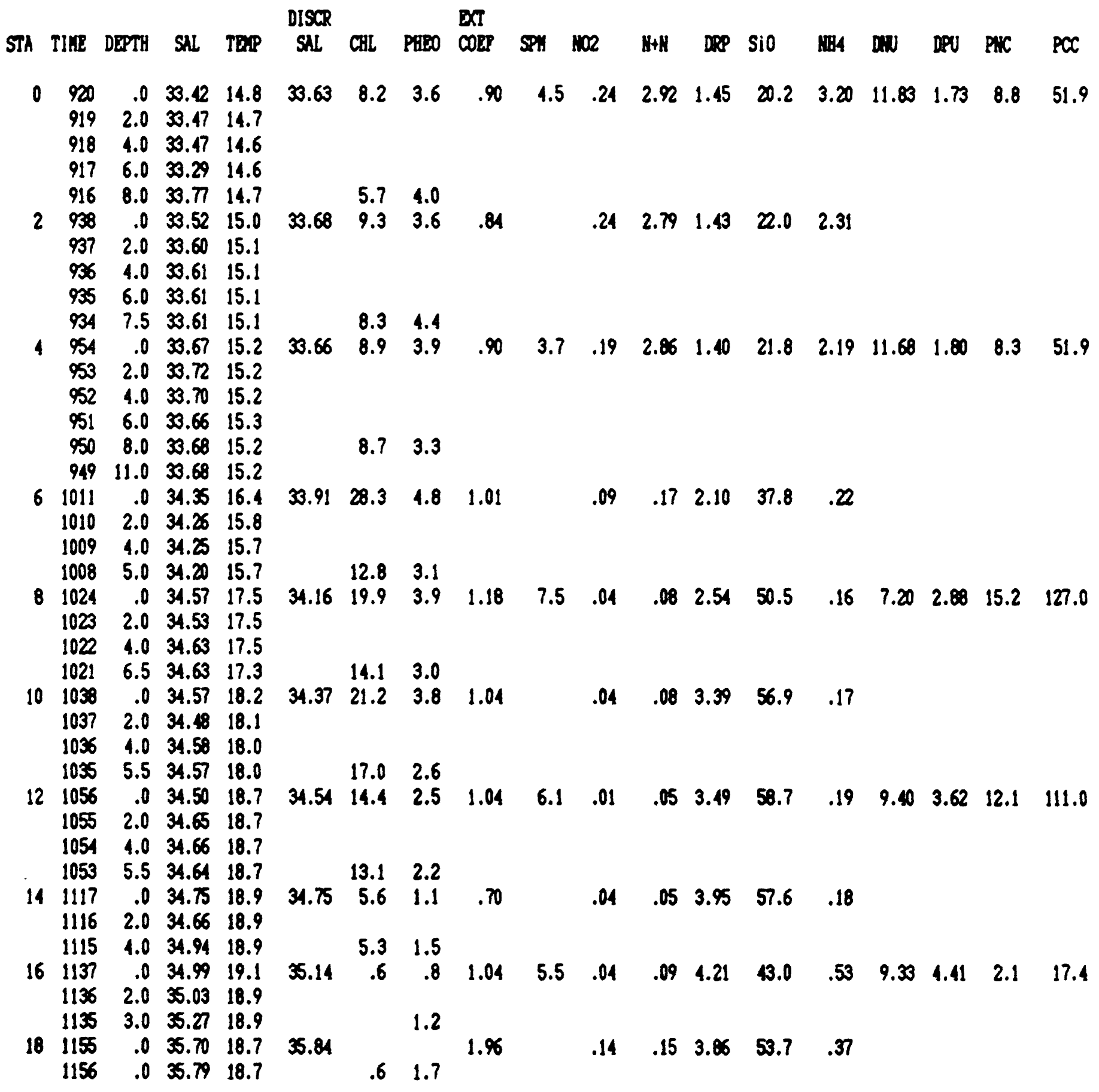




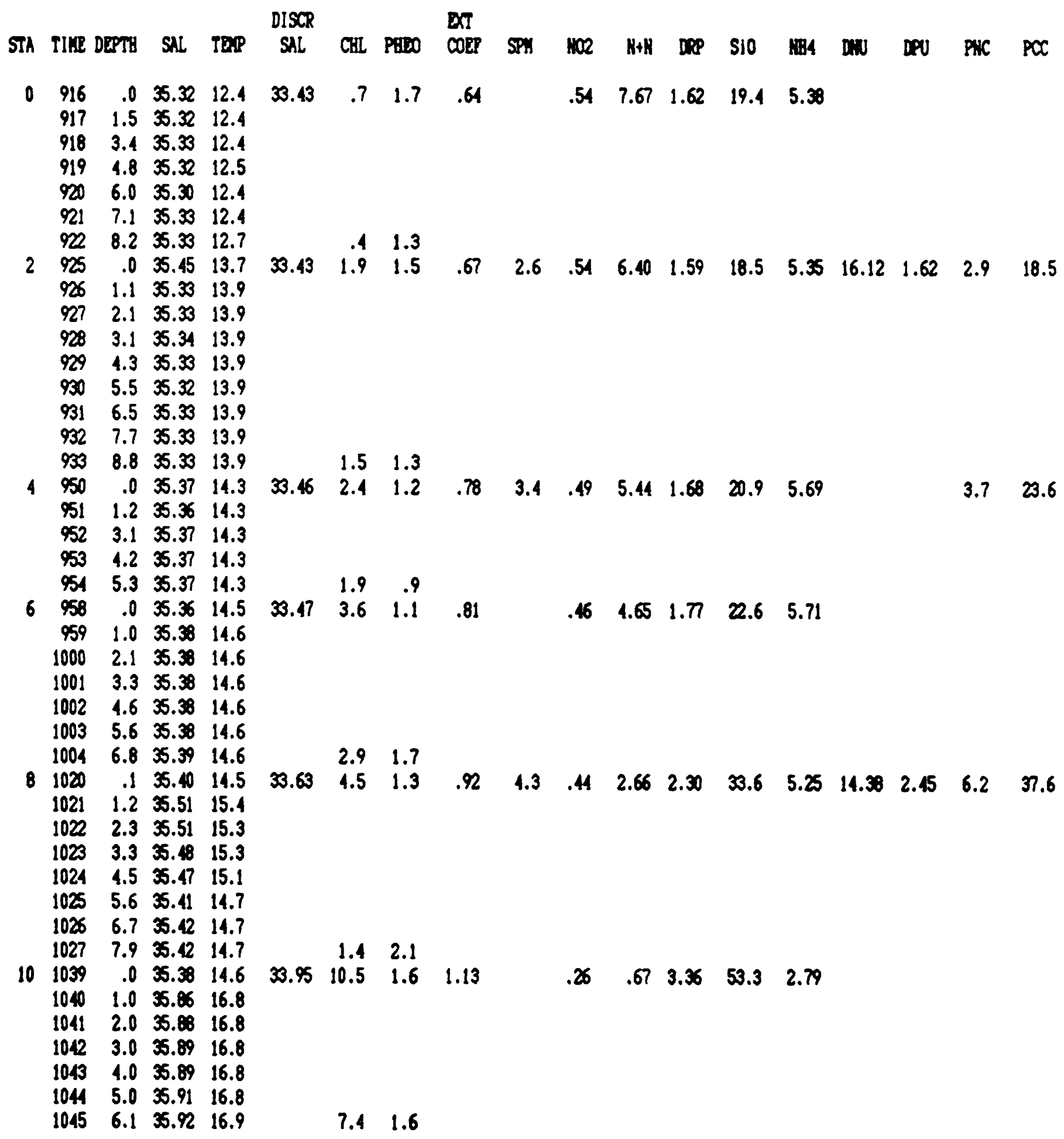




\begin{tabular}{|c|c|c|c|c|c|c|c|c|c|c|c|c|c|c|c|c|c|c|}
\hline STA & TIRE & EPTH & SAL & TDP & $\begin{array}{l}\text { DISCR } \\
\text { SAL }\end{array}$ & CAL & PHEO & $\begin{array}{l}\text { EXI } \\
\text { COBPP }\end{array}$ & SPH & 102 & $\mathrm{~N}+\mathrm{H}$ & $D P P$ & SiO & BRA & L. & $D N$ & PIC & $P C C$ \\
\hline 12 & 1050 & .0 & 35.40 & 14.8 & 34.27 & 10.2 & 1.3 & .84 & 2.8 & .20 & .23 & 4.03 & 59.0 & .63 & 9.38 & 4.09 & 8.6 & 54.8 \\
\hline & $\begin{array}{l}1051 \\
1052\end{array}$ & $\begin{array}{l}1.1 \\
2.1\end{array}$ & $\begin{array}{l}30.19 \\
36.23\end{array}$ & $\begin{array}{l}17.8 \\
17.9\end{array}$ & & 1.7 & .7 & & & & & & & & & & & \\
\hline 14 & 1119 & .0 & 34.48 & 18.3 & & 8.6 & .5 & .85 & & .20 & .26 & 4.76 & 58.6 & .82 & & & & \\
\hline & 1118 & 1.0 & 34.55 & 18.3 & & & & & & & & & & & & & & \\
\hline & 1117 & 2.0 & 34.62 & 18.3 & & & & & & & & & & & & & & \\
\hline & 1116 & 3.0 & 34.62 & 18.4 & & & & & & & & & & & & & & \\
\hline & 1115 & 4.5 & 34.70 & 18.4 & & 6.3 & .5 & & & & & & & & & & & \\
\hline 16 & 1111 & .0 & 34.70 & 18.2 & & 2.0 & .3 & .90 & 3.1 & .25 & .84 & 4.73 & 52.1 & 2.55 & 13.88 & 4.96 & 3.4 & 21.4 \\
\hline & $\begin{array}{l}1140 \\
1139\end{array}$ & $\begin{array}{l}1.0 \\
2.0\end{array}$ & $\begin{array}{l}34.70 \\
34.80\end{array}$ & $\begin{array}{l}18.2 \\
18.2\end{array}$ & & & & & & & & & & & & & & \\
\hline & 1138 & 3.0 & 34.77 & 18.2 & & 1.3 & .5 & & & & & & & & & & & \\
\hline 18 & 1152 & .0 & 34.88 & 17.9 & & 1.2 & .8 & 1.08 & & .22 & .53 & 1.22 & $\$ 0.4$ & 1.42 & & & & \\
\hline & 1153 & 1.0 & 34.87 & 17.8 & & & & & & & & & & & & & & \\
\hline
\end{tabular}




\begin{tabular}{|c|c|c|c|c|c|c|c|c|c|c|c|c|c|c|c|c|c|c|}
\hline STA & \multicolumn{2}{|c|}{ TIME DEPTY } & \multicolumn{5}{|c|}{ DISCR } & $\begin{array}{l}\text { DI } \\
\text { CDEP }\end{array}$ & SPH & \multicolumn{2}{|r|}{$\mathbf{H}+\mathbb{N}$} & DeP & SiO & PreA & and & DPU & PMC & $P C C$ \\
\hline 0 & 956 & 0 & 33.43 & 13.5 & & 1.3 & 1.0 & .60 & & .61 & 8.86 & 1.58 & 17.6 & 5.42 & 17.05 & 1.43 & & \\
\hline 2 & 1011 & 0 & 33.42 & 13.7 & & 1.4 & .8 & .60 & & .63 & 8.2 & 1.66 & 18.5 & $5 . \pi$ & & & & \\
\hline 4 & 1025 & 0 & 33.46 & 13.8 & & 2.7 & 1.3 & .64 & & .60 & 8.00 & 1.80 & 22.0 & 5.90 & 18.71 & 1.87 & & \\
\hline 6 & 1035 & 0 & 33.49 & 14.6 & & 5.0 & 1.4 & .87 & & .55 & 6.25 & 1.95 & 24.6 & 5.66 & & & & \\
\hline 8 & 1046 & 0 & 33.58 & 16.8 & & .9 & .7 & .82 & & .47 & 3.70 & 2.08 & 31.0 & 4.97 & 14.64 & 2.23 & & \\
\hline 10 & 1057 & 0 & 33.91 & 17.7 & & 1.1 & .5 & 1.01 & & .29 & 1.15 & 3.19 & 50.4 & 3.49 & & & & \\
\hline 12 & 1108 & 0 & 34.34 & 18.7 & & .8 & .2 & .90 & & .19 & .34 & 4.17 & 59.4 & .31 & 8.07 & 4.30 & & \\
\hline 14 & 1121 & 0 & 34.45 & 19.1 & & .5 & .3 & .74 & & .18 & .26 & 4.33 & 61.6 & .19 & & & & \\
\hline 16 & 1132 & 0 & 34.69 & 19.5 & & .7 & .4 & .00 & & .25 & .21 & 4.44 & 51.8 & .20 & 11.18 & 1.86 & & \\
\hline 18 & 1143 & 0 & 34.81 & 18.8 & & 1.7 & .5 & 1.13 & & .22 & .27 & 4.11 & 36.8 & .38 & & & & \\
\hline $14 V$ & 1201 & 0 & 34.82 & 19.5 & & .8 & .1 & .80 & & .14 & .25 & 4.49 & 62.6 & .16 & & & & \\
\hline $4 E$ & 1208 & 0 & 34.62 & 19.3 & & 14.2 & 1.5 & 49.95 & & .17 & .26 & 4.58 & 59.1 & .10 & & & & \\
\hline 128 & 1228 & 0 & 34.26 & 19.2 & & 1.3 & .6 & .74 & & .19 & .27 & 4.08 & 56.6 & 1.03 & & & & \\
\hline $12 \mathrm{~V}$ & 1236 & 0 & 34.12 & 18.7 & & .7 & .5 & .95 & & .21 & .61 & 3.83 & 56.2 & 2.71 & & & & \\
\hline $5 \mathrm{~B}$ & 1255 & 0 & 32.61 & 18.4 & & 1.1 & .5 & 1.24 & & .23 & .64 & 1.99 & 21.2 & 1.30 & & & & \\
\hline & 1300 & 0 & 33.55 & 14.3 & & 1.8 & 1.0 & .71 & & .63 & 6.96 & 1.89 & 21.1 & 5.99 & & & & \\
\hline $5 V$ & 1306 & 0 & 33.46 & 14.0 & & .7 & 2.3 & .60 & & .60 & $7.9 \%$ & 1.75 & 20.1 & 5.55 & & & & \\
\hline
\end{tabular}


TOAALES BAY DAFA SWMARY 8 OCtober 1985 Julian Date: 65281

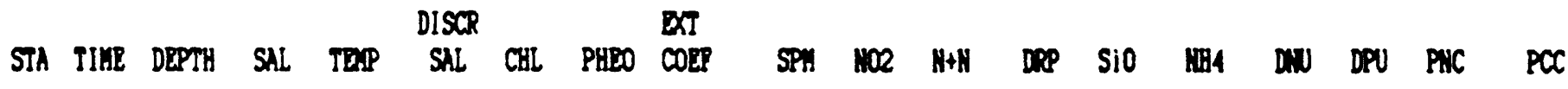

$\begin{array}{rlll}0 & & 0 & 33.35 \\ 2 & & 0 & 33.34 \\ 1 & & 0 & 33.37 \\ 6 & & 0 & 33.52 \\ 8 & & 0 & 33.51 \\ 10 & & 0 & 34.10 \\ 12 & & 0 & 34.43 \\ 14 & & 0 & 34.65 \\ 16 & & 0 & 34.82 \\ 18 & & 0 & 34.57\end{array}$

$\begin{array}{llllllllll}2.8 & .78 & 2.72 & .84 & 7.4 & 2.56 & 9.37 & .93 & 4.4 & 28.6\end{array}$

$\begin{array}{llllllllll}3.2 & .28 & 2.18 & .84 & 7.7 & 2.50 & 8.41 & 1.00 & 4.0 & 25.6\end{array}$

$\begin{array}{llllllllll}3.6 & .31 & 2.44 & 1.28 & 11.8 & 4.44 & 11.88 & 1.39 & 4.6 & 28.5\end{array}$

$\begin{array}{llllllllll}5.2 & .31 & 2.29 & 1.90 & 23.3 & 4.91 & 14.23 & 2.18 & 5.5 & 34.6\end{array}$

$\begin{array}{llllllllll}9.0 & .11 & 3.14 & 2.16 & 26.6 & 5.01 & 13.69 & 2.34 & 7.0 & 44.2\end{array}$

$\begin{array}{llllllllll}6.7 & .22 & 1.01 & 3.7 & 57.6 & 1.28 & 11.59 & 4.05 & 10.2 & 63.2\end{array}$

$\begin{array}{llllllllll}4.7 & .14 & .57 & 4.55 & 62.4 & .76 & 8.81 & 4.72 & 9.2 & 61.8\end{array}$

$\begin{array}{llllllllll}5.3 & .14 & .36 & 5.05 & 58.4 & 2.55 & 12.47 & 5.35 & 6.0 & 37.4\end{array}$

$\begin{array}{llllllllll}4.6 & .29 & .49 & 4.79 & 45.4 & 2.34 & 14.83 & 5.08 & 3.6 & 23.6\end{array}$

$\begin{array}{llllllllll}6.8 & .20 & .21 & 4.81 & 53.2 & 1.06 & 14.06 & 5.11 & 6.6 & 45.9\end{array}$ 


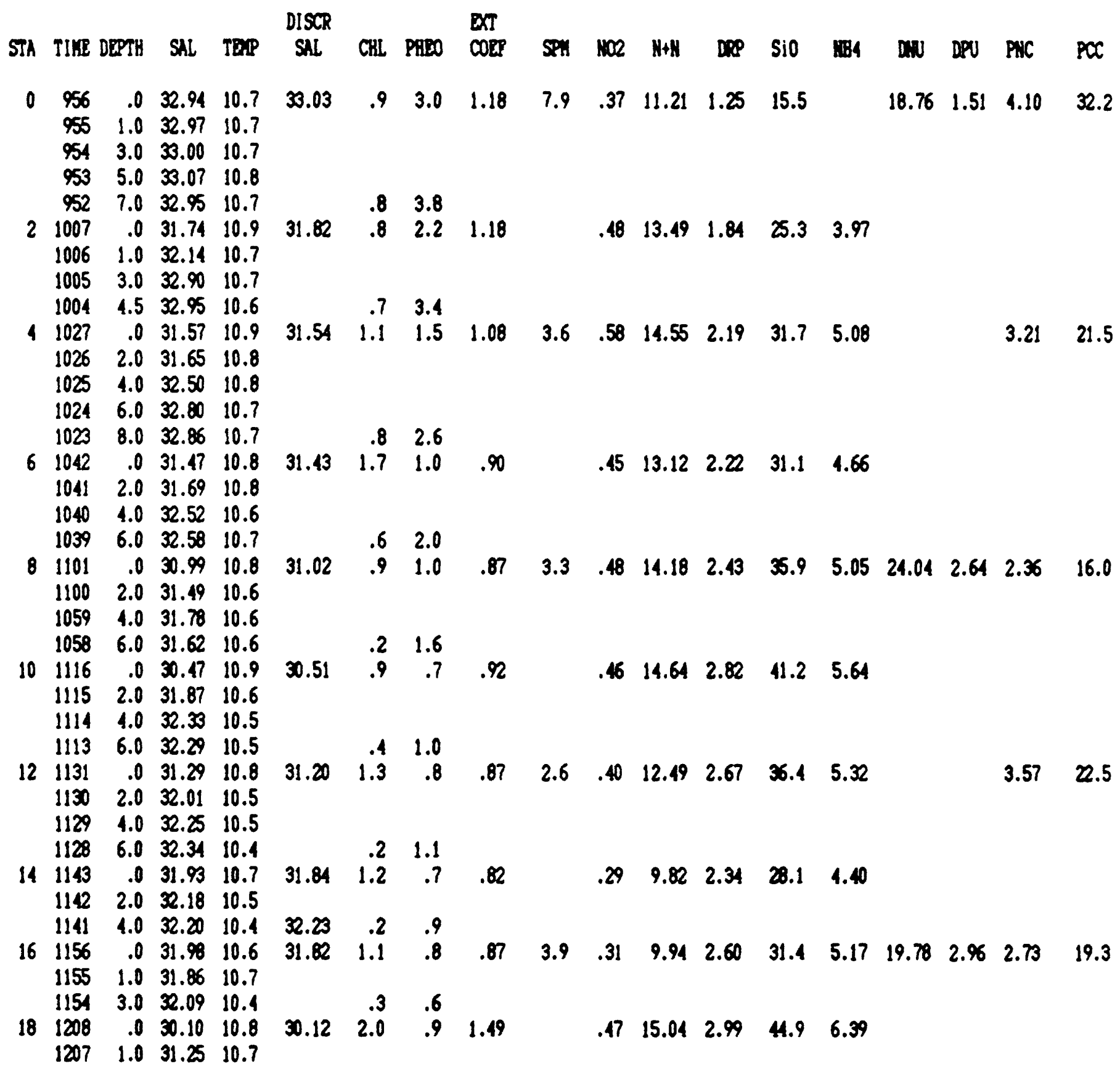


STA TIKE DEPTH SAL TEP $\begin{gathered}\text { DISCR } \\ \text { SAL CHL PHEO }\end{gathered}$

$\begin{array}{lllllllllllllll}18 & 1025 & .0 & 33.26 & 15.0 & 33.36 & 1.6 & .7 & 1.04 & 5.0 & .33 & 2.30 & 3.50 & 26.0 & 2.01\end{array}$ $1024 \quad 1.5 \quad 33.19 \quad 14.8$

$\begin{array}{lllllllllllllll}16 & 1053 & .0 & 33.63 & 15.2 & 33.72 & .3 & .5 & .84 & 3.5 & .38 & 3.95 & 3.80 & 33.0 & 3.39\end{array}$ $\begin{array}{lllll}1052 & 1.0 & 33.76 \quad 15.0\end{array}$

$\begin{array}{llll}1051 & 2.0 & 33.72 & 15.0\end{array}$

$\begin{array}{llll}1050 & 3.0 & 33.73 & 15.0\end{array}$

$\begin{array}{llllllllll} & & .8 & .7 & & 3.7 & & & & \\ 33.94 & .6 & .6 & .87 & 2.5 & .45 & 5.81 & 4.16 & 43.5 & 4.00\end{array}$

$3.14 \quad 19.2$

$14 \quad 1104 \quad .0 \quad 33.8615 .3$

$\begin{array}{llll}1103 & 1.0 & 33.81 & 15.1\end{array}$

$\begin{array}{llll}1102 & 2.0 & 33.81 & 14.9\end{array}$

$\begin{array}{lllll}1101 & 3.0 & 34.13 & 14.9\end{array}$

$\begin{array}{lllll}1100 & 4.0 & 34.02 & 14.9\end{array}$

$\begin{array}{llllll}12 & 1118 & .0 & 33.96 & 14.9\end{array}$

$\begin{array}{llll}1117 & 2.0 & 33.98 & 14.5\end{array}$

$\begin{array}{llll}1116 & 4.0 & 33.98 & 14.5\end{array}$

$\begin{array}{llll}1115 & 6.0 & 33.83 & 14.4\end{array}$

$\begin{array}{llllll}10 & 1136 & .0 & 33.77 & 14.6\end{array}$

$\begin{array}{llll}1135 & 2.0 & 33.73 & 13.6\end{array}$

$\begin{array}{llll}1134 & 4.0 & 33.73 & 13.4\end{array}$

$\begin{array}{llll}1133 & 6.5 & 32.76 & 13.5\end{array}$

$\begin{array}{llllll}8 & 1152 & .0 & 33.58 & 13.4\end{array}$

$\begin{array}{llll}115 ! & 2.0 & 33.50 & 12.5\end{array}$

$\begin{array}{llll}1150 & 1.0 & 33.50 & 12.2\end{array}$

$\begin{array}{llll}1149 & 5.0 & 33.43 & 12.2\end{array}$

$\begin{array}{lllll}6 & 1218 & .0 & 33.47 & 12.8\end{array}$

$\begin{array}{llll}1217 & 2.0 & 33.50 & 12.2\end{array}$

$\begin{array}{llll}1216 & 4.0 & 33.50 & 12.2\end{array}$

$\begin{array}{llll}1215 & 6.0 & 33.28 & 12.0\end{array}$

$\begin{array}{llll}1214 & 8.0 & 33.28 & 11.9\end{array}$

$\begin{array}{llll}1213 & 10.0 & 30.20 & 12.0\end{array}$

$\begin{array}{lllll}1 & 1228 & .033 .59 & 11.8\end{array}$

$\begin{array}{llll}1227 & 2.0 \quad 33.61 \quad 11.8\end{array}$

$\begin{array}{llll}1226 & 4.0 \quad 39.60 \quad 11.6\end{array}$

$\begin{array}{llll}1225 & 6.0 \quad 33.45 & 11.6\end{array}$

$\begin{array}{llllll}2 & 1239 & .0 & 33.34 & 11.5\end{array}$

$\begin{array}{llll}1230 & 2.0 \quad 33.28 & 11.3\end{array}$

$\begin{array}{llll}1237 & 4.0 & 33.28 & 11.2\end{array}$

$\begin{array}{llll}1236 & 7.0 & 33.31 & 11.2\end{array}$

$\begin{array}{lllll}0 & 1251 & .0 & 33.53 & 12 .\end{array}$

$\begin{array}{llll}1250 & 2.0 & 33.49 & 11.8\end{array}$

$\begin{array}{llll}1249 & 4.0 \quad 33.60 \quad 11.4\end{array}$

$\begin{array}{llll}1248 & 6.0 & 39.58 & 11.3\end{array}$

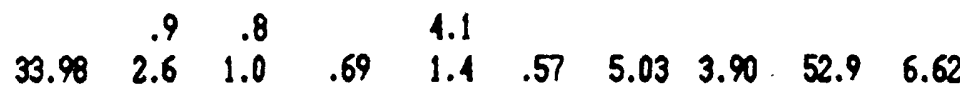

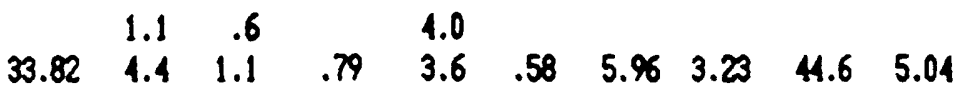

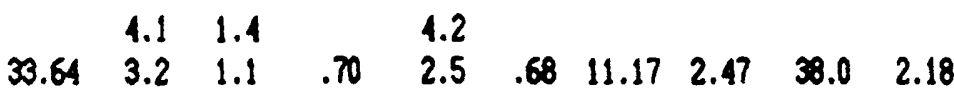

$\begin{array}{llll}2.4 & 1.1 & 2.7\end{array}$

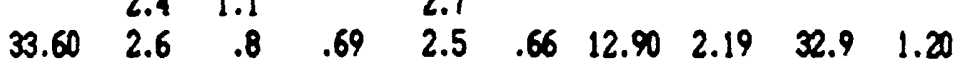

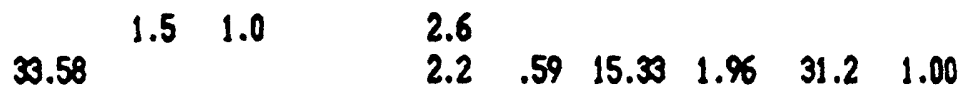

$\begin{array}{llllllllll} & & 1.4 & .9 & & 2.2 & & & & \\ 33.58 & 1.1 & .7 & .58 & 2.0 & .60 & 16.64 & 1.89 & 30.5 & 1.04\end{array}$

$\begin{array}{llllllllll} & & .7 & .7 & & & 1.9 & & & \\ 3.56 & .9 & .59 & 2.6 & .62 & 17.43 & 1.82 & 27.6 & .88\end{array}$

1.7
$3.46 \quad 20.4$

$2.50 \quad 15.5$

$3.99 \quad 25.6$

$4.07 \quad 27.2$

$3.71 \quad 23.6$

$4.21 \quad 27.0$

$3.97 \quad 24.9$

$3.75 \quad 23.6$

$3.36 \quad 21.0$

$2.57 \quad 16.8$

$2.04 \quad 13.4$

$2.68 \quad 17.4$

$2.49 \quad 15.6$

$1.51 \quad 10.3$

$2.04 \quad 14.2$

$1.74 \quad 11.6$

$2.18 \quad 15.0$ 


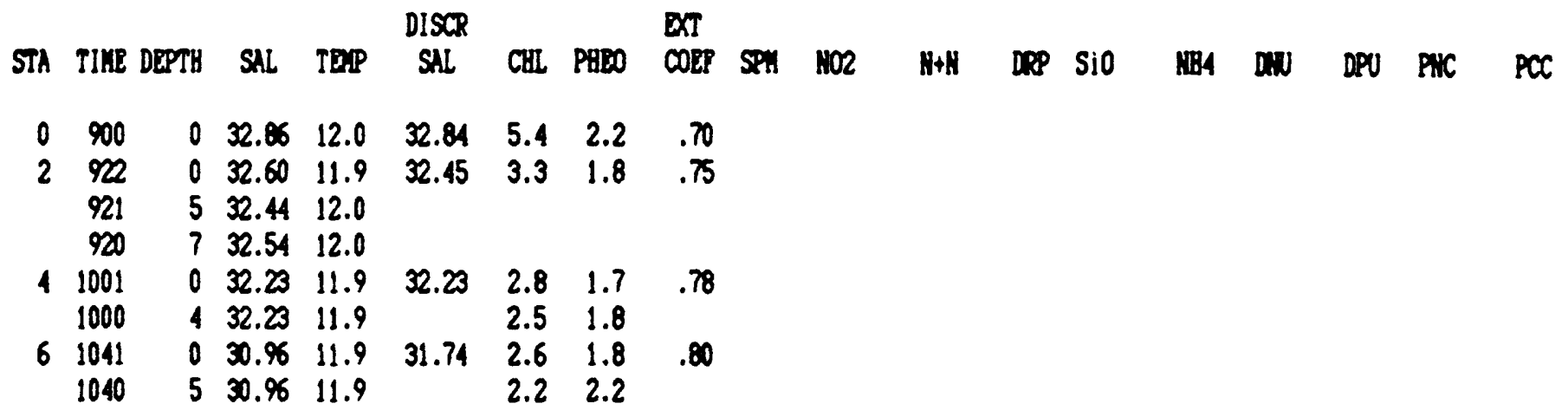




\begin{tabular}{|c|c|c|c|c|c|c|c|c|c|c|c|c|c|c|c|c|c|c|}
\hline SIA & TIRE & EPTI & SNL & TERP & $\begin{array}{c}\text { DISCR } \\
\text { SAL }\end{array}$ & CHL & PRDO & $\begin{array}{l}D X I \\
\operatorname{CoEI}\end{array}$ & SPH. & 102 & $\mathrm{H}+\mathbf{H}$ & DRP & SiO & MBA4 & DiN & DPU & PIIC & $P C C$ \\
\hline 0 & $\begin{array}{l}921 \\
922\end{array}$ & $\begin{array}{r}.0 \\
8.0\end{array}$ & $\begin{array}{l}32.70 \\
32.70\end{array}$ & $\begin{array}{l}12.4 \\
12.3\end{array}$ & 32.66 & 1.3 & 1.7 & .80 & 8.9 & .16 & 3.24 & $.7 \pi$ & 8.5 & .95 & 8.26 & .85 & 3.3 & 27.8 \\
\hline 2 & $\begin{array}{l}934 \\
933 \\
932\end{array}$ & $\begin{array}{r}.0 \\
4.0 \\
8.0\end{array}$ & $\begin{array}{l}32.58 \\
32.76 \\
32.76\end{array}$ & $\begin{array}{l}12.3 \\
12.4 \\
12.4\end{array}$ & 32.61 & 1.0 & 2.0 & 1.01 & & .19 & 3.22 & .83 & 9.0 & 1.09 & & & & \\
\hline 4 & $\begin{array}{l}944 \\
943 \\
942\end{array}$ & $\begin{array}{r}.0 \\
1.0 \\
7.0\end{array}$ & $\begin{array}{l}32.51 \\
32.65 \\
32.59\end{array}$ & $\begin{array}{l}12.4 \\
12.4 \\
12.3\end{array}$ & 32.42 & 1.2 & 1.9 & 1.01 & 6.9 & .16 & 3.56 & .84 & 10.9 & 1.39 & 10.02 & .95 & 3.5 & 28.8 \\
\hline 6 & $\begin{array}{l}954 \\
953\end{array}$ & $\begin{array}{r}.0 \\
2.0\end{array}$ & $\begin{array}{l}29.85 \\
31.27\end{array}$ & $\begin{array}{l}12.3 \\
12.3\end{array}$ & 29.86 & 1.5 & 1.0 & 1.01 & & .28 & 6.99 & 1.27 & 27.7 & 4.16 & & & & \\
\hline & 952 & 4.0 & 31.82 & 12.3 & & 1.1 & 1.2 & & & & & & & & & & & \\
\hline 8 & $\begin{array}{l}1005 \\
1004 \\
1003\end{array}$ & $\begin{array}{r}.0 \\
3.0 \\
5.0\end{array}$ & $\begin{array}{l}28.79 \\
29.10 \\
30.51\end{array}$ & $\begin{array}{l}12.2 \\
12.2 \\
12.4\end{array}$ & 28.70 & 1.9 & .9 & 1.01 & 4.0 & .36 & 9.14 & 1.47 & 36.1 & 5.38 & 21.20 & 1.64 & 2.9 & 18.5 \\
\hline 10 & $\begin{array}{l}1002 \\
1015\end{array}$ & $\begin{array}{r}7.0 \\
.0\end{array}$ & $\begin{array}{l}30.99 \\
28.39\end{array}$ & $\begin{array}{l}12.3 \\
12.2\end{array}$ & 28.25 & $\begin{array}{r}.9 \\
1.5\end{array}$ & $\begin{array}{r}1.1 \\
.8\end{array}$ & 1.04 & & .41 & 10.27 & 1.62 & 39.8 & 5.98 & & & & \\
\hline & $\begin{array}{l}1014 \\
1013\end{array}$ & $\begin{array}{l}2.0 \\
4.0\end{array}$ & $\begin{array}{l}28.32 \\
28.41 \\
\infty\end{array}$ & $\begin{array}{l}12.2 \\
12.3 \\
12\end{array}$ & & & & & & & & & & & & & & \\
\hline 12 & $\begin{array}{l}1012 \\
1028\end{array}$ & $\begin{array}{r}6.0 \\
.0\end{array}$ & $\begin{array}{l}29.05 \\
28.25\end{array}$ & $\begin{array}{l}12.3 \\
12.1\end{array}$ & 28.13 & $\begin{array}{r}.6 \\
1.8\end{array}$ & $\begin{array}{r}.9 \\
1.0\end{array}$ & .92 & 3.5 & .39 & 10.39 & 1.61 & 39.7 & 5.87 & 22.19 & 1.76 & 3.3 & 19.8 \\
\hline & $\begin{array}{l}1027 \\
1026\end{array}$ & $\begin{array}{l}2.0 \\
4.0\end{array}$ & $\begin{array}{l}28.29 \\
28.24\end{array}$ & $\begin{array}{l}12.1 \\
12.1\end{array}$ & & & & & & & & & & & & & & \\
\hline & 1025 & 6.0 & 28.32 & 12.1 & & .6 & .7 & & & & & & & & & & & \\
\hline 14 & $\begin{array}{l}1036 \\
1035\end{array}$ & $\begin{array}{r}.0 \\
2.0\end{array}$ & $\begin{array}{l}27.23 \\
27.36\end{array}$ & $\begin{array}{l}12.2 \\
12.2\end{array}$ & 27.25 & 1.3 & .8 & .97 & & .40 & 11.54 & 1.67 & 47.1 & 6.12 & & & & \\
\hline & 1034 & 4.5 & 28.12 & 12.0 & & .5 & .7 & & & & & & & & & & & \\
\hline 16 & $\begin{array}{l}1046 \\
1045\end{array}$ & $\begin{array}{r}.0 \\
2.0\end{array}$ & $\begin{array}{l}23.46 \\
24.46\end{array}$ & $\begin{array}{l}12.0 \\
11.9\end{array}$ & 23.57 & .9 & .7 & 1.31 & 5.9 & .41 & 13.54 & 1.69 & 65.6 & 6.94 & 29.84 & 1.96 & 3.2 & 22.3 \\
\hline & 1044 & 3.5 & 27.26 & 12.2 & & .4 & .9 & & & & & & & & & & & \\
\hline 18 & $\begin{array}{l}1055 \\
1054\end{array}$ & $\begin{array}{r}.0 \\
1.0\end{array}$ & $\begin{array}{l}15.41 \\
15.55\end{array}$ & $\begin{array}{l}11.7 \\
11.8\end{array}$ & 14.40 & 1.1 & 1.3 & 1.76 & & .47 & 20.76 & 1.99 & 115.0 & 7.62 & & & & \\
\hline
\end{tabular}


DISCR DXT

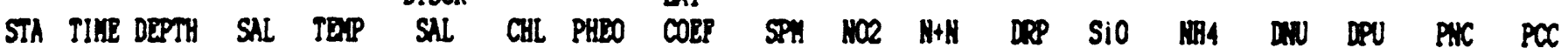

$\begin{array}{lllll}0 & 847 & .0 & 21.93 & 13.1\end{array}$

$\begin{array}{llll}846 & 2.0 & 22.09 & 13.1\end{array}$

$844 \quad 4.0 \quad 22.01 \quad 13.0$

$\begin{array}{llll}840 & 6.0 & 22.29 & 13.0\end{array}$

$\begin{array}{lllll}2 & 900 & .0 & 16.04 & 13.6\end{array}$

$\begin{array}{lllll}859 & 1.0 & 16.65 & 13.4\end{array}$

$\begin{array}{llll}858 & 2.0 & 16.66 & 13.3\end{array}$

$\begin{array}{lllll}857 & 3.0 & 17.21 & 13.2\end{array}$

$\begin{array}{llll}856 & 4.0 & 26.14 & 12.9\end{array}$

$\begin{array}{llll}855 & 5.0 & 28.93 & 12.8\end{array}$

$\begin{array}{lllll}4914 \quad .0 & 14.65 & 13.7\end{array}$

$\begin{array}{llll}913 & 1.0 & 15.22 & 13.5\end{array}$

$\begin{array}{lllll}912 & 3.0 & 17.01 & 13.2\end{array}$

$911 \quad 5.0 \quad 25.12 \quad 13.0$

$\begin{array}{llll}910 & 7.0 & 28.06 & 13.0\end{array}$

$\begin{array}{lllll}6 & 926 & .0 & 14.29 & 13.9\end{array}$

$\begin{array}{llll}925 & 1.0 & 15.34 & 13.1\end{array}$

$\begin{array}{llll}924 & 2.0 & 24.47 & 13.3\end{array}$

$\begin{array}{llll}923 & 3.0 & 27.50 & 13.3\end{array}$

$\begin{array}{llll}922 & 4.0 & 28.28 & 13.3\end{array}$

$\begin{array}{lllll}921 & 5.0 & 28.53 & 13.3\end{array}$

$\begin{array}{lllll}8 & 939 & .0 & 12.14 & 14.1\end{array}$

$\begin{array}{llll}938 & 1.0 & 18.58 & 13.8\end{array}$

$\begin{array}{llll}937 & 2.0 & 21.49 & 13.4\end{array}$

$\begin{array}{llll}936 & 4.0 & 26.83 & 13.3\end{array}$

$\begin{array}{lllll}935 & 6.0 & 28.09 & 13.3\end{array}$

$\begin{array}{lllll}10 & 1009 & .0 & 9.36 & 14.8\end{array}$

$\begin{array}{llll}1008 & 1.0 & 16.98 & 13.9\end{array}$

$\begin{array}{llll}1007 & 2.0 & 22.27 & 13.5\end{array}$

$\begin{array}{llll}1006 & 4.0 & 25.13 & 13.3\end{array}$

$\begin{array}{llll}1005 & 6.0 & 26.74 & 13.4\end{array}$

$\begin{array}{lllll}12 & 1021 & .0 & 13.29 & 14.9\end{array}$

$\begin{array}{llll}1020 & 1.0 & 17.11 & 13.6\end{array}$

$\begin{array}{llll}1019 & 2.0 & 21.96 & 13.5\end{array}$

$\begin{array}{llll}1018 & 4.0 & 24.44 & 13.3\end{array}$

$\begin{array}{llll}1017 & 5.5 & 24.79 & 13.3\end{array}$

$\begin{array}{lllll}14 & 1043 & .0 & 12.60 & 14.8\end{array}$

$\begin{array}{llll}1042 & 1.0 & 17.85 & 13.8\end{array}$

$\begin{array}{llll}1041 & 2.0 & 22.49 & 13.5\end{array}$

$\begin{array}{llll}1040 & 4.0 & 23.89 & 13.5\end{array}$

$\begin{array}{lllll}16 & 1053 & .0 & 5.76 & 15.0\end{array}$

$\begin{array}{lllll}1052 & 1.0 & 20.7 & 13.7\end{array}$

$\begin{array}{llll}1051 & 2.0 & 22.86 & 13.6\end{array}$

$\begin{array}{lllll}18 & 1114 & .0 & 5.31 & 15.6\end{array}$

$\begin{array}{llll}1113 & .5 & 6.51 & 15.7\end{array}$ $\begin{array}{lllllllllllll}1.2 & .2 & 1.13 & 7.3 & .32 & 10.00 & 1.09 & 75.9 & 4.36 & 19.93 & 1.05 & 3.0 & 21.6\end{array}$

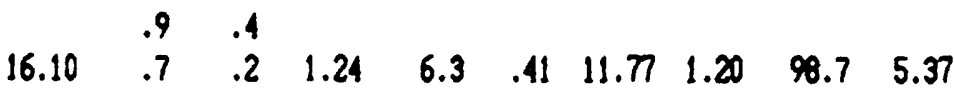

$\begin{array}{rrrrrrrrrrrrrr} & & 1.2 & .6 & & & & & & & \end{array}$

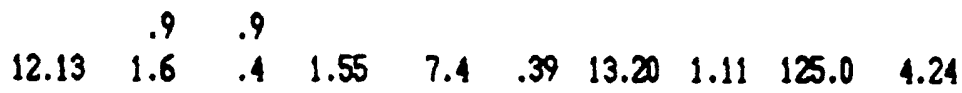

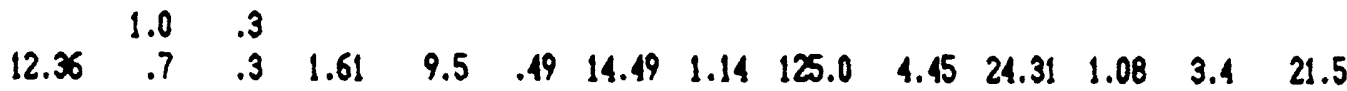

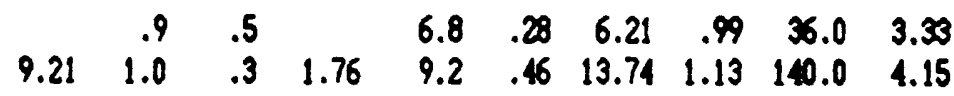

3.120 .4

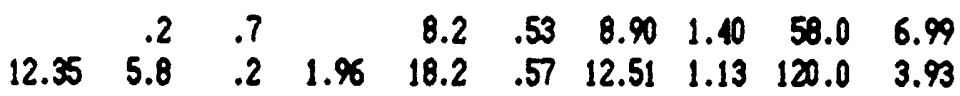

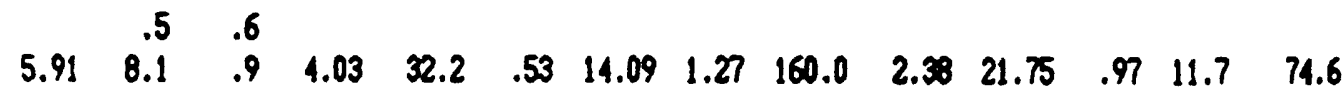

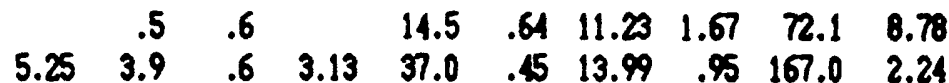

$4.7 \quad 28.8$

4.431 .4 


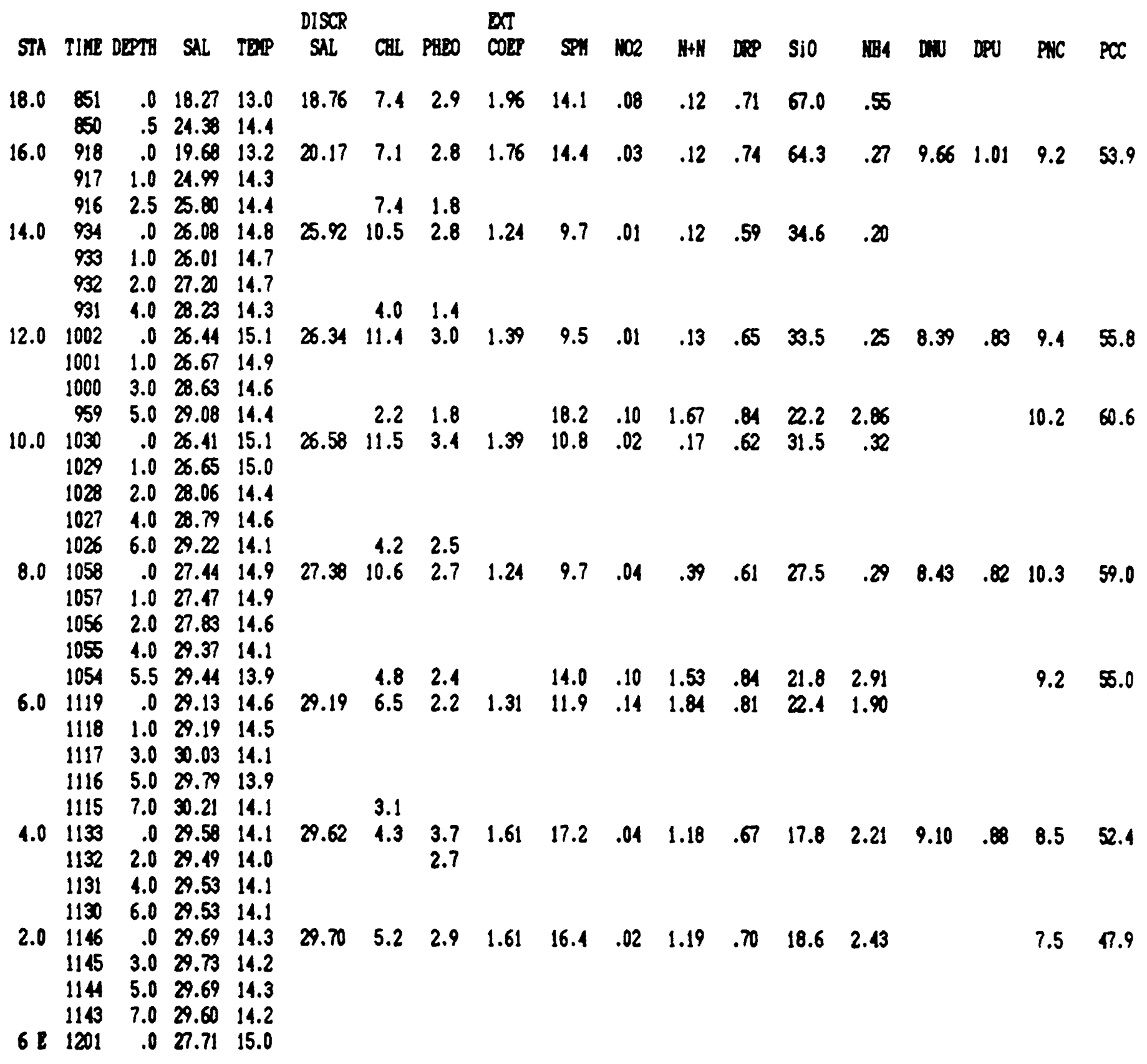




\begin{tabular}{|c|c|c|c|c|c|c|c|c|c|c|c|c|c|c|c|c|c|c|}
\hline STA & TIME & & SAL & TEXP & $\begin{array}{l}\text { DISCR } \\
\text { SAL }\end{array}$ & CHL & PHED & $\begin{array}{l}\mathbb{E X I} \\
\text { CDEP }\end{array}$ & SPH & 102 & $\mathbf{H}+\mathbf{N}$ & DRP & Sio & NHA & DNo & DPU & PIC & $P C C$ \\
\hline \multirow[t]{5}{*}{0} & 904 & .0 & 32.01 & 12.6 & 31.92 & 9.7 & 3.0 & 1.13 & 12.4 & & 7.29 & .82 & 13.5 & .51 & 11.11 & .93 & 6.6 & 40.4 \\
\hline & 903 & 2.0 & 32.10 & 12.5 & & & & & & & & & & & & & & \\
\hline & 902 & 4.0 & 32.10 & 12.5 & & & & & & & & & & & & & & \\
\hline & 901 & 6.0 & 32.01 & 12.5 & & & & & & & & & & & & & & \\
\hline & 900 & 8.0 & 32.10 & 12.5 & & 8.8 & 2.9 & & & & & & & & & & & \\
\hline \multirow[t]{5}{*}{2} & 933 & .0 & 31.31 & 12.9 & 32.12 & 10.3 & 2.8 & 1.24 & 16.3 & & 3.38 & .56 & 9.2 & 2.47 & & & & \\
\hline & 932 & 1.0 & 31.92 & 12.7 & & & & & & & & & & & & & & \\
\hline & $93 !$ & 3.0 & 31.92 & 12.8 & & & & & & & & & & & & & & \\
\hline & 930 & 5.0 & 32.01 & 12.6 & & & & & & & & & & & & & & \\
\hline & 929 & 7.0 & 31.83 & 12.6 & & 8.1 & 2.8 & & & & & & & & & & & \\
\hline \multirow[t]{5}{*}{4} & 949 & .0 & 30.23 & 14.4 & 30.33 & 9.0 & 3.7 & 1.85 & 25.3 & & .71 & .38 & 2.2 & .13 & 6.25 & .63 & 11.4 & $\pi .6$ \\
\hline & 948 & 2.0 & 30.26 & 14.3 & & & & & & & & & & & & & 11. & \\
\hline & 947 & 4.0 & 30.63 & 14.0 & & & & & & & & & & & & & & \\
\hline & 946 & 6.0 & 31.09 & 13.7 & & & & & & & & & & & & & & \\
\hline & 945 & 8.0 & 31.28 & 13.4 & & 10.6 & 2.9 & & & & & & & & & & & \\
\hline \multirow[t]{5}{*}{6} & 1004 & .0 & 29.90 & 14.7 & 29.85 & 10.6 & 3.1 & 1.13 & 9.2 & & .24 & .46 & 4.2 & .00 & & & 7.4 & 46.9 \\
\hline & 1003 & 2.0 & 29.95 & 14.6 & & & & & & & & & & & & & & \\
\hline & 1002 & 4.0 & 32.33 & 12.4 & & & & & & & & & & & & & & \\
\hline & 1001 & 6.0 & 33.07 & 11.5 & & & & & & & & & & & & & & \\
\hline & 1000 & 8.0 & 33.10 & 11.3 & & 6.6 & 2.1 & & & & & & & & & & & \\
\hline \multirow[t]{4}{*}{8} & 1013 & .0 & 29.53 & 15.1 & 32.50 & 11.3 & 2.2 & 1.61 & 8.5 & & .16 & .53 & 8.1 & .02 & 5.68 & .77 & 8.8 & 5.4 \\
\hline & 1012 & 1.0 & 29.71 & 14.9 & & & & & & & & & & & & & & \\
\hline & 1011 & 3.0 & 32.41 & 12.3 & & & & & & & & & & & & & & \\
\hline & 1010 & 5.0 & 32.88 & 11.7 & & 6.8 & 2.0 & & 6.4 & & 11.00 & 1.06 & 18.0 & 1.02 & & & 6.6 & 37.5 \\
\hline \multirow[t]{4}{*}{10} & 1023 & .0 & 29.40 & 15.2 & 29.37 & 10.2 & 2.3 & 1.18 & 7.9 & & .15 & .56 & 8.5 & .00 & & & & \\
\hline & 1022 & 2.0 & 30.12 & 14.5 & & & & & & & & & & & & & & \\
\hline & 1021 & 4.0 & 32.33 & 12.5 & & & & & & & & & & & & & & \\
\hline & 1020 & 6.0 & 32.52 & 12.3 & & 4.5 & 3.0 & & & & & & & & & & & \\
\hline \multirow[t]{4}{*}{12} & 1043 & .0 & 29.04 & 15.3 & 28.80 & 8.0 & 1.7 & 1.21 & 7.1 & & .15 & .68 & 18.7 & .12 & 4.89 & .90 & 8.4 & 48.9 \\
\hline & 1042 & 2.0 & 29.34 & 15.0 & & & & & & & & & & & & & & \\
\hline & 1041 & 3.0 & 30.82 & 14.1 & & & & & & & & & & & & & & \\
\hline & 1040 & 5.0 & 32.05 & 13.0 & & 3.4 & 1.4 & & 6.4 & & 8.19 & 1.22 & 21.7 & 3.02 & & & 4.3 & 24.9 \\
\hline \multirow[t]{3}{*}{14} & 1103 & .0 & 20.46 & 15.4 & 20.33 & 4.4 & 1.3 & 1.44 & 6.7 & & 1.40 & .96 & 37.3 & 2.18 & & & & \\
\hline & 1102 & 2.0 & 31.14 & 14.4 & & & & & & & & & & & & & & \\
\hline & 1101 & 3.5 & 31.92 & 13.4 & & 1.8 & 2.1 & & & & & & & & & & & \\
\hline \multirow[t]{3}{*}{16} & 1117 & .0 & 23.57 & 15.7 & 23.51 & 5.5 & 1.3 & 1.44 & 8.6 & & 1.29 & .9 & 49.2 & 1.63 & 10.47 & 1.15 & 7.3 & 41.6 \\
\hline & 1116 & 1.0 & 29.59 & 14.9 & & & & & & & & & & & & & & \\
\hline & 1115 & 2.0 & 30.82 & 13.9 & & 2.1 & 1.6 & & & & & & & & & & & \\
\hline 18 & 1130 & .0 & 22.99 & 16.5 & 22.04 & 9.1 & 2.7 & 2.22 & 14.3 & & 1.36 & .87 & 56.2 & 1.29 & & & & \\
\hline
\end{tabular}




\begin{tabular}{|c|c|c|c|c|c|c|c|c|c|c|c|c|c|c|c|c|c|c|}
\hline STh & TIKE & EPTH & SAL & TER & $\begin{array}{c}\text { DISCR } \\
\text { SAL }\end{array}$ & CAI & PALD & $\begin{array}{l}D X I \\
\text { CoPR }\end{array}$ & SPH & 1902 & $\mathrm{H}+\mathrm{H}$ & DPP & SiO & IBB & Div & DPO & PIX & $P C C$ \\
\hline \multirow[t]{5}{*}{0} & 922 & .0 & 33.33 & 11.4 & 33.39 & 15.4 & 6.0 & 1.13 & 17.3 & .26 & 8.75 & .90 & 16.2 & .90 & 15.00 & 1.02 & 10.5 & 64.3 \\
\hline & 921 & 2.0 & 33.30 & 11.4 & & & & & & & & & & & & & & \\
\hline & 920 & 4.0 & 33.35 & 11.4 & & & & & & & & & & & & & & \\
\hline & 919 & 6.0 & 33.34 & 11.4 & & & & & & & & & & & & & & \\
\hline & 918 & 8.0 & 33.30 & 11.2 & & & & & & & & & & & & & & \\
\hline \multirow[t]{4}{*}{2} & 938 & .0 & 33.30 & 11.8 & 33.21 & 16.8 & 5.8 & 1.24 & 14.9 & .19 & 5.07 & .63 & 10.3 & .52 & & & & \\
\hline & 937 & 2.0 & 33.12 & 11.8 & & & & & & & & & & & & & & \\
\hline & 936 & 4.0 & 33.26 & 11.8 & & & & & & & & & & & & & & \\
\hline & 935 & 6.0 & 33.28 & 11.9 & & 15.2 & 7.1 & & & & & & & & & & & \\
\hline \multirow[t]{4}{*}{4} & 951 & .0 & 32.75 & 12.3 & 33.05 & 16.1 & 5.9 & 1.24 & 14.5 & .19 & 4.13 & .67 & 9.5 & .60 & 11.80 & .88 & 11.5 & 69.4 \\
\hline & 950 & 2.0 & 32.76 & 12.2 & & & & & & & & & & & & & & \\
\hline & 949 & 4.0 & 33.01 & 12.3 & & & & & & & & & & & & & & \\
\hline & 948 & 5.0 & 32.86 & 12.2 & & 16.3 & 5.0 & & & & & & & & & & & \\
\hline \multirow[t]{5}{*}{6} & 1012 & .0 & 31.73 & 14.4 & 31.87 & 5.3 & 3.5 & 1.21 & 9.9 & .13 & .40 & .62 & .9 & .13 & & & & \\
\hline & 1011 & 2.0 & 32.25 & 13.3 & & & & & & & & & & & & & & \\
\hline & 1010 & 4.0 & 32.59 & 13.0 & & & & & & & & & & & & & & \\
\hline & 1009 & 6.0 & 33.33 & 11.1 & & & & & & & & & & & & & & \\
\hline & 1008 & 7.0 & 33.35 & 11.0 & & 10.6 & 3.7 & & & & & & & & & & & \\
\hline \multirow[t]{3}{*}{8} & 1035 & .0 & 30.71 & 15.0 & 30.83 & 2.6 & 1.5 & 1.08 & 8.0 & .11 & .27 & .86 & .6 & .55 & 8.75 & 1.23 & 4.7 & 33.5 \\
\hline & 1034 & 2.0 & 31.62 & 14.0 & & & & & & & & & & & & & & \\
\hline & 1033 & 4.0 & 32.47 & 13.1 & & 17.6 & 7.0 & & & & & & & & & & & \\
\hline \multirow[t]{4}{*}{10} & 1059 & .0 & 30.59 & 15.0 & 30.58 & 2.7 & 1.6 & 1.18 & 7.7 & .11 & .23 & .93 & .8 & .42 & & & & \\
\hline & 1058 & 2.0 & 30.66 & 14.1 & & & & & & & & & & & & & & \\
\hline & 1057 & 4.0 & 31.59 & 14.0 & & & & & & & & & & & & & & \\
\hline & 1056 & 6.0 & 32.70 & 12.7 & & 16.8 & 6.7 & & & & & & & & & & & \\
\hline \multirow[t]{2}{*}{12} & $\begin{array}{l}1116 \\
1115\end{array}$ & $\begin{array}{r}.0 \\
2.0\end{array}$ & $\begin{array}{l}30.11 \\
30.91\end{array}$ & $\begin{array}{l}14.9 \\
14.8\end{array}$ & 30.33 & 2.9 & 1.5 & 1.13 & 9.5 & .11 & .22 & 1.06 & .9 & .58 & 8.12 & 1.34 & 5.3 & 36.2 \\
\hline & 1114 & 4.0 & 31.58 & 14.4 & & 5.1 & 2.3 & & 11.7 & .09 & .28 & .80 & 1.9 & .63 & & & 6.9 & 45.6 \\
\hline \multirow[t]{3}{*}{14} & 1155 & .0 & 29.61 & 15.5 & 29.63 & 3.3 & 1.5 & 1.31 & 11.6 & .11 & .25 & .99 & 2.1 & .41 & & & & \\
\hline & 1154 & 2.0 & 30.18 & 14.4 & & & & & & & & & & & & & & \\
\hline & 1153 & 4.0 & 31.20 & 14.7 & & 2.9 & 1.7 & & & & & & & & & & & \\
\hline \multirow[t]{2}{*}{16} & 1208 & .0 & 20.80 & 15.5 & 26.67 & 4.1 & 1.9 & 1.61 & 16.0 & .09 & .21 & .82 & 8.5 & .25 & 11.30 & 1.43 & 8.0 & 56.7 \\
\hline & 1207 & 2.0 & 30.30 & 15.1 & & 2.9 & 1.9 & & 16.6 & .07 & .49 & 1.07 & 3.2 & 1.01 & & & 7.4 & 53.8 \\
\hline 17 & 1240 & .0 & $\mathbf{2 5 . 6 1}$ & 17.1 & & & & & 16.9 & .11 & .50 & .94 & 24.0 & .60 & & & & \\
\hline
\end{tabular}




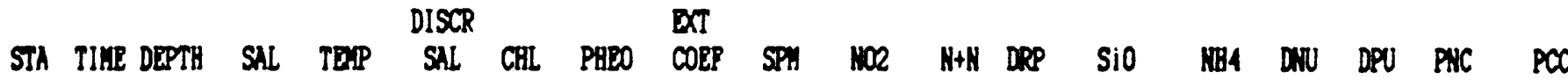

\begin{tabular}{|c|c|c|c|c|c|c|c|c|c|c|c|c|c|c|c|c|c|c|}
\hline 18 & 745 & .5 & 29.03 & 14.7 & 29.01 & 12.0 & 4.7 & 4.03 & 53.1 & .15 & .25 & 1.05 & 24.0 & .69 & & & & \\
\hline 16 & $\begin{array}{l}757 \\
756\end{array}$ & $\begin{array}{r}.0 \\
3.0\end{array}$ & $\begin{array}{l}30.36 \\
30.65\end{array}$ & $\begin{array}{l}15.5 \\
15.6\end{array}$ & 30.49 & $\begin{array}{l}9.1 \\
6.3\end{array}$ & $\begin{array}{l}3.0 \\
3.5\end{array}$ & 2.82 & $\begin{array}{l}24.5 \\
30.3\end{array}$ & $\begin{array}{l}.16 \\
.13\end{array}$ & $\begin{array}{l}.29 \\
.29\end{array}$ & $\begin{array}{l}1.07 \\
1.04\end{array}$ & $\begin{array}{l}19.9 \\
17.7\end{array}$ & $\begin{array}{l}.91 \\
.89\end{array}$ & 10.70 & 1.10 & $\begin{array}{l}12.2 \\
11.0\end{array}$ & $\begin{array}{r}87.7 \\
111.0\end{array}$ \\
\hline 14 & $\begin{array}{l}824 \\
826 \\
825 \\
823\end{array}$ & $\begin{array}{r}.0 \\
1.0 \\
2.0 \\
3.5\end{array}$ & $\begin{array}{l}31.26 \\
31.37 \\
31.55 \\
32.07\end{array}$ & $\begin{array}{l}15.8 \\
15.8 \\
15.8 \\
15.4\end{array}$ & 31.46 & 5.1 & 1.6 & 1.31 & 9.5 & .16 & .36 & 1.04 & 15.9 &.$\pi$ & & & & \\
\hline 12 & $\begin{array}{l}845 \\
844 \\
843\end{array}$ & $\begin{array}{r}.0 \\
1.0 \\
3.0\end{array}$ & $\begin{array}{l}31.88 \\
31.98 \\
32.05\end{array}$ & $\begin{array}{l}15.5 \\
15.5 \\
15.5\end{array}$ & 32.16 & 3.5 & 1.9 & 1.31 & 8.8 & .13 & .37 & .89 & 14.2 & .67 & 8.03 & 1.10 & 6.1 & 40.0 \\
\hline & 842 & 5.0 & $\begin{array}{l}33.59 \\
30>0\end{array}$ & $\begin{array}{l}15.0 \\
15 ?\end{array}$ & & 2.2 & 1.3 & & 7.5 & .16 & .94 & .93 & 16.3 & 1.14 & & & 5.3 & 38.1 \\
\hline 10 & $\begin{array}{l}933 \\
932 \\
931 \\
031\end{array}$ & $\begin{array}{r}.0 \\
2.0 \\
4.0\end{array}$ & $\begin{array}{l}32.39 \\
32.49 \\
32.53 \\
\end{array}$ & $\begin{array}{l}15.3 \\
15.1 \\
14.9\end{array}$ & 32.44 & 4.9 & 2.0 & 1.01 & 5.3 & & & & 15.7 & .89 & & & & \\
\hline 8 & $\begin{array}{l}950 \\
949 \\
948 \\
947\end{array}$ & $\begin{array}{r}6.0 \\
.0 \\
1.0 \\
3.0\end{array}$ & $\begin{array}{l}32.62 \\
32.44 \\
32.62 \\
32.32\end{array}$ & $\begin{array}{l}14.0 \\
15.0 \\
15.0 \\
14.9\end{array}$ & $32.5 !$ & $\begin{array}{l}3.2 \\
6.2\end{array}$ & $\begin{array}{l}2.6 \\
2.0\end{array}$ & 1.13 & 6.1 & .16 & 1.51 & .84 & 16.0 & .75 & 10.80 & 1.13 & 7.2 & 4.7 \\
\hline 6 & $\begin{array}{r}946 \\
1011 \\
1010\end{array}$ & $\begin{array}{r}5.0 \\
.0 \\
2.0\end{array}$ & $\begin{array}{l}33.04 \\
32.99 \\
33.12\end{array}$ & $\begin{array}{l}13.8 \\
13.9 \\
13.7\end{array}$ & 33.04 & $\begin{array}{r}6.6 \\
11.1\end{array}$ & $\begin{array}{l}3.9 \\
3.8\end{array}$ & 1.49 & $\begin{array}{l}12.9 \\
12.3\end{array}$ & .22 & $\begin{array}{l}4.25 \\
5.29\end{array}$ & $\begin{array}{r}1.04 \\
.87\end{array}$ & $\begin{array}{l}19.6 \\
19.9\end{array}$ & $\begin{array}{r}1.29 \\
.00\end{array}$ & 12.90 & .93 & 9.3 & 62.7 \\
\hline
\end{tabular}


Appendix B.

Hydrographic and Nutrient Data for

Walker and Lagunitas Creeks 


\section{WLLER CRERI DATA SUAARY}

\begin{tabular}{|c|c|c|c|c|c|c|c|c|c|c|c|c|}
\hline \multirow{2}{*}{ DATE } & \multicolumn{4}{|c|}{ DISCR } & \multirow[b]{2}{*}{$N+N$} & \multirow[b]{2}{*}{ DRP } & \multirow[b]{2}{*}{ SiO } & \multirow[b]{2}{*}{ KBA } & \multirow[b]{2}{*}{ WW } & \multirow[b]{2}{*}{ DPO } & \multirow[b]{2}{*}{ PUC } & \multirow[b]{2}{*}{$P C C$} \\
\hline & TIKe & SAL & SPHI & 1002 & & & & & & & & \\
\hline 11 MR 85 & & & 69.3 & 1.23 & 27.00 & 3.79 & 139.0 & 10.50 & & & 16.5 & 177.0 \\
\hline $8 A P R 85$ & & & 9.1 & .43 & 31.20 & 2.46 & 156.0 & 1.90 & & & 4.9 & 38.5 \\
\hline 17 APR 85 & & & 7.8 & .70 & 47.80 & 6.04 & 122.0 & 1.40 & 78.30 & 7.63 & 3.4 & 31.2 \\
\hline 17 MY 85 & & & 5.0 & .22 & 1.00 & 6.07 & 80.3 & 2.40 & & & 2.3 & 22.6 \\
\hline 11 JW 85 & & .70 & 4.6 & .20 & 2.10 & 2.63 & 140.0 & 2.00 & 23.40 & 3.02 & 1.8 & 19.1 \\
\hline 16 JUL 85 & & 4.50 & 6.7 & .23 & 1.10 & 2.28 & 129.0 & 1.80 & & & 3.2 & 28.3 \\
\hline 21 AUG 85 & & .60 & 3.7 & .23 & .90 & 2.00 & 139.0 & 1.70 & 22.80 & 2.49 & 1.5 & 15.6 \\
\hline 30 SEP 85 & & 14.40 & 7.1 & .16 & .80 & 1.48 & 58.0 & 1.40 & 16.20 & $1.7 \pi$ & 5.5 & 34.3 \\
\hline 4 DEC 85 & 1430 & & 13.2 & 1.08 & 71.40 & 2.24 & 162.0 & 3.60 & 64.50 & 2.60 & 2.6 & 21.9 \\
\hline 29 JAH 86 & & & 13.9 & & & & & & & & 4.7 & 54.4 \\
\hline 5 PEB 86 & & & 87.8 & .93 & 49.90 & 3.41 & 173.0 & 6.00 & 53.20 & 3.76 & 14.1 & 162.0 \\
\hline$B B 86$ & 1710 & & 960.0 & 1.52 & 32.50 & 5.84 & 160.0 & 17.20 & & & 82.2 & 999.0 \\
\hline 19 VIRR 86 & & & 140.0 & & 38.20 & 4.28 & 187.0 & 5.70 & 53.80 & 5.19 & 17.3 & 161.0 \\
\hline 2 APR 86 & 1445 & & 18.9 & & 17.50 & 4.26 & 152.0 & .80 & 39.40 & 5.20 & 3.7 & 25.6 \\
\hline 16 APR \&6 & & & 20.6 & & 22.40 & 5.04 & 73.6 & .60 & 57.60 & 8.33 & 14.5 & 105.0 \\
\hline $30 A$ & 1500 & .50 & 17.6 & .92 & 11.20 & 4.83 & 118.0 & 1.30 & 53.20 & 7.49 & 14.0 & 102.0 \\
\hline & & .40 & 9.7 & .16 & 1.60 & 1.87 & 111.0 & 3.30 & 33.50 & 2.97 & 6.9 & 46.9 \\
\hline 1 JUL 8 & & 1.00 & 7.0 & .11 & .70 & 1.19 & 112.0 & 1.70 & & & & \\
\hline 27 AUG 86 & & 1.00 & 14.6 & .10 & .70 & 1.44 & 149.0 & 1.70 & & & & \\
\hline $100 T 86$ & & 14.60 & 11.0 & .07 & .80 &.$\%$ & 82.2 & .80 & & & & \\
\hline
\end{tabular}




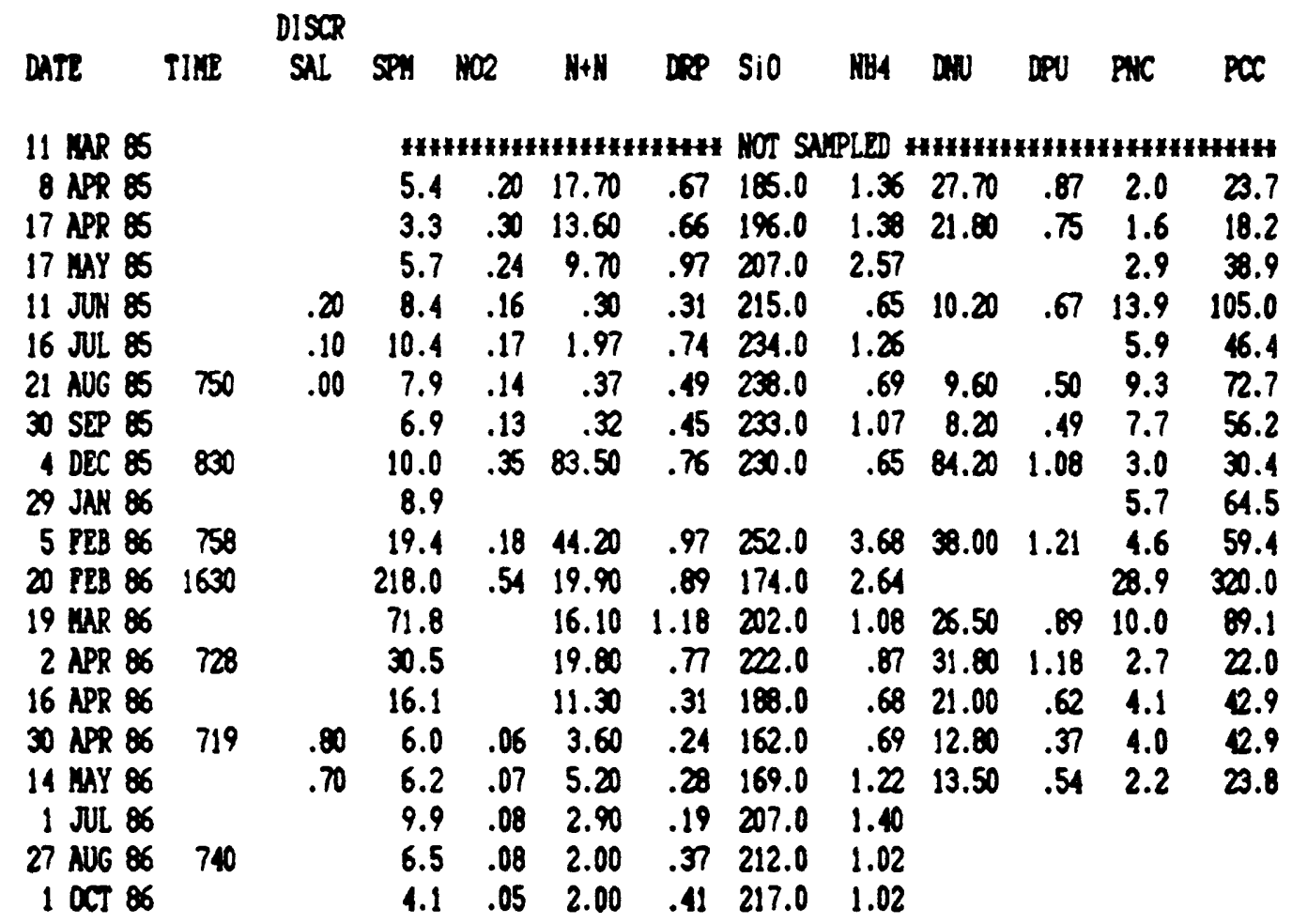


Appendix C.

Phytoplankton Productivity Data 
CARBON UPTAKE DATA SUIAARY

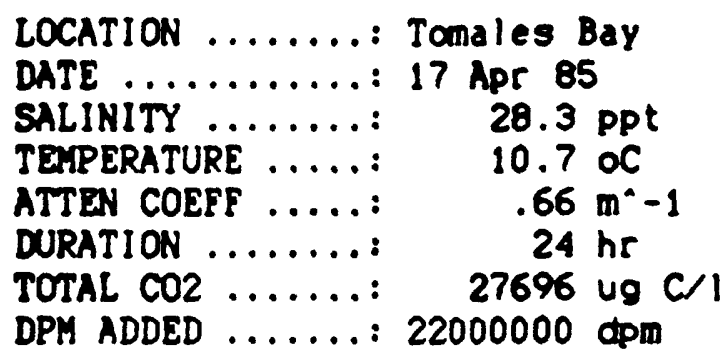

\begin{tabular}{|c|c|}
\hline 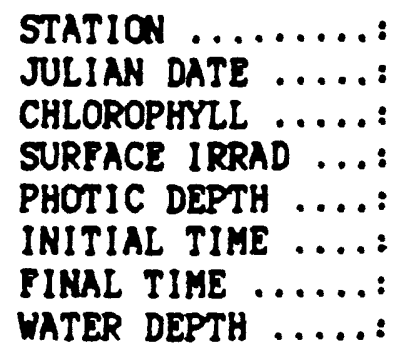 & $\begin{array}{l}2 \\
85107 \\
8.48 \mathrm{mg} / \mathrm{m}^{\wedge} 3 \\
46.63 \mathrm{E} / \mathrm{m}^{\wedge} 2 / \mathrm{d} \\
6.98 \mathrm{~m} \\
1340 \mathrm{hr} \\
1340 \mathrm{hr} \\
3.6 \mathrm{~m}\end{array}$ \\
\hline
\end{tabular}

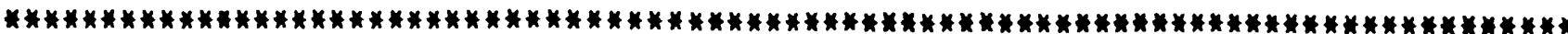

$\begin{array}{ccrrrr}\begin{array}{c}\text { DEPTH } \\ \mathrm{m}\end{array} & \text { LIGHT } & \begin{array}{r}\text { LIGHT } \\ \text { E/m²/d }\end{array} & \begin{array}{r}\text { CARBON UPTAKE } \\ \text { corrected } \\ \text { mg C/L/h }\end{array} & \begin{array}{c}\text { ASSIMILATION } \\ \text { mg } / L / h\end{array} & \\ .00 & 100 & 46.63 & 26.69 & 26.84 & 3.15 \\ .93 & 54.2 & 25.27 & 27.53 & 27.68 & 3.25 \\ 1.76 & 31.3 & 14.59 & 29.81 & 29.95 & 3.51 \\ 2.93 & 14.5 & 6.76 & 12.85 & 13.00 & 1.51 \\ 3.83 & 7.97 & 3.72 & 6.30 & 6.44 & .74 \\ 4.75 & 4.35 & 2.03 & 2.43 & 2.58 & .29 \\ 6.06 & 1.83 & .85 & .84 & .99 & .10 \\ 6.98 & \text { DARK BOTTLE } & .05 & .00 & .15 & .00\end{array}$

$\begin{array}{rc}\text { Uptake over photlc zone } & 89.08 \mathrm{mg} \mathrm{C/m} \cdot 2 / \mathrm{h} \\ \text { water depth } & 80.00 \\ & \\ \text { photle zone } & 2138 \mathrm{mg} \mathrm{C/m} \cdot 2 / \mathrm{d} \\ \text { water depth } & 1920\end{array}$


CARBON UPTAKE DATA SUMMARY

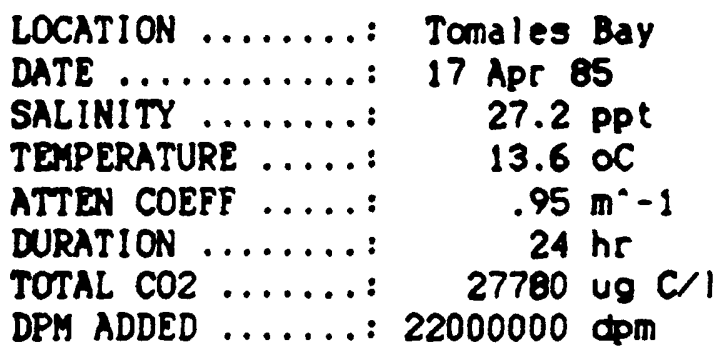
STATION ........ 8
JULIAN DATE .....: 85107
CHLOROPHYLL .....: $8.98 \mathrm{mg} / \mathrm{m}^{\circ} 3$
SURFACE IRRAD ...: $\quad 46.63 \mathrm{E} / \mathrm{m}^{\star} 2 / \mathrm{d}$
PHOTIC DEPTH ....: $4.87 \mathrm{~m}$
INITIAL TIME ....: $1340 \mathrm{hr}$
FINAL TIME ......: $1340 \mathrm{hr}$
WATER DEPTH .....: 6 m

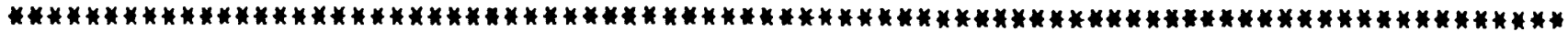

\begin{tabular}{|c|c|c|c|c|c|}
\hline \multirow[b]{2}{*}{$\begin{array}{l}\text { DEPTH } \\
\mathbf{m}\end{array}$} & \multirow[b]{2}{*}{$\underset{t}{\text { LIGHT }}$} & \multirow[b]{2}{*}{$\begin{array}{r}\text { LIGHT } \\
\mathrm{E} / \mathrm{m}^{\circ} 2 / d\end{array}$} & \multicolumn{2}{|c|}{ CARBON UPTAKE } & \multirow{2}{*}{ ASSIMILATION } \\
\hline & & & $\begin{array}{c}\text { corrected } \\
\text { mg } \mathrm{C} / \mathrm{L} / \mathrm{h}\end{array}$ & $\begin{array}{l}\text { measured } \\
\text { mg } C / L / h\end{array}$ & \\
\hline $\begin{array}{l}.00 \\
.60 \\
1.20 \\
1.89 \\
2.50 \\
3.23 \\
3.91 \\
4.87\end{array}$ & $\begin{array}{r}100 \\
56.8 \\
32.3 \\
16.7 \\
9.38 \\
4.73 \\
2.48 \\
\text { DARK BOTTLE }\end{array}$ & $\begin{array}{r}46.63 \\
26.49 \\
15.06 \\
7.79 \\
4.37 \\
2.21 \\
1.16 \\
.05\end{array}$ & $\begin{array}{r}29.10 \\
30.68 \\
29.84 \\
19.17 \\
11.25 \\
4.79 \\
3.09 \\
.00\end{array}$ & $\begin{array}{r}29.24 \\
30.82 \\
29.98 \\
19.31 \\
11.39 \\
4.93 \\
3.23 \\
.14\end{array}$ & $\begin{array}{l}3.24 \\
3.42 \\
3.32 \\
2.14 \\
1.25 \\
.53 \\
.34 \\
.00\end{array}$ \\
\hline
\end{tabular}

Uptake over photic zone

$72.35 \mathrm{mg} \mathrm{C} / \mathrm{m} \cdot 2 / \mathrm{h}$ water depth

72.35

photic zone

$1736 \mathrm{mg} C / \mathrm{m}^{\bullet 2} / d$

water depth

1736 
CARBON UPTAKE DATA SUMMARY

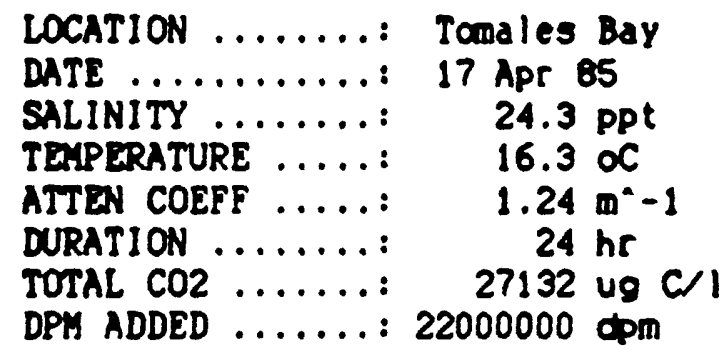

STATION ..........

JULIAN DATE .....8: 85107

CHLOROPHYLL .....: $\quad 1.94 \mathrm{mg} / \mathrm{m} * 3$

SURPACE IRRAD ...: $46.63 \mathrm{E} / \mathrm{m}^{*} 2 / \mathrm{d}$

PHOTIC DEPTH ....: $\quad 3.71 \mathrm{~m}$

INITIAL TIME ....: $\quad 1340 \mathrm{hr}$

FINAL TIME ......: $1340 \mathrm{hr}$

WATER DEPTH .....: $1 \mathrm{~m}$

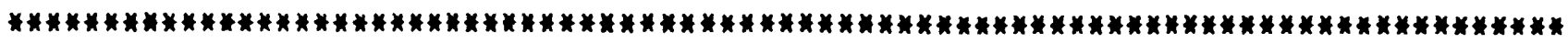

\begin{tabular}{|c|c|c|c|c|c|}
\hline & & & CARBON & PTAKE & ASSIHI \\
\hline $\begin{array}{l}\text { DEPTH } \\
\mathbf{n}\end{array}$ & $\underset{*}{\text { LIGHT }}$ & $\begin{array}{r}\text { LIGHT } \\
\mathrm{E} / \mathrm{m}^{\wedge} 2 / \mathrm{d}\end{array}$ & $\begin{array}{l}\text { corrected } \\
\text { mg chloh }\end{array}$ & $\begin{array}{l}\text { measured } \\
\text { mo c/Lh }\end{array}$ & 1 \\
\hline $\begin{array}{l}.00 \\
.49 \\
.94 \\
1.50 \\
1.99 \\
2.47 \\
3.22 \\
3.71\end{array}$ & $\begin{array}{r}100 \\
54.8 \\
31.3 \\
15.5 \\
8.5 \\
4.65 \\
1.85 \\
\text { DARK BOTTLE }\end{array}$ & $\begin{array}{r}46.63 \\
25.55 \\
14.59 \\
7.23 \\
3.96 \\
2.17 \\
.86 \\
.05\end{array}$ & $\begin{array}{l}5.91 \\
7.10 \\
7.00 \\
4.65 \\
2.50 \\
1.62 \\
1.47 \\
.00\end{array}$ & $\begin{array}{l}5.98 \\
7.17 \\
7.08 \\
4.73 \\
2.57 \\
1.69 \\
1.54 \\
.08\end{array}$ & $\begin{array}{l}3.05 \\
3.66 \\
3.61 \\
2.40 \\
1.29 \\
.83 \\
.76 \\
.00\end{array}$ \\
\hline
\end{tabular}

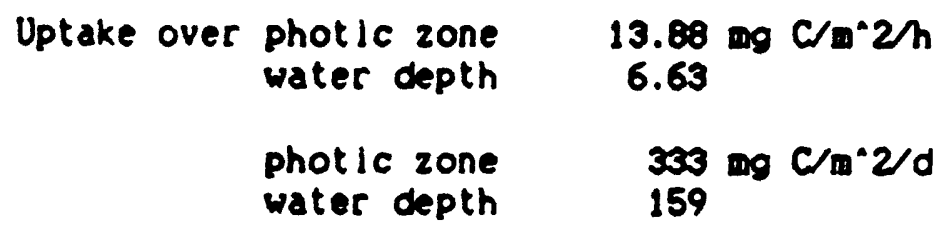


CARBON UPTAKE DATA SUMMARY

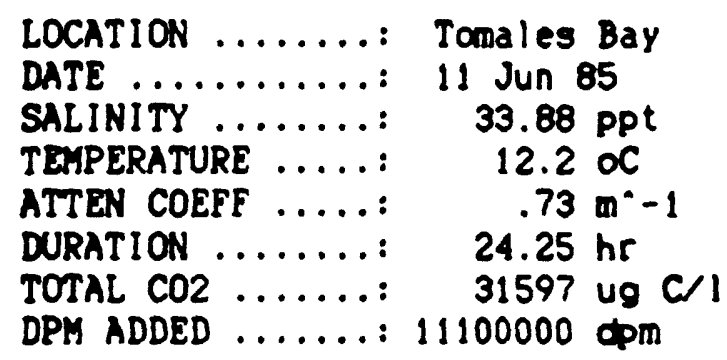
STATION
JULIAN DATE
2
CHLOROPHYLL
SURFACE IRRAD
85162
PHOTIC DEPTH
$5.7 \mathrm{mg} / \mathrm{m}^{\wedge} 3$
INITIAL TIME
$50.36 \mathrm{E} / \mathrm{m}^{\wedge} 2 / 0$
$6.31 \mathrm{~m}$
$1430 \mathrm{hr}$
FIMAL TIME .......
$1445 \mathrm{hr}$
WATER DEPTH .....: $\quad 3.6 \mathrm{~m}$

\begin{tabular}{|c|c|c|c|c|c|}
\hline $\begin{array}{c}\text { DEPTH } \\
m\end{array}$ & $\underset{*}{\mathrm{LIGHT}}$ & $\begin{array}{r}\text { LIGHT } \\
E / m^{\circ} 2 / d\end{array}$ & $\begin{array}{l}\text { CARBOH } \\
\text { corrected } \\
\text { mg C/L/h }\end{array}$ & $\begin{array}{l}\text { JPTAKE } \\
\text { measured } \\
\text { mg } C / L / h\end{array}$ & ASSIMILATION \\
\hline $\begin{array}{l}.00 \\
.82 \\
1.59 \\
2.55 \\
3.38 \\
4.20 \\
5.47 \\
6.31\end{array}$ & $\begin{array}{c}100 \\
54.8 \\
31.3 \\
15.5 \\
8.5 \\
4.65 \\
1.85 \\
\text { DARK BOTTLE }\end{array}$ & $\begin{array}{r}50.36 \\
27.60 \\
15.76 \\
7.81 \\
4.28 \\
2.34 \\
.93 \\
.05\end{array}$ & $\begin{array}{r}182.25 \\
166.59 \\
135.93 \\
40.33 \\
15.90 \\
8.75 \\
2.77 \\
.00\end{array}$ & $\begin{array}{r}182.68 \\
167.02 \\
136.36 \\
40.75 \\
16.33 \\
9.18 \\
3.20 \\
.43\end{array}$ & $\begin{array}{r}31.97 \\
29.23 \\
23.85 \\
7.07 \\
2.79 \\
1.53 \\
.49 \\
.00\end{array}$ \\
\hline
\end{tabular}

\footnotetext{
Uptake over photic zone $\quad 386.38 \mathrm{mg} \mathrm{C/m²/h}$ water depth 370.18

Photic zone $9273 \mathrm{mg} \mathrm{C/m} 2 / d$ water depth $\mathbf{8 8 8 4}$
} 
CARBON UPTAKE DATA SUMAARY

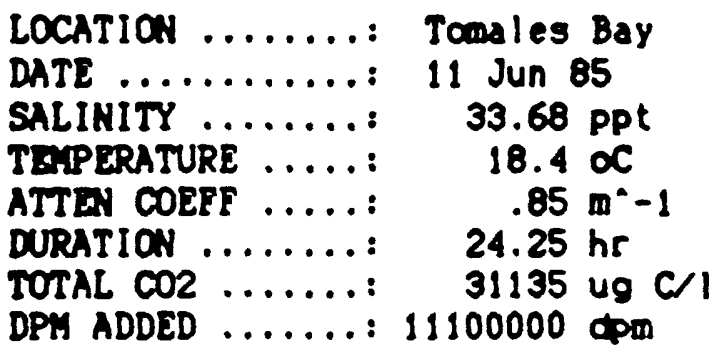
STATION ......... 8
JULIAN DATE .....8 85162
CHLOROPHYLL .....: $\quad 3.7 \mathrm{mg} / \mathrm{m}^{\wedge} 3$
SURPACE IRRAD ...: $50.36 \mathrm{E} / \mathrm{m}^{\wedge} 2 / 0$
PHOTIC DEPTH ....: $\quad 5.42 \mathrm{~m}$
INITIAL TIME ....: $\quad 1430 \mathrm{hr}$
PINAL TIME ....... $\quad 1445 \mathrm{hr}$
WATER DEPTH .....: 6 m

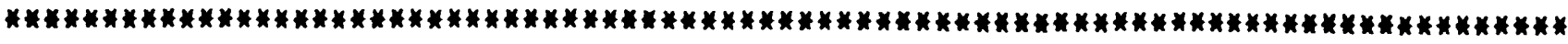

\begin{tabular}{|c|c|}
\hline $\begin{array}{l}\text { DEPTH } \\
\text { m }\end{array}$ & $\underset{*}{\mathrm{LIGHT}}$ \\
\hline $\begin{array}{l}.00 \\
.74 \\
1.39 \\
2.34 \\
3.00 \\
3.73 \\
4.84 \\
5.42\end{array}$ & $\begin{array}{r}100 \\
53.5 \\
30.7 \\
13.7 \\
7.83 \\
4.21 \\
1.64\end{array}$ \\
\hline
\end{tabular}

Uptake over photic zone water depth

photle zone water depth
CARBON UPTAKE corrected measured mo C/L/h mg C/Lh

$39.00 \quad 39.36$

$38.92 \quad 39.28$

$36.61 \quad 36.97$

$20.46 \quad 20.82$

$9.19 \quad 9.55$

5.20

1.48

.00

5.56

1.84

.36

ASSIMILATION

*

10.54

10.52

9.89

5.53

2.48

1.41

.40

.00

$99.58 \mathrm{mg} \mathrm{C/m} 2 / \mathrm{h}$

99.58

$2390 \operatorname{mog} \mathrm{C} \mathrm{m}^{\wedge} 2 / d$

2390 
CARBON UPTAKE DATA SUMMARY

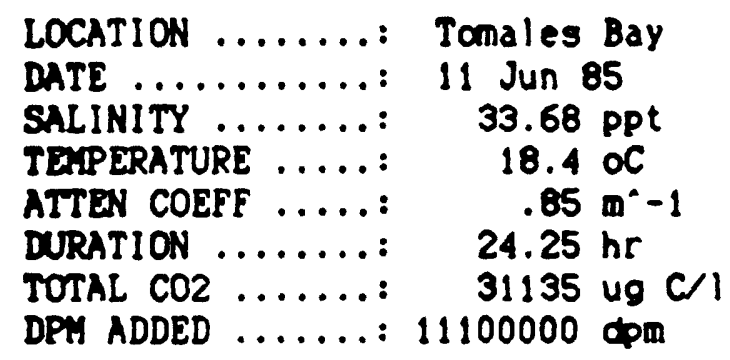

STATION ......... 8 w/ NH4 sp/ke JULIAN DATE .....: CHLOROPHYLL ...... SURPACE IRRAD ...: PHOTIC DEPTH ..... INITIAL TIME ....: PINAL TIME ......: WATER DEPTH .....
85162

$3.7 \mathrm{mg} / \mathrm{m} \cdot 3$

$50.36 \mathrm{E} / \mathrm{m}^{*} 2 / \mathrm{d}$

$5.42 \mathrm{~m}$

$1430 \mathrm{hr}$

$1445 \mathrm{hr}$

$6 \mathrm{~m}$

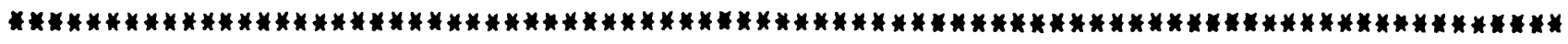

$\begin{array}{cc}\text { DEPTH } & \text { LIGHT } \\ \text { m } & t \\ .00 & 100 \\ .72 & 54.2 \\ 1.37 & 31.3 \\ 2.27 & 14.5 \\ 2.98 & 7.97 \\ 3.69 & 4.35 \\ 4.71 & 1.83 \\ 5.42 & \text { DARK BOTTLE }\end{array}$

Uptake over photic zone water depth

photic zone water depth
LIGHT

$E / m \wedge 2 / d$

50.36

27.30

15.76

7.30

2.19

.92

.05
4.01
CARBON UPTAKE corrected measured mo c/L/h ing $\mathrm{c} / \mathrm{L} / \mathrm{h}$

$\begin{array}{rrr}109.23 & 109.58 & 29.52 \\ 118.04 & 118.39 & 31.90 \\ 98.82 & 99.17 & 26.71 \\ 37.85 & 38.21 & 10.23 \\ 15.14 & 15.50 & 4.09 \\ 5.92 & 6.28 & 1.60 \\ 1.72 & 2.08 & .47 \\ .00 & .36 & .00\end{array}$
*
ASSIMILATION

$244.44 \mathrm{mg} \mathrm{C/m} 2 / \mathrm{h}$

244.44

$5866 \mathrm{mg} \mathrm{C/m}{ }^{\wedge} 2 / d$ 5866 
CARBON UPTAKE DATA SUMAARY

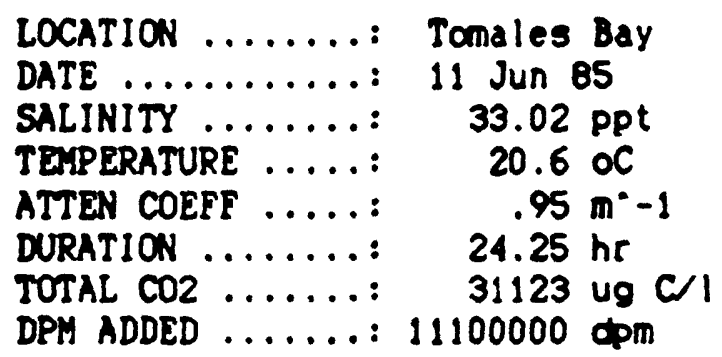

\begin{tabular}{|c|c|}
\hline $\begin{array}{l}\text { STATION } \ldots \ldots \ldots . \\
\text { JULIAN DATE } \\
\text { CHLOROPHYLL } \\
\text { SURFACE IRRAD } \ldots . . \\
\text { PHOTIC DEPTH } \\
\text { PHITIAL } \\
\text { INITIAL TIME } \\
\text { FINAL TIME } \\
\text { WATER DEPTH }\end{array}$ & $\begin{array}{l}16 \\
85162 \\
1.1 \mathrm{mg} / \mathrm{m} \cdot 3 \\
50.36 \mathrm{E} / \mathrm{m} \cdot 2 / 0 \\
4.85 \mathrm{~m} \\
1430 \mathrm{hr} \\
1445 \mathrm{hr} \\
2 \mathrm{~m}\end{array}$ \\
\hline
\end{tabular}

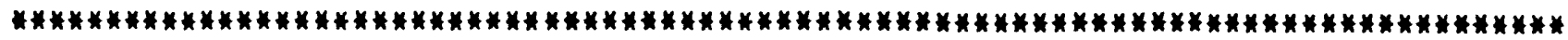

\begin{tabular}{|c|c|c|c|c|c|}
\hline $\begin{array}{l}\text { DEPTH } \\
\mathbf{m}\end{array}$ & $\begin{array}{l}\text { LIGHT } \\
*\end{array}$ & $\begin{array}{r}\text { LIGHT } \\
E / m^{2} 2 / d\end{array}$ & $\begin{array}{l}\text { CARBON U } \\
\text { corrected } \\
\text { mg C/L/h }\end{array}$ & $\begin{array}{l}\text { PTAKE } \\
\text { meagured } \\
\text { mg } C / L / h\end{array}$ & ASSIMILATION \\
\hline $\begin{array}{l}.00 \\
.00 \\
.68 \\
2.15 \\
3.00 \\
3.76 \\
4.33 \\
4.85\end{array}$ & $\begin{array}{r}100 \\
100 \\
52.5 \\
13 \\
5.8 \\
2.8 \\
1.64 \\
\text { DARK BOTTLE }\end{array}$ & $\begin{array}{r}50.36 \\
50.36 \\
26.44 \\
6.55 \\
2.92 \\
1.41 \\
.83 \\
.05\end{array}$ & $\begin{array}{r}10.30 \\
9.90 \\
10.24 \\
4.62 \\
1.18 \\
.91 \\
.30 \\
.00\end{array}$ & $\begin{array}{r}10.48 \\
10.09 \\
10.43 \\
4.81 \\
1.37 \\
1.09 \\
.49 \\
.19\end{array}$ & $\begin{array}{l}9.36 \\
9.00 \\
9.31 \\
4.20 \\
1.08 \\
.82 \\
.28 \\
.00\end{array}$ \\
\hline
\end{tabular}

Uptake over photic zone water depth

$21.44 \mathrm{mg} C / \mathrm{m}^{2} 2 \mathrm{~h}$ 16.26

photic zone water depth 
CARBON UPTAKE DATA SUMMARY

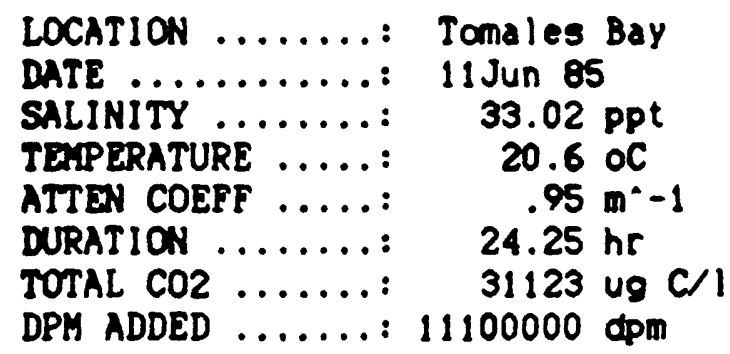

STATION ......... 16 w NH4 spike

JULIAN DATE .....: 85162

CHLOROPHYLL ......

SURFACE IRRAD ...:

PHOTIC DEPTH ....:

INITIAL TIME ....:

PINAL TIME ......:

WATER DEPTH .....
$1.1 \mathrm{mg} / \mathrm{m}^{\circ} 3$

$50.36 \mathrm{E} / \mathrm{m}^{\circ} 2 / 0$

$4.85 \mathrm{~m}$

$1430 \mathrm{hr}$

$1445 \mathrm{hr}$

$2 \mathrm{~m}$

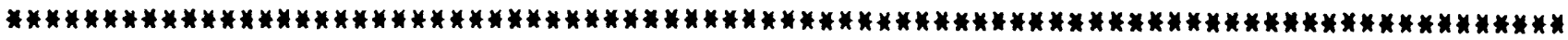

$\begin{array}{cc}\text { DEPTH } & \text { LIGHT } \\ \mathrm{m} & t \\ & \\ .00 & 100 \\ .00 & 100 \\ .69 & 51.8 \\ 2.15 & 13 \\ 3.08 & 5.37 \\ 3.82 & 2.65 \\ 4.77 & 1.08 \\ 4.85 & \text { DARK BOTTLE }\end{array}$

Uptake over photle zone water depth

photic zone water depth
CARBON UPTAKE corrected measured mg C/L/h mg C/L/h

ASSIMILATION

$E / m^{\bullet} 2 / d$

50.36

50.36

26.09

6.55

2.70

1.33

.54

.05

$\begin{array}{rrr}9.80 & 10.02 & 8.91 \\ 12.08 & 12.30 & 10.98 \\ 12.16 & 12.38 & 11.06 \\ 5.23 & 5.44 & 4.75 \\ 1.74 & 1.96 & 1.58 \\ .51 & .73 & .46 \\ .19 & .41 & .18 \\ .00 & .22 & .00\end{array}$

$25.46 \mathrm{mg} \mathrm{C} / \mathrm{m}^{\wedge} 2 / \mathrm{h}$

19.40

$611 \mathrm{mg} \mathrm{C} / \mathrm{m}^{\wedge} 2 / d$ 466 
CARBON UPTARE DATA SUMMARY

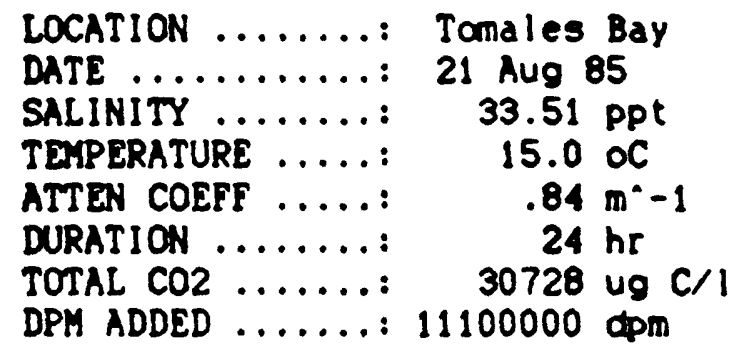

STATION .......: 2

JULIAN DATE ....: 85233

CHLOROPHYLL .....: $\quad 9.3 \mathrm{mg} / \mathrm{m}^{*} 3$

SURFACE IRRAD ...: $\quad 42.26 \mathrm{E} / \mathrm{m}^{\wedge} 2 / d$

PHOTIC DEPTH ....: $\quad 5.48 \mathrm{~m}$

INITIAL TIME ....: $1507 \mathrm{hr}$

FINAL TIME ......: $1505 \mathrm{hr}$

DPM ADDED ......: $11100000 \mathrm{dpm}$

WATER DEPTH ..... $3.6 \mathrm{~m}$

\begin{tabular}{|c|c|c|c|c|c|}
\hline $\begin{array}{l}\text { DEPTH } \\
m\end{array}$ & $\begin{array}{c}\text { LIGHT } \\
*\end{array}$ & $\begin{array}{l}\text { LIGHT } \\
E / m^{*} 2 / d\end{array}$ & $\begin{array}{l}\text { CARBON } \\
\text { corrected } \\
\text { m } \mathrm{c} / \mathrm{h}\end{array}$ & $\begin{array}{l}\text { UPTAKE } \\
\text { measured } \\
\text { mg } \mathrm{C} / \mathrm{Lh}\end{array}$ & ASSIMILATION \\
\hline $\begin{array}{l}.00 \\
.74 \\
1.41 \\
2.37 \\
3.03 \\
3.77 \\
4.89 \\
5.48\end{array}$ & $\begin{array}{c}100 \\
53.5 \\
30.7 \\
13.7 \\
7.83 \\
4.21 \\
1.64 \\
\text { DARK BOTTLE }\end{array}$ & $\begin{array}{r}42.26 \\
22.61 \\
12.98 \\
5.79 \\
3.31 \\
1.78 \\
.69 \\
.04\end{array}$ & $\begin{array}{r}41.89 \\
43.34 \\
36.77 \\
18.46 \\
7.66 \\
4.09 \\
1.25 \\
.00\end{array}$ & $\begin{array}{r}42.47 \\
43.92 \\
37.35 \\
19.04 \\
8.24 \\
4.66 \\
1.83 \\
.58\end{array}$ & $\begin{array}{r}4.50 \\
4.66 \\
3.95 \\
1.99 \\
.82 \\
.44 \\
.13 \\
.00\end{array}$ \\
\hline
\end{tabular}

\footnotetext{
Uptake over photle zone $101.15 \mathrm{mg} \mathrm{C/m} 2 / \mathrm{h}$ water depth $\quad 96.65$

photlc zone $\quad 2427 \mathrm{mg} \mathrm{C} / \mathrm{m} * 2 / d$ water depth 2320
} 
CARBON UPTAKE DATA SUMMARY

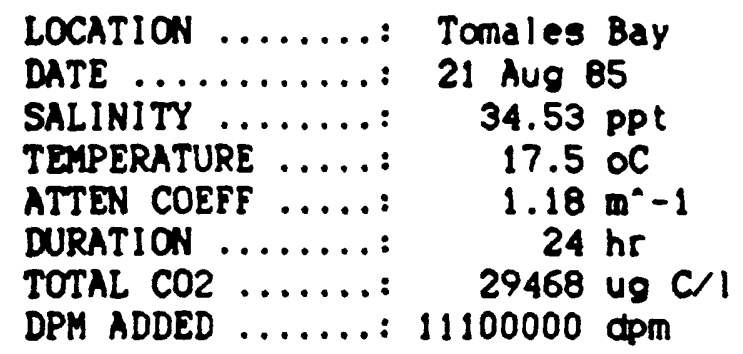
STATION ........: 8 JULIAN DATE .....: 85233
CHLOROPHYLL .....: $\quad 19.9 \mathrm{mg}^{-3} 3$
SURFACE IRRAD ...: $\quad 42.26 \mathrm{E} / \mathrm{m}^{*} 2 / \mathrm{d}$
PHOTIC DEPTH ....: $\quad 3.90 \mathrm{~m}$
INITIAL TIME ....: $1507 \mathrm{hr}$
BINAL TIME ......: $1505 \mathrm{hr}$
WATER DEPTH ..... 6 : 6

\begin{tabular}{|c|c|c|c|c|c|}
\hline $\begin{array}{c}\text { DEPTH } \\
\mathbf{m}\end{array}$ & $\underset{*}{\text { LIGHT }}$ & $\begin{array}{r}\text { LIGHT } \\
\mathrm{E} / \mathrm{m}^{-2 / d}\end{array}$ & $\begin{array}{l}\text { CARBON U } \\
\text { corrected } \\
\text { mg } \mathrm{C} / \mathrm{L} / \mathrm{h}\end{array}$ & $\begin{array}{l}\text { PTAKE } \\
\text { measured } \\
\text { mg C/Lh }\end{array}$ & ASSIMILATION \\
\hline $\begin{array}{l}.00 \\
.56 \\
1.07 \\
1.73 \\
2.48 \\
3.08 \\
3.84 \\
3.90\end{array}$ & $\begin{array}{c}100 \\
51.8 \\
28.3 \\
13 \\
5.37 \\
2.65 \\
1.08 \\
\text { DARK BOTTLE }\end{array}$ & $\begin{array}{r}42.26 \\
21.89 \\
11.96 \\
5.49 \\
2.27 \\
1.12 \\
.46 \\
.04\end{array}$ & $\begin{array}{r}38.53 \\
37.71 \\
38.87 \\
26.57 \\
12.83 \\
5.18 \\
.84 \\
.00\end{array}$ & $\begin{array}{r}39.42 \\
38.60 \\
39.76 \\
27.47 \\
13.73 \\
6.08 \\
1.73 \\
.89\end{array}$ & $\begin{array}{l}1.94 \\
1.89 \\
1.95 \\
1.34 \\
.64 \\
.26 \\
.04 \\
.00\end{array}$ \\
\hline
\end{tabular}

$\begin{array}{rr}\text { Uptake over photic zone } & 84.90 \mathrm{mg} \mathrm{C/m} \text {-2/h } \\ \text { water depth } & 84.90 \\ & \\ \text { photic zone } & 2038 \mathrm{mg} \mathrm{C/m} \mathrm{m}^{-2 / d} \\ \text { water depth } & 2038\end{array}$


CARBON UPTAKE DATA SUMARARY

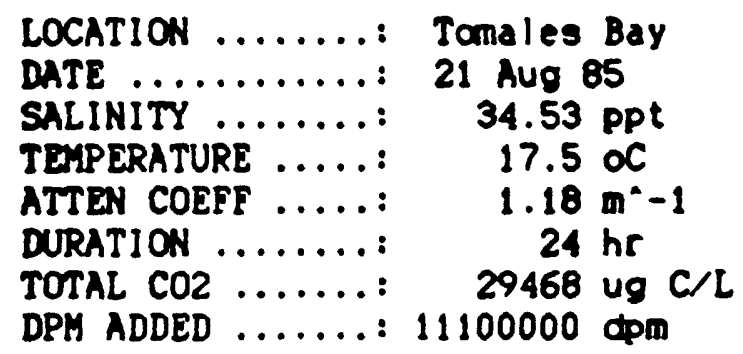

\begin{tabular}{|c|c|}
\hline 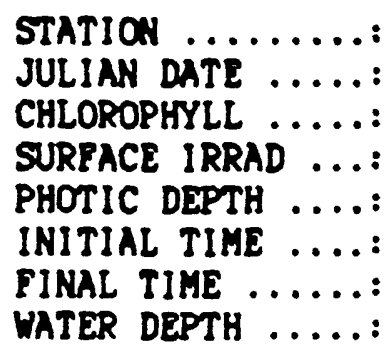 & $\begin{array}{c}8 \text { NH4 spike } \\
85233 \\
19.9 \mathrm{mg} / \mathrm{m}^{*} 3 \\
42.26 \mathrm{E} / \mathrm{m}^{*} 2 / d \\
3.90 \mathrm{~m} \\
1507 \mathrm{hr} \\
1505 \mathrm{hr} \\
6 \mathrm{~m}\end{array}$ \\
\hline
\end{tabular}

\#*****************************************************************************

$\begin{array}{cc}\begin{array}{c}\text { DEPTH } \\ \mathrm{m}\end{array} & \begin{array}{c}\text { LIGHT } \\ \mathbf{t}\end{array} \\ .00 & 100 \\ .52 & 54.2 \\ .98 & 31.3 \\ 1.64 & 14.5 \\ 2.14 & 7.97 \\ 2.66 & 4.35 \\ 3.39 & 1.83 \\ 3.90 & \text { DARK BOTTLE }\end{array}$

LIGHT
$E / m^{\wedge} 2 / d$

42.26

22.91

13.23

6.13

3.37

1.84

.77

.04
CARBON UPTAKE corrected measured $\mathrm{mg} C / \mathrm{Lh}$ mg C/Lh
ASSIMILATION *

$\begin{array}{rrr}59.04 & 60.70 & 2.97 \\ 60.34 & 62.01 & 3.03 \\ 60.60 & 62.26 & 3.05 \\ 39.42 & 11.08 & 1.98 \\ 18.91 & 20.57 & .95 \\ 10.37 & 12.03 & .52 \\ 2.24 & 3.91 & .11 \\ .00 & 1.66 & .00\end{array}$
Uptake over photic zone $121.43 \mathrm{mg} \mathrm{C} / \mathrm{m}^{\wedge} 2 \mathrm{~h}$ water depth 121.43
photic zone water depth


CARBON UPTAKE DATA SUMAARY

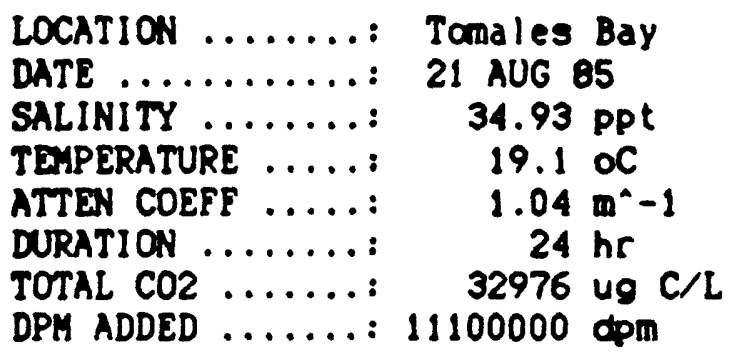

\begin{tabular}{|c|c|}
\hline 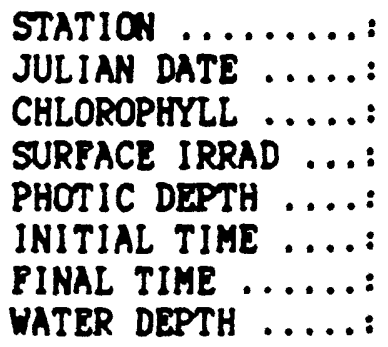 & $\begin{array}{l}16 \\
85233 \\
.6 \mathrm{mg} / \mathrm{m}^{\cdot 3} \\
42.26 \mathrm{E} / \mathrm{m}^{*} 2 / \mathrm{d} \\
4.43 \mathrm{~m} \\
1507 \mathrm{hr} \\
1505 \mathrm{hr} \\
2 \mathrm{~m}\end{array}$ \\
\hline
\end{tabular}

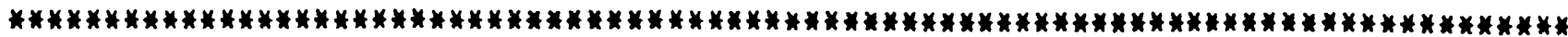

$\begin{array}{cc}\begin{array}{c}\text { DEPTH } \\ \mathrm{m}\end{array} & \begin{array}{c}\text { LIGHT } \\ \end{array} \\ .00 & 100 \\ .54 & 56.8 \\ 1.09 & 32.3 \\ 1.72 & 16.7 \\ 2.28 & 9.38 \\ 2.93 & 4.73 \\ 3.55 & 2.48 \\ 4.43 & \text { DARK BOTTLE }\end{array}$
LIGHT
$E / m^{\wedge} 2 / d$

42.26

24.01

13.65

7.06

3.96

2.00

1.05

.04
CARBON UPTAKE
corrected measured
mg $\mathrm{C} / \mathrm{L} / \mathrm{h}$ mg $\mathrm{C} / \mathrm{L} / \mathrm{h}$

\subsection{2}

2.26

2.77

1.36

.80

.34

.20

.00

3.13

2.48

2.98

1.58

1.02

.56

.42

.22

ASSIMILATION

*

4.86

3.77

4.61

2.26

1.34

.57

.34

.00
Uptake over photlc zone water depth

photle zone water depth
$5.32 \mathrm{mg} C / \mathrm{m} \cdot 2 \mathrm{n}$

4.36

$128 \mathrm{mg} \mathrm{C} / \mathrm{m}^{\wedge} 2 / d$ 105 


\section{CARBON UPTAKE DATA SUMAARY}

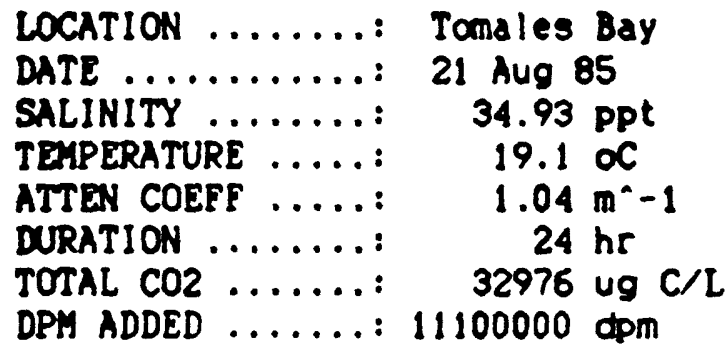

STATION .........: 16 w NH4 splke JULIAN DATE .....: 85233

CHLOROPHYLL .....: $\quad .6 \mathrm{mg} / \mathrm{m}^{* 3}$

SURPACE IRRAD ...: $42.26 \mathrm{E} / \mathrm{m}^{\wedge} 2 / \mathrm{d}$

PHOTIC DEPTH ....: $4.43 \mathrm{~m}$

INITIAL TIME ....: $\quad 1507 \mathrm{hr}$

FINAL TIME ......: $\quad 1505 \mathrm{hr}$

WATER DEPTH $\ldots . .$. : $2 \mathrm{~m}$

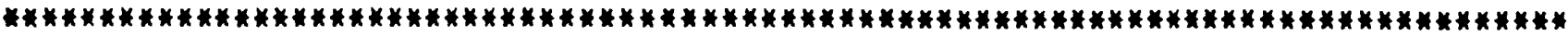

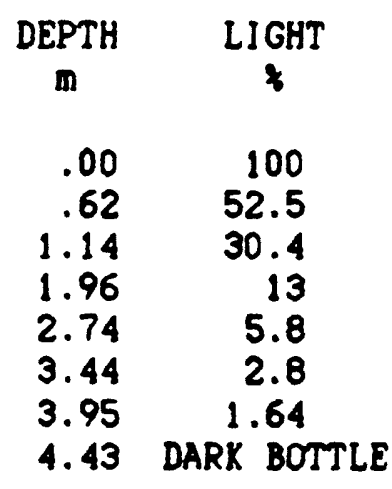

Uptake over photic zone
water depth
photic zone
water depth
CARBON UPTAKE corrected measured ing $\mathrm{C} / \mathrm{L} / \mathrm{h}$ ing $\mathrm{C} / \mathrm{L} / \mathrm{h}$

ASSIMILATION

*

$\begin{array}{rrr}2.08 & 2.47 & 3.46 \\ 2.83 & 3.22 & 4.72 \\ 2.51 & 2.90 & 4.18 \\ 2.19 & 2.58 & 3.64 \\ .21 & .60 & .35 \\ .26 & .65 & .43 \\ .06 & .45 & .10 \\ .00 & .39 & .00\end{array}$


CARBON UPTAKE DATA SUMMARY

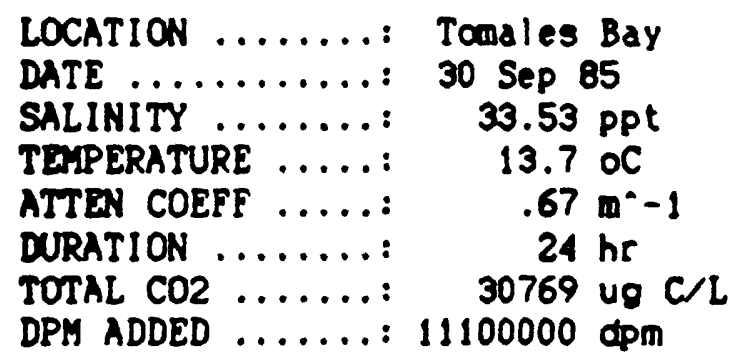

STATION ........:

JULIAN DATE .....:

2
85273

CHLOROPHYLL ......

SURPACE IRRAD ....:

PHOTIC DEPTH ....:

INITIAL TIME ....:

PINAL TIME ......

WATER DEPTH ......
$1.92 \mathrm{mg} / \mathrm{m}^{*} 3$

$21.62 \mathrm{E} / \mathrm{m}^{\circ} 2 \mathrm{~d}$

$6.87 \mathrm{~m}$

$1425 \mathrm{hr}$

$1430 \mathrm{hr}$

$3.6 \mathrm{~m}$

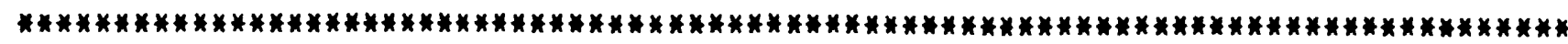

$\begin{array}{cc}\begin{array}{c}\text { DEPTH } \\ \mathrm{m}\end{array} & \text { LIGHT } \\ & + \\ .00 & 100 \\ .91 & 54.2 \\ 1.73 & 31.3 \\ 2.88 & 14.5 \\ 3.78 & 7.97 \\ 4.68 & 4.35 \\ 5.97 & 1.83 \\ 6.87 & \text { DARK BOTTLE }\end{array}$

Uptake over photic zone water depth

phot le zone water depth
CARBON UPTAKE corrected measured $m g \mathrm{C} / \mathrm{L} / \mathrm{h}$ mg $\mathrm{C} / \mathrm{L} / \mathrm{h}$

$$
\begin{array}{r}
6.71 \\
6.11 \\
4.07 \\
.91 \\
.41 \\
.22 \\
-.08 \\
.00
\end{array}
$$

ASSIMILATION

औ

3.49
3.18
2.12
.47
.22
.11
-.04
.00

$13.82 \mathrm{mg} \mathrm{C} / \mathrm{m}^{\wedge} 2 / \mathrm{h}$ 13.35

$332 \mathrm{mg} \mathrm{c} / \mathrm{m}^{\wedge} 2 / d$ 320 
CARBON UPTAKE DATA SUMMARY

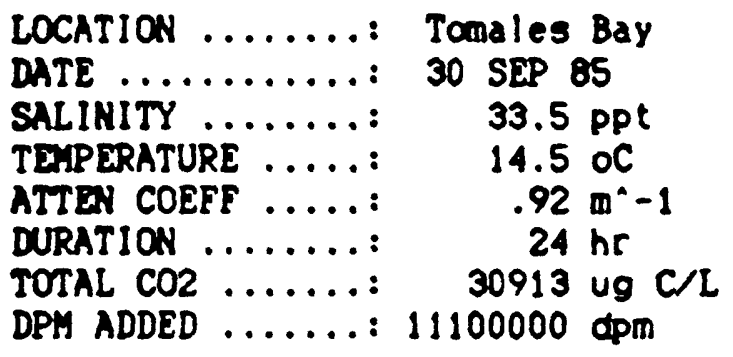

\begin{tabular}{|c|c|}
\hline $\begin{array}{l}\text { STATION ......... } \\
\text { JULIAN DATE } \ldots . . . \\
\text { CHLOROPHYLL } \\
\text { SURFACE IRRAD } \ldots . . \\
\text { PHOTIC DEPTH } \\
\text { INITIAL TIME } \ldots . . \\
\text { PINAL TIME } \\
\text { WATER DEPTH } \ldots . . .\end{array}$ & $\begin{array}{l}8 \\
85273 \\
4.47 \mathrm{mg} / \mathrm{m}^{\wedge} 3 \\
21.62 \mathrm{E} / \mathrm{m}^{*} 2 / d \\
5.01 \mathrm{~m} \\
1425 \mathrm{hr} \\
1430 \mathrm{hr} \\
6 \mathrm{~m}\end{array}$ \\
\hline
\end{tabular}

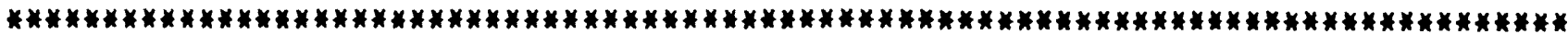

$\begin{array}{cc}\begin{array}{c}\text { DEPTH } \\ \mathrm{m}\end{array} & \begin{array}{c}\text { LIGHT } \\ \end{array} \\ .00 & 100 \\ .61 & 56.8 \\ 1.23 & 32.3 \\ 1.95 & 16.7 \\ 2.57 & 9.38 \\ 3.32 & 4.73 \\ 4.02 & 2.48 \\ 5.01 & \text { DARK BOTTLE }\end{array}$

Uptake over photlc zone water depth

photle zone water depth

LIGHT
$E / m^{\circ} 2 / d$

21.62

12.28

6.98

3.61

2.03

1.02

.54

.02
CARBON UPTAKE

corrected measured mg C/Lh ar $\mathrm{ClLh}$

$\begin{array}{rrr}19.22 & 19.65 & 4.30 \\ 17.60 & 18.02 & 3.94 \\ 12.33 & 12.75 & 2.76 \\ 5.01 & 5.43 & 1.12 \\ 2.94 & 3.37 & .66 \\ 1.56 & 1.98 & .35 \\ .63 & 1.06 & .14 \\ .00 & .42 & .00\end{array}$

$31.96 \mathrm{mg} C / \mathrm{m}^{\circ} 2 / \mathrm{h}$ 31.96

767 mg C/a'2/d 767
ASSIMILATION

*

00 


\section{CARBON UPTAKE DATA SUMMARY}

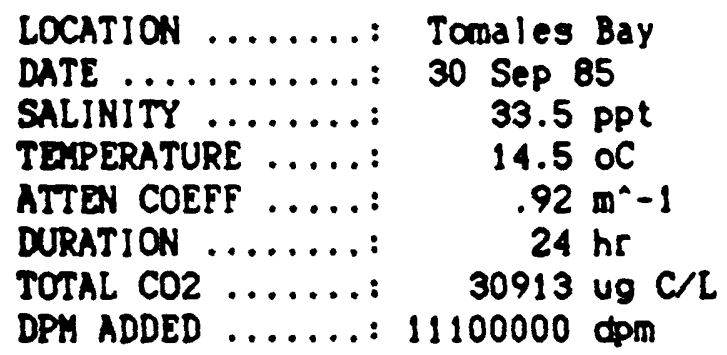
STATION ........: 8 w NH4 splke JULIAN DATE .....: 85273
CHLOROPHYLL .....: $\quad 4.47 \mathrm{mg} / \mathrm{m}^{\star 3} 3$
SURPACE IRRAD ...: $21.62 \mathrm{E} / \mathrm{m}^{*} 2 / \mathrm{d}$
PHOTIC DEPTH ....: $5.01 \mathrm{~m}$
INITIAL TIME ....: $1425 \mathrm{hr}$
FINAL TIME ....... $1430 \mathrm{hr}$
WATER DEPTH .....: $6 \mathrm{~m}$

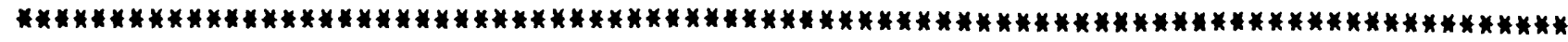

$\begin{array}{ccc}\begin{array}{c}\text { DEPTH } \\ \text { m }\end{array} & \begin{array}{c}\text { LIGHT } \\ t\end{array} & \begin{array}{c}\text { LIGHT } \\ \mathrm{E} / \mathrm{m}^{\wedge} 2 / \mathrm{d}\end{array} \\ .00 & 100 & 21.62 \\ .71 & 51.8 & 11.20 \\ 1.37 & 28.3 & 6.12 \\ 2.22 & 13 & 2.81 \\ 3.18 & 5.37 & 1.16 \\ 3.95 & 2.65 & .57 \\ 4.92 & 1.08 & .23 \\ 5.01 & \text { DARK BOTTLE } & .02\end{array}$

CARBON UPTAKE ASSIMILATION

corrected measured

mg $\mathrm{C} / \mathrm{L} / \mathrm{h}$ mg $\mathrm{C} / \mathrm{L} / \mathrm{h}$

*

$\begin{array}{rrr}8.21 & 19.92 & 1.84 \\ 18.25 & 29.96 & 4.08 \\ 10.38 & 22.10 & 2.32 \\ 3.44 & 15.15 & .77 \\ .01 & 11.72 & .00 \\ 1.09 & 12.81 & .24 \\ 1.17 & 12.89 & .26 \\ .00 & 11.71 & .00\end{array}$

$27.94 \mathrm{mg} \mathrm{C} / \mathrm{m}^{\wedge} 2 / \mathrm{h}$

27.94

$671 \mathrm{mg} \mathrm{C} / \mathrm{m}^{\wedge} 2 \mathrm{~d}$ 671 


\section{CARBON UPTAKE DATA SUMAARY}

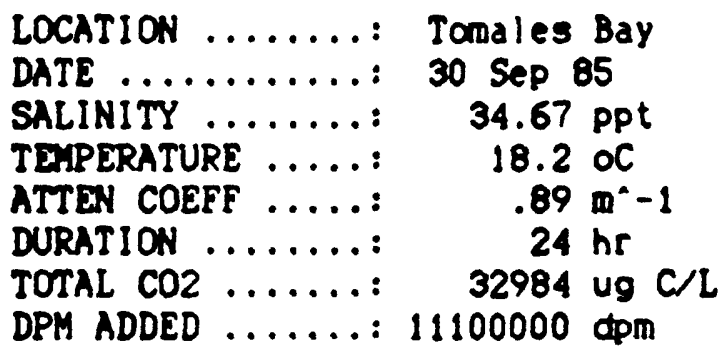
STATION ......... 16 JULIAN DATE .....: 85273
CHLOROPHYLL .....: $\quad 2.02 \mathrm{mg} / \mathrm{m}^{\wedge} 3$
SUREACE IRRAD ...: $21.62 \mathrm{E} /$ m $^{\wedge} 2 / 0$ PHOTIC DEPTH ....: $5.17 \mathrm{~m}$ INITIAL TIME ....: $1425 \mathrm{hr}$ PINAL TIME ......: $\quad 1430 \mathrm{hr}$ WATER DEPTH... : 2 m

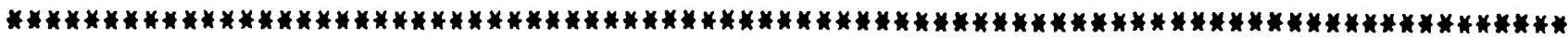

\begin{tabular}{|c|c|c|c|c|c|}
\hline $\begin{array}{l}\text { DEPTH } \\
\text { m }\end{array}$ & LIGHT & $\begin{array}{r}\text { LIGHT } \\
\mathrm{E} / \mathrm{m}^{\wedge} 2 / d\end{array}$ & $\begin{array}{l}\text { CARBON U } \\
\text { corrected }\end{array}$ & $\begin{array}{l}\text { PPTAKE } \\
\text { measured }\end{array}$ & ASSIMILATION \\
\hline $\begin{array}{l}.00 \\
.72 \\
1.34 \\
2.29 \\
3.20 \\
4.02 \\
4.62 \\
5.17\end{array}$ & $\begin{array}{r}100 \\
52.5 \\
30.4 \\
13 \\
5.8 \\
2.8 \\
1.64 \\
\text { DARK BOTTLE }\end{array}$ & $\begin{array}{r}21.62 \\
11.35 \\
6.57 \\
2.81 \\
1.25 \\
.61 \\
.35 \\
.02\end{array}$ & $\begin{array}{l}5.70 \\
5.80 \\
5.36 \\
1.99 \\
.21 \\
.32 \\
.39 \\
.00\end{array}$ & $\begin{array}{l}5.97 \\
6.07 \\
5.64 \\
2.26 \\
.49 \\
.60 \\
.67 \\
.27\end{array}$ & $\begin{array}{l}2.82 \\
2.87 \\
2.65 \\
.98 \\
.11 \\
.16 \\
.19 \\
.00\end{array}$ \\
\hline
\end{tabular}
Uptake over photlc zone water depth
$12.63 \mathrm{mgC/m} 2 / \mathrm{h}$ 9.83
photle zone water depth $303 \mathrm{mg} \mathrm{C} / \mathrm{m} \cdot 2 / \mathrm{d}$ 236


CARBON UPTAKE DATA SUMATARY

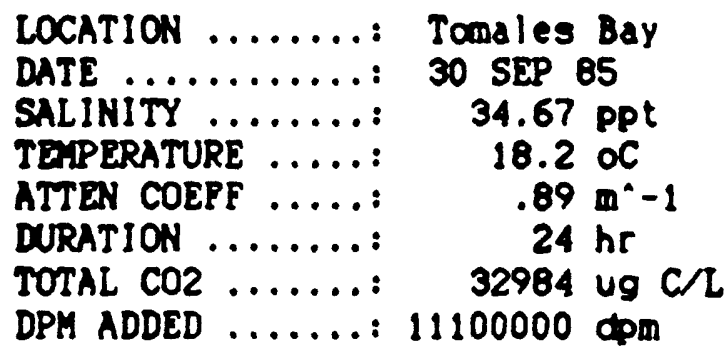

STATION JULIAN DATE CHLOROPHYLL ...... SURPACE IRRAD ....: PHOTIC DEPTH .....: INITIAL TIME ..... PINAL TIME ....... WATER DEPTH ......
16 w NH4 splke 85273

$2.02 \mathrm{mg} / \mathrm{m}^{* 3}$ $21.62 \mathrm{E} / \mathrm{m}^{\wedge} 2 / d$ $5.17 \mathrm{~m}$ $1425 \mathrm{hr}$ $1430 \mathrm{hr}$

$2 \mathrm{~m}$

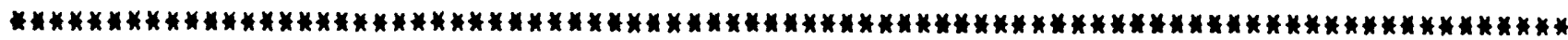

$\begin{array}{cc}\begin{array}{c}\text { DEPTH } \\ \mathrm{m}\end{array} & \begin{array}{c}\text { LIGHT } \\ \end{array} \\ .00 & 100 \\ .70 & 53.5 \\ 1.33 & 30.7 \\ 2.23 & 13.7 \\ 2.86 & 7.83 \\ 3.56 & 4.21 \\ 4.62 & 1.64 \\ 5.17 & \text { DARK BOTTLE }\end{array}$

LIGHT
$\mathrm{E} / \mathrm{m}^{\circ} 2 \mathrm{~d}$
21.62
11.57
6.64
2.96
1.69
.91
.35
.02

Uptake over photic zone water depth

photic zone water depth
CARBON UPTAKE corrected measured mg $\mathrm{C} / \mathrm{L} / \mathrm{h}$ mo $\mathrm{CL} / \mathrm{h}$

$\begin{array}{rr}8.59 & 9.33 \\ 10.36 & 11.10 \\ 6.87 & 7.61 \\ 5.97 & 6.72 \\ 2.54 & 3.28 \\ 3.29 & 4.04 \\ 2.78 & 3.53 \\ .00 & .74\end{array}$

4.25

5.13

3.40

2.96

1.26

1.63

1.38

.00 
CARBON UPTAKE DATA SUMAARY

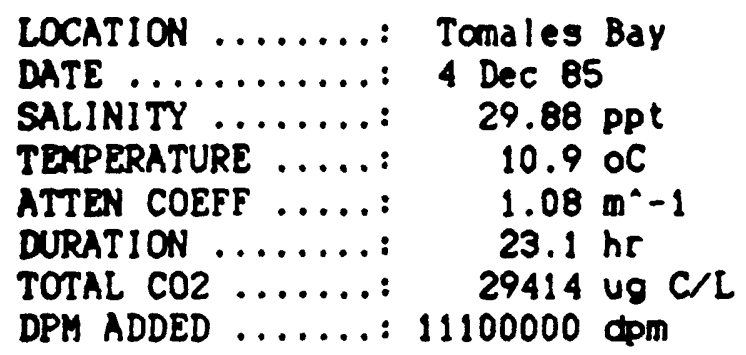
STATION JULIAN DATE .....: 85338
CHLOROPHYLL .....: $\quad 1.1 \mathrm{mg}^{\circ} 3$
SURFACE IRRAD ...: $11.21 \mathrm{E} / \mathrm{m}^{\star} 2 / 0$
PHOTIC DEPTH ....: $\quad 4.26 \mathrm{~m}$
INITIAL TIME ....: $1535 \mathrm{hr}$
FINAL TIME ......: $1442 \mathrm{hr}$
WATER DEPTH .....: $8 \mathrm{~m}$

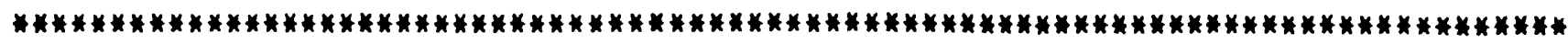

\begin{tabular}{|c|c|c|c|c|c|}
\hline \multirow[b]{2}{*}{$\underset{\mathbf{m}}{\text { DEPTH }}$} & \multirow[b]{2}{*}{$\underset{t}{\text { LIGHT }}$} & \multirow[b]{2}{*}{$\begin{array}{r}\text { LIGHT } \\
E / m^{-} 2 / d\end{array}$} & \multicolumn{2}{|c|}{ CARBON UPTAKE } & \multirow{2}{*}{ ASSIMILATION } \\
\hline & & & $\begin{array}{l}\text { corrected } \\
\text { mg } \mathrm{C} / \mathrm{L}\end{array}$ & $\begin{array}{l}\text { measured } \\
\text { mg } C / L h\end{array}$ & \\
\hline $\begin{array}{l}.00 \\
.61 \\
1.17 \\
1.89 \\
2.71 \\
3.36 \\
4.19 \\
4.26\end{array}$ & $\begin{array}{r}100 \\
51.8 \\
28.3 \\
13 \\
5.37 \\
2.65 \\
1.08 \\
\text { DARK BOTTLE }\end{array}$ & $\begin{array}{r}11.21 \\
5.81 \\
3.17 \\
1.46 \\
.60 \\
.30 \\
.12 \\
.01\end{array}$ & $\begin{array}{l}3.58 \\
3.12 \\
2.02 \\
.66 \\
.21 \\
.06 \\
.01 \\
.00\end{array}$ & $\begin{array}{r}3.82 \\
3.35 \\
2.26 \\
.89 \\
.45 \\
.29 \\
.25 \\
.23\end{array}$ & $\begin{array}{l}3.26 \\
2.84 \\
1.84 \\
.60 \\
.19 \\
.05 \\
.01 \\
.00\end{array}$ \\
\hline
\end{tabular}

$\begin{aligned} \text { Uptake over phot lc zone } & 4.92 \mathrm{mg} \mathrm{C/m}{ }^{-2} / \mathrm{h} \\ \text { water depth } & 4.92 \\ \text { photlc zone } & 118 \mathrm{mg} \mathrm{C/m} \cdot 2 / \mathrm{d} \\ \text { water depth } & 118\end{aligned}$


CARBON UPTAKE DATA SUMMARY

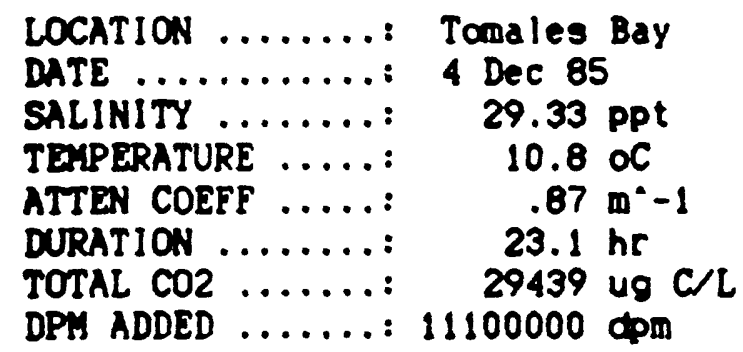

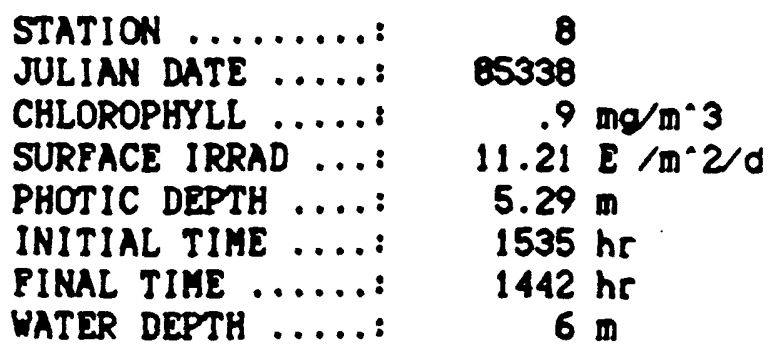

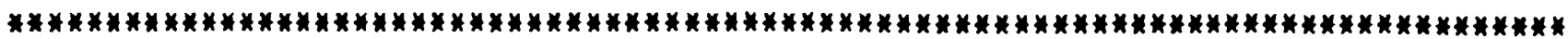

\begin{tabular}{|c|c|c|c|c|c|}
\hline $\begin{array}{l}\text { DEPTH } \\
\text { m }\end{array}$ & $\underset{t}{\mathrm{LIGHT}}$ & $\begin{array}{r}\text { LIGHT } \\
\mathbb{E} / \mathbf{m}^{*} 2 / d\end{array}$ & $\begin{array}{l}\text { CARBON } \\
\text { corrected } \\
\text { mg C/Lh }\end{array}$ & $\begin{array}{l}\text { PTAKE } \\
\text { measured } \\
\text { mg } C / L / h\end{array}$ & ASSIMI \\
\hline $\begin{array}{l}.00 \\
.72 \\
1.36 \\
2.28 \\
2.93 \\
3.64 \\
4.72 \\
5.29\end{array}$ & $\begin{array}{c}100 \\
53.5 \\
30.7 \\
13.7 \\
7.83 \\
4.21 \\
1.64 \\
\text { DARK BOTTLE }\end{array}$ & $\begin{array}{r}11.21 \\
6.00 \\
3.44 \\
1.54 \\
.88 \\
.47 \\
.18 \\
.01\end{array}$ & $\begin{array}{r}2.83 \\
2.43 \\
1.79 \\
.40 \\
.10 \\
-.01 \\
-.10 \\
.00\end{array}$ & $\begin{array}{l}3.22 \\
2.82 \\
2.19 \\
.79 \\
.50 \\
.38 \\
.29 \\
.40\end{array}$ & $\begin{array}{r}3.14 \\
2.70 \\
1.99 \\
.44 \\
.12 \\
-.01 \\
-.11 \\
.00\end{array}$ \\
\hline
\end{tabular}

\begin{tabular}{|c|c|c|}
\hline Uptake ove & Photic zone & $4.36 \mathrm{mg} C / \mathrm{m}^{\wedge} 2 \mathrm{~h}$ \\
\hline & $\begin{array}{l}\text { photle zone } \\
\text { water depth }\end{array}$ & $\begin{array}{l}105 \mathrm{mg} \mathrm{C/m`2/d} \\
105\end{array}$ \\
\hline
\end{tabular}




\section{CARBON UPTAKE DATA SUMMARY}

LOCATION ........: TOmales Bay

DATE ............ 4 Dec 85

SALINITY ........: 29.33 ppt

TEMPERATURE .....: $\quad 10.8$ oC

ATTEN COEFF .....: $\quad .87 \mathrm{~m}^{4}-1$

DURATION ........: $23.1 \mathrm{hr}$

TOTAL CO2 ....... 29439 ug $\mathrm{C} / \mathrm{L}$

DPM ADDED ....... $11100000 \mathrm{cpm}$
STATION .........: 8 W NH4 splke

JULIAN DATE .....: 85338

CHLOROPHYLL .....: $\quad .9 \mathrm{mg} / \mathrm{m}^{*} 3$

SURFACE IRRAD ...: $11.21 \mathrm{E} / \mathrm{m}^{`} 2 / \mathrm{d}$

PHOTIC DEPTH ....: $\quad 5.29 \mathrm{~m}$

INITIAL TIME ....: $\quad 1535 \mathrm{hr}$

PINAL TIME ......: $1442 \mathrm{hr}$

WATER DEPTH .....: $6 \mathrm{~m}$

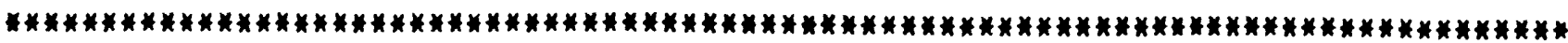

$\begin{array}{ccc}\begin{array}{c}\text { DEPTH } \\ \mathrm{m}\end{array} & \text { LIGHT } & \begin{array}{r}\text { LIGHT } \\ \text { E/m } 2 / \mathrm{d}\end{array} \\ .00 & 100 & 11.21 \\ .70 & 54.2 & 6.08 \\ 1.34 & 31.3 & 3.51 \\ 2.22 & 14.5 & 1.63 \\ 2.91 & 7.97 & .89 \\ 3.60 & 4.35 & .49 \\ 4.60 & 1.83 & .21 \\ 5.29 & \text { DARK BOTTLE } & .01\end{array}$

Uptake over photic zone water depth

photle zone water depth
CARBON UPTAKE

corrected measured

$m g \mathrm{Cl} / \mathrm{h}$ mg C/Lh

3.25

3.14

2.02

.73

.25

.11

.05

.00

3.60

3.49

2.37

1.08

.60

.46

.40

.35

ASSIMILATION

*

3.61

3.48

2.25

.81

.28

.13

.06

.00 
CARBON UPTAKE DATA SUMMARY

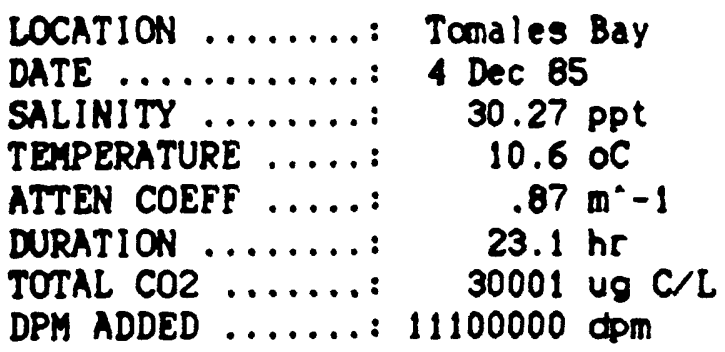

$$
\begin{array}{lc}
\text { STATION } \ldots \ldots \ldots: & 16 \\
\text { JULIAN DATE } \ldots \ldots: & 85338 \\
\text { CHLOROPHYLL } \ldots \ldots: & 1.1 \mathrm{mg} / \mathrm{m} \cdot 3 \\
\text { SURFACE IRRAD } \ldots .: & 11.21 \mathrm{E} / \mathrm{m} \cdot 2 / \mathrm{d} \\
\text { PHOTIC DEPTH } \ldots .: & 5.29 \mathrm{~m} \\
\text { INITIAL TIHE } \ldots \ldots: & 1535 \mathrm{hr} \\
\text { FINAL TIME } \ldots \ldots: & 1442 \mathrm{hr} \\
\text { WATER DEPTH } \ldots \ldots: & 2 \mathrm{~m}
\end{array}
$$

\begin{tabular}{|c|c|c|c|c|c|}
\hline $\begin{array}{c}\text { DEPTH } \\
\mathbf{m}\end{array}$ & $\underset{*}{\text { LIGHT }}$ & $\begin{array}{r}\text { LIGHT } \\
E / m^{*} 2 / d\end{array}$ & $\begin{array}{l}\text { CARBON U } \\
\text { corrected } \\
\text { mg } C / L / h\end{array}$ & $\begin{array}{l}\text { UPTAKE } \\
\text { measured } \\
\text { mg } C / L / h\end{array}$ & ASSIMILATION \\
\hline $\begin{array}{r}.00 \\
.74 \\
1.37 \\
2.35 \\
3.27 \\
4.11 \\
4.72 \\
5.29\end{array}$ & $\begin{array}{c}100 \\
52.5 \\
30.4 \\
13 \\
5.8 \\
2.8 \\
1.64 \\
\text { DARK BOTTLE }\end{array}$ & $\begin{array}{r}11.21 \\
5.89 \\
3.41 \\
1.46 \\
.65 \\
.31 \\
.18 \\
.01\end{array}$ & $\begin{array}{l}3.87 \\
3.43 \\
2.54 \\
1.27 \\
.13 \\
.13 \\
.05 \\
.00\end{array}$ & $\begin{array}{l}4.11 \\
3.68 \\
2.78 \\
1.52 \\
.38 \\
.38 \\
.29 \\
.25\end{array}$ & $\begin{array}{l}3.52 \\
3.12 \\
2.31 \\
1.15 \\
.12 \\
.12 \\
.04 \\
.00\end{array}$ \\
\hline
\end{tabular}

$\begin{aligned} \text { Uptake over photic zone } & 7.26 \mathrm{mg} \mathrm{C} / \mathrm{m}^{*} 2 / \mathrm{h} \\ \text { water depth } & 5.64 \\ & \\ \text { photic zone } & 174 \mathrm{mg} \mathrm{C} / \mathrm{m}^{\wedge} 2 / \mathrm{d} \\ \text { water depth } & 135\end{aligned}$


CARBON UPTAKE DATA SUMMARY

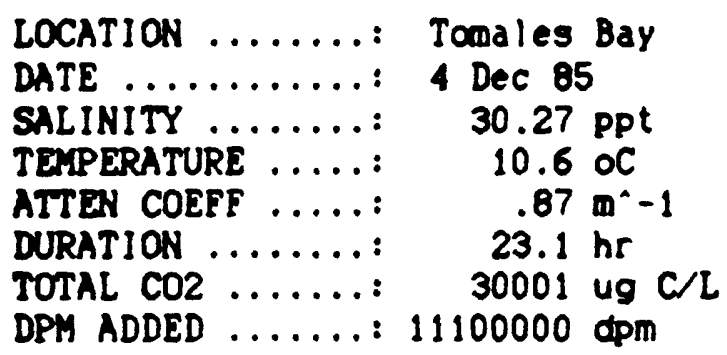

STATION ........: 16 w NH4 splke JULIAN DATE .....: 85338

CHLOROPHYLL .....: $\quad 1.1 \mathrm{mg} / \mathrm{m}^{\wedge} 3$

SURFACE IRRAD ...: $11.21 \mathrm{E} / \mathrm{m}^{\wedge} 2 / 0$

PHOTIC DEPTH ....: $\quad 5.29 \mathrm{~m}$

INITIAL TIME ....: $\quad 1535 \mathrm{hr}$

PINAL TIME ....... $1442 \mathrm{hr}$

WATER DEPTH .....: $2 \mathrm{~m}$

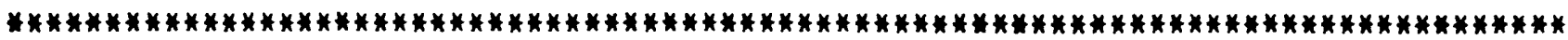

$\begin{array}{cccccc}\begin{array}{c}\text { DEPTH } \\ \mathrm{m}\end{array} & \begin{array}{c}\text { LIGHT } \\ \boldsymbol{t}\end{array} & \begin{array}{c}\text { LIGHT } \\ \mathrm{E} / \mathrm{m}^{\wedge} 2 / \mathrm{d}\end{array} & \begin{array}{c}\text { CARBON UPTAKE } \\ \text { corrected } \\ \text { mg C/L/h }\end{array} & \begin{array}{c}\text { ASSIMILATION } \\ \text { mg } \mathrm{C} / \mathrm{L} / \mathrm{h}\end{array} & \\ .00 & 100 & 11.21 & 3.98 & 4.18 & 3.62 \\ .65 & 56.8 & 6.37 & 3.81 & 4.01 & 3.46 \\ 1.30 & 32.3 & 3.62 & 2.71 & 2.91 & 2.46 \\ 2.06 & 16.7 & 1.87 & 1.00 & 1.20 & .91 \\ 2.72 & 9.38 & 1.05 & .53 & .72 & .48 \\ 3.51 & 4.73 & .53 & .24 & .44 & .22 \\ 4.25 & 2.48 & .28 & .14 & .34 & .13 \\ 5.29 & \text { DARK BOTTLE } & .01 & .00 & .20 & .00\end{array}$

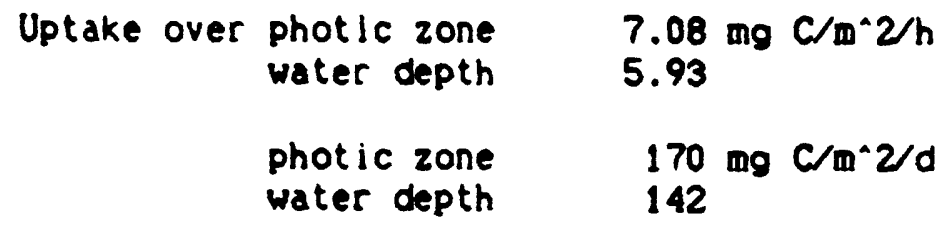


CARBON UPTAKE DATA SUMMARY

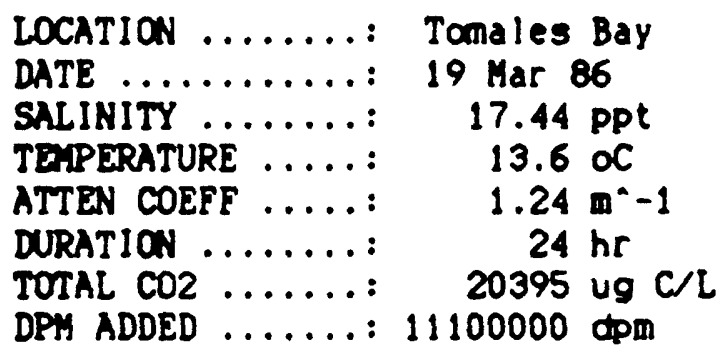

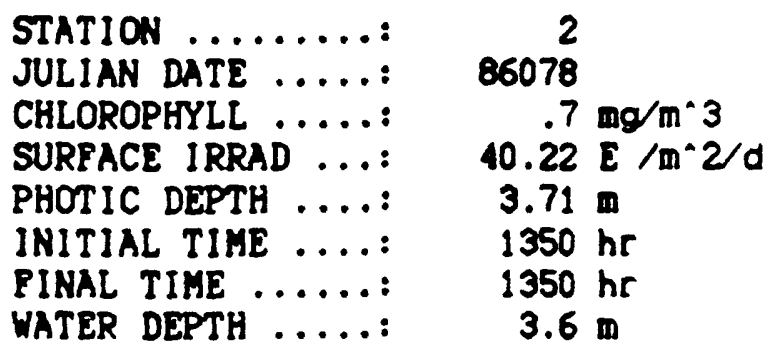

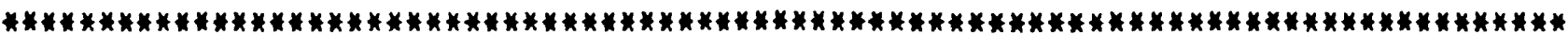

$\begin{array}{cccrrr}\begin{array}{c}\text { DEPTH } \\ \text { m }\end{array} & \text { LIGHT } & \begin{array}{r}\text { LIGHT } \\ \text { E/m^2/d }\end{array} & \begin{array}{r}\text { CARBON UPTAKE } \\ \text { corrected } \\ \text { mg } C / L / h\end{array} & \begin{array}{l}\text { measured } \\ \text { mg } C / L / h\end{array} & \\ .00 & 100 & 40.22 & 46.98 & 47.44 & 67.12 \\ .52 & 52.5 & 21.11 & 50.05 & 50.51 & 71.50 \\ .96 & 30.4 & 12.23 & 37.41 & 37.87 & 53.45 \\ 1.65 & 13 & 5.23 & 18.28 & 18.74 & 26.12 \\ 2.30 & 5.8 & 2.33 & 4.53 & 4.98 & 6.47 \\ 2.88 & 2.8 & 1.13 & 2.84 & 3.30 & 4.06 \\ 3.31 & 1.64 & .66 & .71 & 1.16 & 1.01 \\ 3.71 & \text { DARK BOTTLE } & .04 & .00 & .45 & .00\end{array}$

$\begin{array}{ll}\text { Uptake over photlc zone } & 74.05 \mathrm{mg} \mathrm{C/m} 2 / \mathrm{h} \\ \text { water depth } & 74.01 \\ & \\ \begin{array}{l}\text { photic zone } \\ \text { water depth }\end{array} & 1777 \mathrm{mg} \mathrm{C/m} 2 / \mathrm{d} \\ & 1776\end{array}$


CARBON UPTAKE DATA SUMMARY

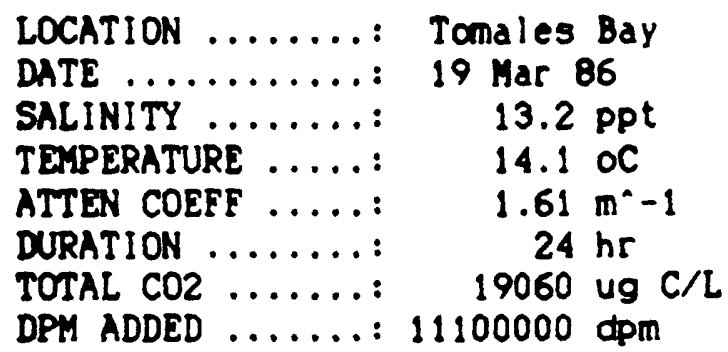
STATION ........: 8 JULIAN DATE .....: 86078
CHLOROPHYLL .....: $\quad .7 \mathrm{mg} / \mathrm{m}^{\star 3}$ SURPACE IRRAD ...: $40.22 \mathrm{E} / \mathrm{m}^{\star} 2 / \mathrm{d}$ PHOTIC DEPTH ....: $2.86 \mathrm{~m}$ INITIAL TIME ....: $1350 \mathrm{hr}$ PINAL TIME ......: $1350 \mathrm{hr}$ WATER DEPTH .....: $6 \mathrm{~m}$

\begin{tabular}{|c|c|c|c|c|c|}
\hline $\begin{array}{c}\text { DEPTH } \\
\mathbf{m}\end{array}$ & $\underset{*}{\text { LIGHT }}$ & $\begin{array}{r}\text { LIGHT } \\
\mathrm{E} / \mathrm{m}^{\wedge} 2 / d\end{array}$ & $\begin{array}{l}\text { CARBON } \\
\text { corrected } \\
\text { mg } \mathrm{C} / \mathrm{L} / \mathrm{h}\end{array}$ & $\begin{array}{l}\text { PTAKE } \\
\text { measured } \\
\text { mg } C / L / h\end{array}$ & ASSIMILATION \\
\hline $\begin{array}{r}.00 \\
.38 \\
.72 \\
1.20 \\
1.57 \\
1.95 \\
2.49 \\
2.86\end{array}$ & $\begin{array}{c}100 \\
54.2 \\
31.3 \\
14.5 \\
7.97 \\
4.35 \\
1.83 \\
\text { DARK BOTTLE }\end{array}$ & $\begin{array}{r}40.22 \\
21.80 \\
12.59 \\
5.83 \\
3.21 \\
1.75 \\
.74 \\
.04\end{array}$ & $\begin{array}{l}4.46 \\
4.88 \\
3.47 \\
2.45 \\
.28 \\
.36 \\
.12 \\
.00\end{array}$ & $\begin{array}{l}4.58 \\
5.00 \\
3.59 \\
2.57 \\
.40 \\
.48 \\
.24 \\
.12\end{array}$ & $\begin{array}{l}6.36 \\
6.97 \\
4.96 \\
3.49 \\
.40 \\
.51 \\
.17 \\
.00\end{array}$ \\
\hline
\end{tabular}

$\begin{array}{cc}\text { Uptake over photic zone } & 5.39 \mathrm{mg} \mathrm{C} / \mathrm{m}^{\wedge} 2 / \mathrm{h} \\ \text { water depth } & 5.39 \\ & 129 \mathrm{mg} \mathrm{C} / \mathrm{m}^{\wedge} 2 / d \\ \text { photic zone } & 129 \\ \text { water depth } & \end{array}$




\section{CARBON UPTAKE DATA SUMMARY}

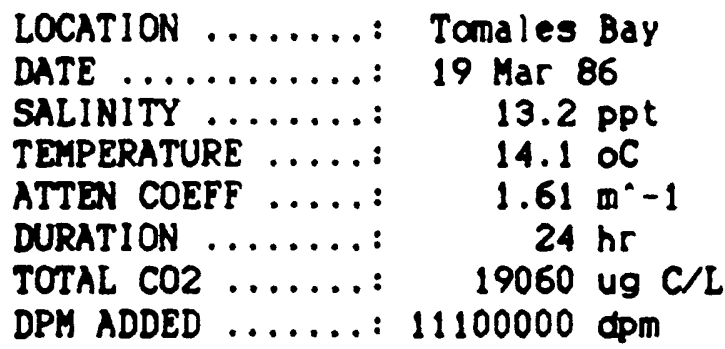

STATION

JULIAN DATE

CHLOROPHYLL ......:

SURFACE IRRAD ...:

PHOTIC DEPTH .....

INITIAL TIME .....

FINAL TIME .......

WATER DEPTH $\ldots .$. .
O w NH4 splke 86078

$.7 \mathrm{mg} / \mathrm{m}^{* 3}$

$40.22 \mathrm{E} / \mathrm{m}^{\wedge} 2 / \mathrm{d}$

2.86 m $1350 \mathrm{hr}$ $1350 \mathrm{hr}$

6 m

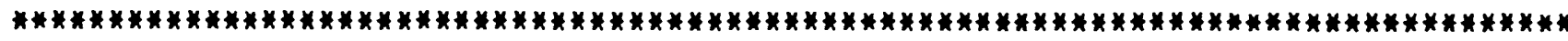

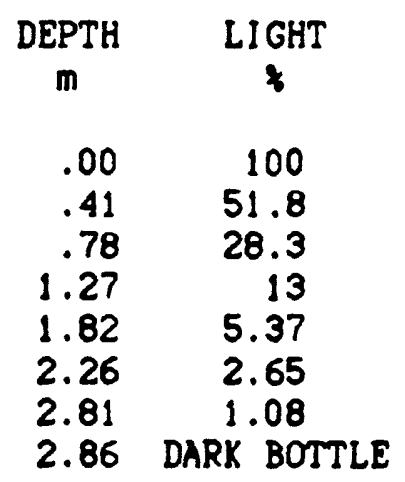

Uptake over photic zone water depth

photic zone water depth
CARBON UPTAKE corrected measured $\mathrm{mg} \mathrm{C} / \mathrm{L} / \mathrm{h} \operatorname{mg} \mathrm{C} / \mathrm{L} / \mathrm{h}$

$\begin{array}{rrr}33.97 & 36.09 & 48.52 \\ 36.80 & 38.93 & 52.57 \\ 27.62 & 29.75 & 39.46 \\ 14.42 & 16.55 & 20.60 \\ 5.70 & 7.83 & 8.14 \\ 3.04 & 5.17 & 4.35 \\ 1.47 & 3.60 & 2.10 \\ .00 & 2.13 & .00\end{array}$

$45.44 \mathrm{mg} \mathrm{C} / \mathrm{m}^{\wedge} 2 / \mathrm{h}$ 45.44

$1091 \mathrm{mg} \mathrm{C} / \mathrm{m}^{\wedge} 2 / \mathrm{d}$ 1091

\section{ASSIMILATION}

*
8.52
39.46
20.60
4.35
.00 
CARBON UPTAKE DATA SUMMARY

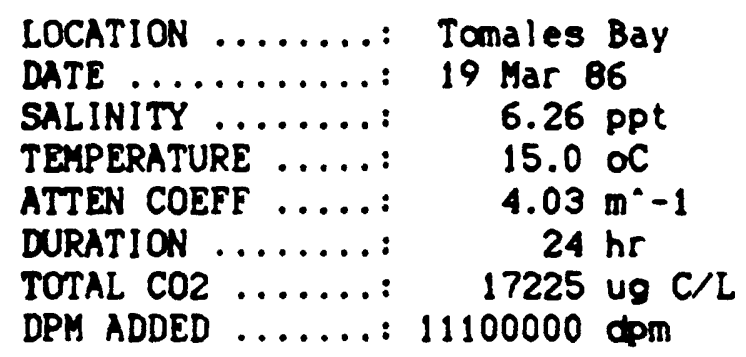

STATION .........

JULIAN DATE ......

16

CHLOROPHYLL $\ldots \ldots$ :

SURFACE IRRAD ...:

PHOTIC DEPTH $\ldots$...

INITIAL TIME $\ldots .$. :

86078

$8.1 \mathrm{mg} / \mathrm{m}^{\wedge} 3$

$40.22 \mathrm{E} / \mathrm{m}^{\wedge} 2 / d$

$1.14 \mathrm{~m}$

$1350 \mathrm{hr}$

FINAL TIME ......: $1350 \mathrm{hr}$

WATER DEPTH .....: $2 \mathrm{~m}$

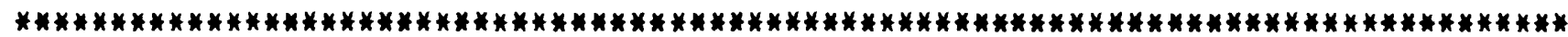

$\begin{array}{cc}\text { DEPTH } & \text { LIGHT } \\ \mathrm{m} & t \\ .00 & 100 \\ .14 & 56.8 \\ .28 & 32.3 \\ .44 & 16.7 \\ .59 & 9.38 \\ .76 & 4.73 \\ .92 & 2.48 \\ 1.14 & \text { DARK BOTTLE }\end{array}$

LIGHT
$\mathrm{E} / \mathrm{m}^{\star} 2 / d$

40.22

22.84

12.99

6.72

3.77

1.90

1.00

.04

CARBON UPTAKE
corrected measured ASSIMILATION
mg $\mathrm{C} / \mathrm{L} / \mathrm{h}$ mg C/L/h

5.98

6.47

.74

6.29

4.95

6.78

.78

2.36

5.44

.61

.34

2.85

.83

.33

.21

.49

.29

.04

$-.15$

$-.27$

.00

$-.02$

$-.03$

.00

\author{
Uptake over photic zone \\ water depth \\ photic zone \\ water depth
}
$2.39 \mathrm{mg} C / \mathrm{m}^{\wedge} 2 / \mathrm{h}$ 2.39
$57 \mathrm{mg} \mathrm{C} / \mathrm{m}^{\wedge} 2 / d$ 57


CARBON UPTAKE DATA SUMMARY

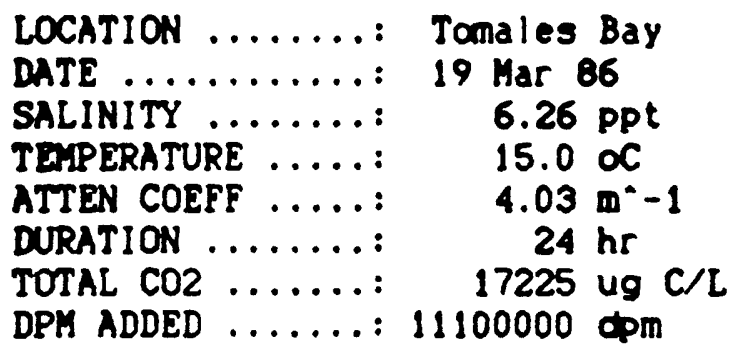

STATION $\ldots \ldots \ldots$ : 16 w NH4

JULIAN DATE .....: 86078

CHLOROPHYLL .....: $8.1 \mathrm{mg} / \mathrm{m}^{\wedge} 3$

SURFACE IRRAD ...: $40.22 \mathrm{E} / \mathrm{m}^{\wedge} 2 / \mathrm{d}$

PHOTIC DEPTH ....: $1.14 \mathrm{~m}$

INITIAL TIME ....: $1350 \mathrm{hr}$

PINAL TIME ...... $1350 \mathrm{hr}$

WATER DEPTH ....: $2 \mathrm{~m}$

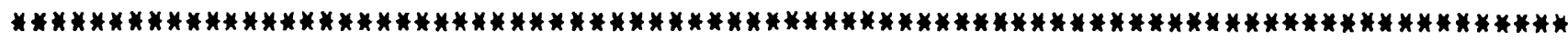

\begin{tabular}{|c|c|c|c|c|c|}
\hline $\begin{array}{l}\text { DEPTH } \\
\mathbf{m}\end{array}$ & $\begin{array}{c}\text { LIGHT } \\
t\end{array}$ & $\begin{array}{r}\text { LIGHT } \\
E / m^{*} 2 / d\end{array}$ & $\begin{array}{c}\text { CARBON } \\
\text { corrected } \\
m g \mathrm{C} / \mathrm{L} / \mathrm{h}\end{array}$ & $\begin{array}{l}\text { PTAKE } \\
\text { measured } \\
\text { mg } C / L / h\end{array}$ & ASSIMILATION \\
\hline $\begin{array}{l}.00 \\
.16 \\
.29 \\
.49 \\
.63 \\
.79 \\
1.02 \\
1.14\end{array}$ & $\begin{array}{r}100 \\
53.5 \\
30.7 \\
13.7 \\
7.83 \\
4.21 \\
1.64 \\
\text { DARK BOTTLE }\end{array}$ & $\begin{array}{r}40.22 \\
21.52 \\
12.35 \\
5.51 \\
3.15 \\
1.69 \\
.66 \\
.04\end{array}$ & $\begin{array}{l}6.25 \\
5.44 \\
5.20 \\
2.51 \\
.85 \\
.37 \\
.13 \\
.00\end{array}$ & $\begin{array}{r}6.37 \\
5.56 \\
5.32 \\
2.63 \\
.97 \\
.48 \\
.25 \\
.12\end{array}$ & $\begin{array}{l}.77 \\
.67 \\
.64 \\
.31 \\
.11 \\
.05 \\
.02 \\
.00\end{array}$ \\
\hline
\end{tabular}

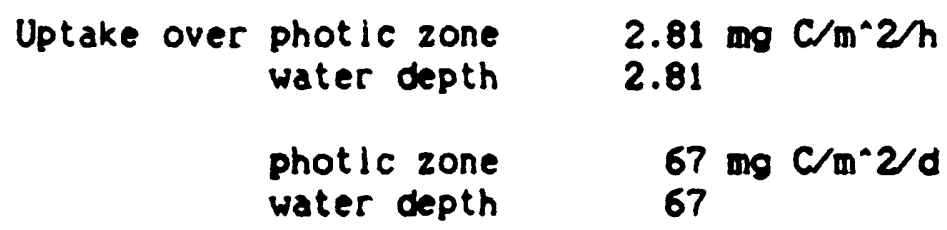


Appendix D.

Phytoplankton Identifications and Enumerations 
Species list for Tomales Bay phytoplankton samples

dinoflagellates:

?Cachonina niei

Ceratium lineatum

Dinophysis \# 1

Gymnodinium splendens

Gyrodinium \#1

?Katodinium \# 1

Prorocentrum micans

Prorocentrum redfieldii

Prorocentrum \#1

Protoperidinium \#1

diatoms:

Amphiprora spp.

Asterionella japonica

Bacteriastrum \#1

Chaetoceros curvisetus

Chaetoceros didymus

Chaetoceros socialis

Chaetoceros \#1

Chaetoceros \#2

Chaetoceros \#3

Chaetoceros \#4

Chaetoceros \#5

Chaetoceros \#8

Cocconeis spp.

Corethron hystrix

Coscinodiscus \# 1

Ditylum brightwelli

Eucampia zoodiacus

Leptocylindrus danicus

Licmophora spp.

silicoflagellates:

Distephanus speculum

Ebria tripartita

Mesocema \#1

miscellaneous:

?Chlamydomonas \# 1

chlorophyte

flagellate \#1

flagellate \#2

flagellate *3

flagellate \#4

?coccolithophorid

unknown (this could be a dinoflagellate or a ppt from the Lugols?)
Protoperidinium \#2

Protoperidinium \#4

Protoperidinium \#5

Protoperidinium \#6

Protoperidinium \#7

dinoflagellate \#3

dinoflagellate \#4

dinoflagellate \#5

dinoflagellate \#6

dinoflagellate \#7

Navicula spp.

Nitzschia closterium

Nitzschia longissima

Nitzchia seriata

Nitzschia spp.

Pleurosigma spp.

Rhizosolenia stolterfothii

Rhizosolenia ?styliformis

Skeletonema costatum

Thalassionema nitzchioides

Thalassiosira \#1

Thalassiosira \#2

centric \#1

centric \#2

centric \#3

pennate $C$

pennate $F$

pennate $\mathbf{G}$

pennate $H$ 
Illustrations of some phytoplankton not Identiflable

\section{Dinoflagellates}

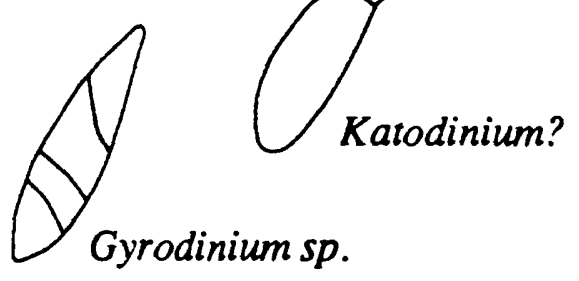

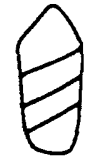

dinoflagellate \#3

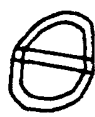

dinoflagellate \#5<smiles>C1C2CC1C2</smiles>

dinoflagellate \#7

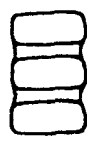

dinoflagellate \#4

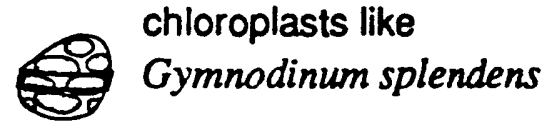

dinoflagellate \#6

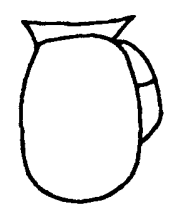

Dinophysis sp. (acuta?) 


\section{Protoperidinium}

$\# 1$

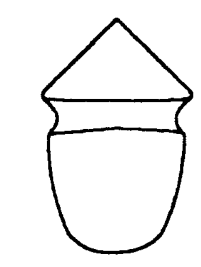

\#2

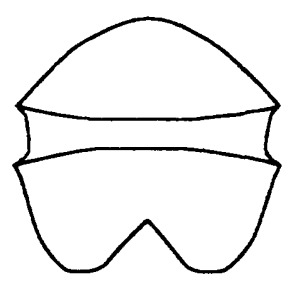

\#6

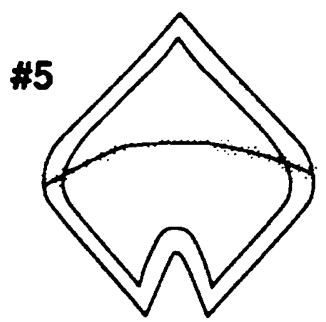

\#4

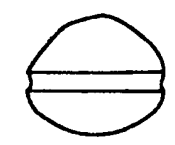

\#7

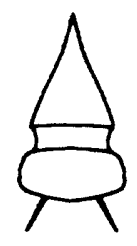


Flagellates
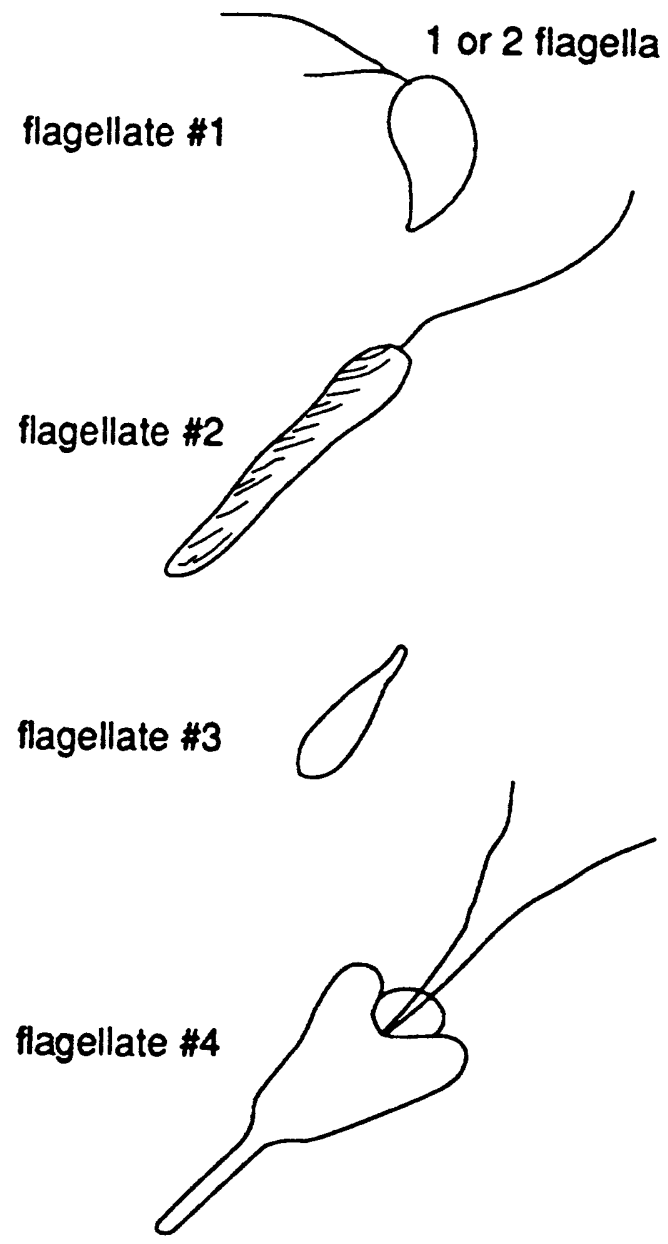

76 


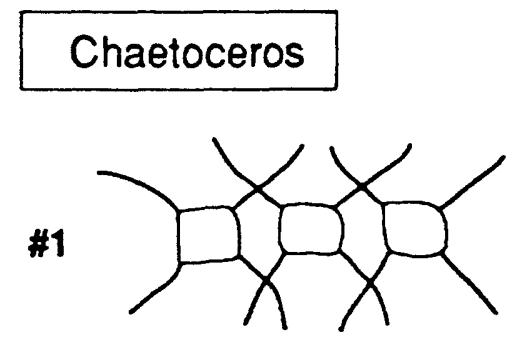

(ends may have stronger spines)

\#4

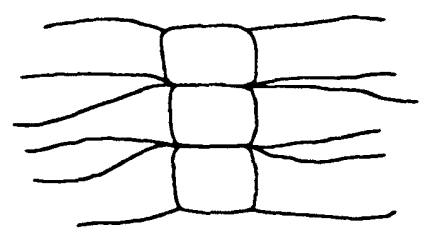

48

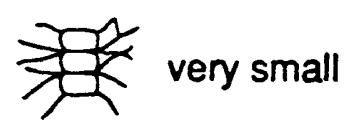

Pennate diatoms

C

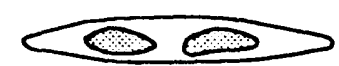

$F$ वक्णिक
\#2

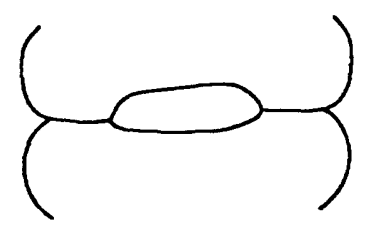

\#5

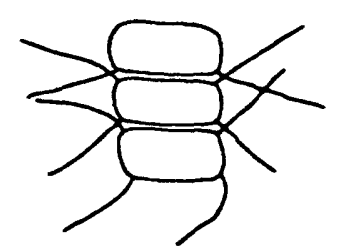

warped spines and chains 
March 11, 1985

\begin{tabular}{|c|c|c|c|}
\hline \multirow[b]{2}{*}{ species } & \multicolumn{3}{|c|}{$\frac{\text { cells/ml }}{\text { station number }}$} \\
\hline & 4 & 8 & 18 \\
\hline ?Cachonina niei & - & 44 & 161 \\
\hline Gymnodinium splendens & 23 & 2 & 36 \\
\hline Protoperidinium \# 1 & 41 & $\cdot$ & $\cdot$ \\
\hline Protoperidinium \#2 & 9 & - & • \\
\hline dinoflagellate \#6 & $\cdot$ & 3 & 6 \\
\hline Asterionella japonica & 9 & 5 & - \\
\hline Chaetoceros \#1 & 602 & 111 & 11 \\
\hline Chaetoceros \#2 & 109 & 26 & • \\
\hline Chaetoceros \#4 & 9 & - & - \\
\hline Cocconeis sp. & 1 & - & 1 \\
\hline Coscinodiscus \#1 & 15 & - & - \\
\hline Ditylum brightwelli & 2 & 1 & - \\
\hline Eucampia zoodiacus & - & 4 & - \\
\hline Leptocylindrus danicus & $\cdot$ & 43 & 24 \\
\hline Licmophora spp. & 8 & • & • \\
\hline Navicula spp. & 2 & 4 & 3 \\
\hline Nitzschia closterium & 8 & - & 11 \\
\hline Nitzchia seriata & 58 & 20 & - \\
\hline Pleurosigma spp. & - & 4 & 8 \\
\hline Rhizosolenia stolterfothii & 2 & - & - \\
\hline Skeletonema costatum & 208 & 16 & $\cdot$ \\
\hline Thalassionema nitzchioides & $\cdot$ & 4 & $\cdot$ \\
\hline Thalassiosira \#1 & 105 & 45 & 3 \\
\hline Thalassiosira \#2 & 17 & 3 & - \\
\hline centric \#1 & $\cdot$ & 2 & - \\
\hline centric \#3 & - & - & 3 \\
\hline pennate C & 24 & 52 & $\cdot$ \\
\hline chlorophyte & 64 & - & - \\
\hline flagellate \#1 & 2 & 5 & 2443 \\
\hline flagellate \#3 & - & 5 & • \\
\hline unknown & 67 & 68 & 64 \\
\hline
\end{tabular}

Note: The samples from stations \#8 and \#18 contained many aggregates of unidentifiable (uncountable) green particles which may be $\mu$-flagellates or possibly chloroplasts. Cells of flagellate \#1 also tended to clump together. 
April 17, 1985

\begin{tabular}{|c|c|c|c|}
\hline & \multicolumn{3}{|c|}{ cells/ml } \\
\hline species & 2 & 8 & 18 \\
\hline Gymnodinium splendens & - & $\cdot$ & 3 \\
\hline Protoperidınium \# 1 & 1 & - & - \\
\hline Amphiprora sp. & 1 & - & - \\
\hline Asterionella japonica & 150 & 476 & 35 \\
\hline Chaetoceros \#1 & 543 & 324 & 39 \\
\hline Chaetoceros \#2 & 26 & 58 & - \\
\hline Chaetoceros \#4 & 129 & 29 & - \\
\hline Leptocylindrus danicus & - & - & 10 \\
\hline Navicula spp. & 8 & 12 & - \\
\hline Nitzschia closterium & 58 & 6 & 6 \\
\hline Nitzchia seriata & 79 & 64 & - \\
\hline Nitzschia spp. & - & - & 6 \\
\hline Rhizosolenia ?styliformis & 1 & - & $\cdot$ \\
\hline Skeletonema costatum & 886 & 5210 & 1846 \\
\hline Thalassionema nitzchioides & 40 & 23 & • \\
\hline Thalassiosira \#1 & 13 & 12 & - \\
\hline Thalassiosira \#2 & 8 & - & - \\
\hline centric \#1 & 5 & 29 & - \\
\hline pennate C & 24 & 46 & 19 \\
\hline pennate $F$ & 16 & 29 & - \\
\hline Distephanus speculum & 1 & - & - \\
\hline flagellate \#1 & 21 & - & - \\
\hline unknown & 108 & 145 & 36 \\
\hline
\end{tabular}

Note: Skeletonema from station \# 18 at small end of size range and did not look very healthy. 
June 11.1985

cells/ml

\begin{tabular}{|c|c|c|c|}
\hline & \multicolumn{3}{|c|}{ station number } \\
\hline species & 2 & 8 & 16 \\
\hline Gymnodinium splendens & - & 3 & 2 \\
\hline Gyrodinium \# 1 & - & 3 & - \\
\hline Prorocentrum redfieldii & - & 6 & - \\
\hline Prorocentrum \# 1 & - & 131 & - \\
\hline Protoperidinium \# 1 & 12 & 6 & - \\
\hline Protoperidinium \#2 & 1 & - & - \\
\hline Protoperidinium \#7 & - & 4 & - \\
\hline Asterionella japonica & 95 & 11 & - \\
\hline Chaetoceros socialis & 932 & • & - \\
\hline Chaetoceros \#1 & 408 & 29 & - \\
\hline Chaetoceros \#2 & 58 & 4 & - \\
\hline Chaetoceros \#4 & 89 & 10 & - \\
\hline Corethron hystrix & - & 1 & - \\
\hline Navicula spp. & 6 & 4 & 4 \\
\hline Nitzschia closterium & 21 & 10 & - \\
\hline Nitzschia longissima & $\cdot$ & - & 1 \\
\hline Nitzchia seriata & 19 & - & - \\
\hline Rhizosolenia ?styliformis & - & 1 & - \\
\hline Skeletonema costatum & 429 & 2173 & - \\
\hline Thalassiosira \#1 & 54 & 9 & - \\
\hline centric \#1 & 91 & 96 & - \\
\hline pennate C & $\bullet$ & 7 & - \\
\hline pennate $\mathrm{F}$ & 8 & - & 1 \\
\hline flagellate \#1 & 31 & - & 187 \\
\hline flagellate \#3 & & 2 & 1 \\
\hline unknown & 100 & 84 & 68 \\
\hline
\end{tabular}


August 21. 1985

\begin{tabular}{|c|c|c|c|}
\hline \multirow[b]{2}{*}{ species } & \multicolumn{3}{|c|}{ cells/ml } \\
\hline & 2 & 8 & 16 \\
\hline Ceratium lineatum & 13 & 1 & 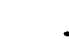 \\
\hline Dinophysis \# 1 & 5 & 5 & . \\
\hline Gymnodinium splendens & 64 & 409 & . \\
\hline ?Katodinium \#1 & 6 & 3 & . \\
\hline Prorocentrum redfieldii & 9 & 3 & . \\
\hline Prorocentrum \#1 & 8 & 5 & . \\
\hline Protoperidinium \# 1 & 4 & • & . \\
\hline Protoperidinium \#4 & 13 & 2 & . \\
\hline Protoperidinium \#5 & 4 & . & . \\
\hline Amphiprora sp. & 1 & $\cdot$ & . \\
\hline Asterionella japonica & 2 & - & . \\
\hline Chaetoceros \#1 & 67 & - & . \\
\hline Chaetoceros \#4 & 3 & • & . \\
\hline Chaetoceros \#5 & 115 & 19 & - \\
\hline Eucampia zoodiacus & 2 & - & - \\
\hline Leptocylindrus danicus & 12 & • & . \\
\hline Navicula spp. & 5 & 2 & 1 \\
\hline Nitzschia closterium & 12 & 4 & . \\
\hline Nitzchia seriata & 16 & - & . \\
\hline Pleurosigma spp. & 1 & 4 & • \\
\hline Rhizosolenia stolterfothii & 13 & 7 & - \\
\hline Thalassiosira \# 1 & 5 & 2 & - \\
\hline centric \#1 & - & 1 & • \\
\hline centric \#2 & - & 4 & - \\
\hline pennate C & 23 & 3 & - \\
\hline pennate $\mathbf{F}$ & 1 & 2 & - \\
\hline pennate $\mathbf{G}$ & - & 3 & - \\
\hline Mesocema \#1 & - & 2 & - \\
\hline flagellate \#1 & 1 & 7 & 224 \\
\hline unknown & 82 & 59 & 72 \\
\hline
\end{tabular}


September 30. 1985

cells $/ \mathrm{ml}$

\begin{tabular}{|c|c|c|c|}
\hline \multicolumn{4}{|c|}{ station numbe } \\
\hline species & 2 & 8 & 16 \\
\hline Ceratium lineatum & 2 & - & \\
\hline Dinophysis \#1 & 1 & 1 & \\
\hline Gymnodinium splendens & 2 & 25 & 16 \\
\hline Gyrodinium \#1 & - & 1 & \\
\hline Prorocentrum micans & - & 1 & \\
\hline Prorocentrum redfieldii & • & 4 & \\
\hline Protoperidinium \# I & - & 1 & \\
\hline Protoperidinium \#4 & 1 & - & 1 \\
\hline Protoperidinium \#5 & 1 & - & - \\
\hline Protoperidinium \#6 & 1 & - & - \\
\hline dinoflagellate \#3 & 15 & 131 & \\
\hline dinoflagellate \#6 & - & 16 & \\
\hline Chaetoceros \#2 & 2 & - & \\
\hline Navicula sp. & 1 & - & \\
\hline Nitzschia closterium & 10 & 26 & 1 \\
\hline Nitzchia seriata & 2 & - & \\
\hline Pleurosigma sp. & 1 & • & - \\
\hline centric \#1 & 2 & 1 & • \\
\hline pennate C & 2 & 9 & - \\
\hline pennate $F$ & 1 & 1 & - \\
\hline Mesocema \#1 & 1 & 1 & \\
\hline flagellate \# 1 & 26 & 58 & 42 \\
\hline flagellate \#4 & • & 10 & \\
\hline unknown & 53 & 76 & 64 \\
\hline
\end{tabular}


December 4. 1985

cells $/ \mathrm{ml}$

\begin{tabular}{|c|c|c|c|}
\hline & \multicolumn{3}{|c|}{ station number } \\
\hline species & 2 & 8 & 18 \\
\hline Ceratium lineatum & - & 1 & \\
\hline Dinophysis \#1 & $\cdot$ & 1 & \\
\hline Gymnodinium splendens & - & 3 & \\
\hline Gyrodinium \#1 & 5 & - & \\
\hline Prorocentrum redfieldii & $\cdot$ & 1 & 1 \\
\hline Prorocentrum \#1 & 1 & - & \\
\hline Protoperidinium \#1 & 1 & 1 & \\
\hline Protoperidinium \#4 & 1 & - & \\
\hline Protoperidinium \#6 & $\cdot$ & 1 & \\
\hline Protoperidinium \#7 & 1 & - & \\
\hline dinoflagellate \#4 & 5 & 14 & \\
\hline dinoflagellate \#5 & 11 & 21 & \\
\hline Chae & 2 & - & \\
\hline Eucampia zoodiacus & 1 & - & \\
\hline Navicula sp. & 1 & - & \\
\hline Nitzschia closterium & 2 & 3 & \\
\hline Skeletonema costatum & 3 & - & \\
\hline Thalassiosira \#2 & 1 & - & \\
\hline pennate $\mathrm{H}$ & - & 1 & \\
\hline ?Chlamydomonas \# 1 & 14 & 30 & \\
\hline flagellate \# 1 & 43 & 215 & 998 \\
\hline flagellate \#2 & 1 & - & \\
\hline flagellate \#4 & 3 & 1 & \\
\hline ?coccolithophorid & - & 3 & \\
\hline unknown & 57 & 52 & 33 \\
\hline
\end{tabular}


March 19, 1986

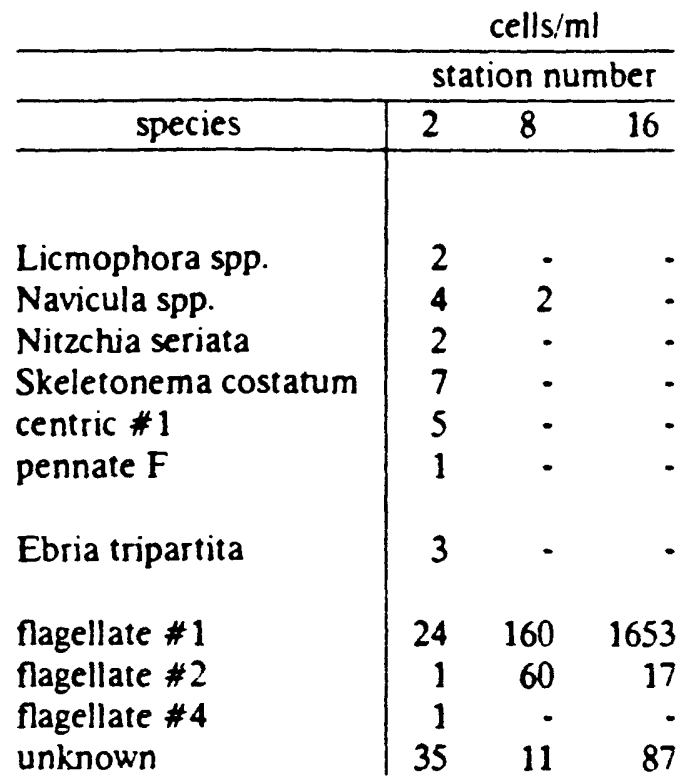

Note: Sample from station \#16 contained a high concentration of particulate material. 
April 16, 1986

cell $\mathrm{s} / \mathrm{ml}$

\begin{tabular}{|c|c|c|c|}
\hline & \multicolumn{3}{|c|}{ station number } \\
\hline species & 2 & 8 & 16 \\
\hline Gymnodinium splendens & - & - & 1 \\
\hline Prorocentrum \#1 & - & 54 & • \\
\hline Protoperidinium $\# 5$ & 3 & - & . \\
\hline Protoperidinium \#6 & - & - & 4 \\
\hline Protoperidinium \#7 & - & - & 1 \\
\hline dinoflagellate $\# 5$ & - & 4 & 4 \\
\hline dinoflagellate \#6 & - & - & 13 \\
\hline dinoflagellate \#7 & - & - & 116 \\
\hline Asterionella japonica & 93 & 113 & 1 \\
\hline Bacteriastrum \#1 & - & - & 3 \\
\hline Chaetoceros curvisetus & 1351 & 2668 & 137 \\
\hline Chaetoceros didymus & 806 & 2886 & - \\
\hline Chaetoceros \#1 & 9 & - & - \\
\hline Chaetoceros \#5 & - & - & 9 \\
\hline Chaetoceros \#8 & - & - & 12 \\
\hline Navicula spp. & 10 & - & 1 \\
\hline Nitzschia longissima & - & - & 9 \\
\hline Nitzchia seriata & - & 1 & - \\
\hline Rhizosolenia ?styliformis & 1 & - & $\cdot$ \\
\hline Skeletonema costatum & 22 & 145 & 6 \\
\hline Thalassionema nitzchioides & 4 & - & $\cdot$ \\
\hline Thalassiosira \#1 & - & - & 1 \\
\hline centric \#1 & - & - & 3 \\
\hline Ebria tripartita & - & 1 & - \\
\hline flagellate \#1 & 16 & 10 & 309 \\
\hline flagellate \#2 & - & - & 11 \\
\hline unknown & 63 & 79 & 42 \\
\hline
\end{tabular}

Note: Sample from station \#16 contained a large amount of particulate material - especially difficult to distinguish organisms. 
Appendix E.

Bacterioplankton Abundance and Productivity 
BACTERIA ABUNDANCE AND PRODUCTIVITY

\begin{tabular}{|c|c|c|c|c|c|c|}
\hline DATE & STA & $\begin{array}{c}\text { DEPTH } \\
\text { m }\end{array}$ & $\begin{array}{l}\text { THYMIDINE } \\
\text { UPTAKE } \\
\text { P Mole/h }\end{array}$ & $\begin{array}{l}\text { LABEL IN } \\
\text { DNA + RNA } \\
\end{array}$ & $\begin{array}{l}\text { BACTERIA } \\
\text { DENSITY } \\
10^{\wedge} 6 / \mathrm{mL}\end{array}$ & $\begin{array}{l}\text { BLUE-GREEN } \\
\text { DENSITY } \\
10^{\wedge} 5 / \mathrm{mL}\end{array}$ \\
\hline 11 MAR 85 & $\begin{array}{r}0 \\
2 \\
4 \\
6 \\
8 \\
10 \\
12 \\
12 \\
14 \\
16 \\
18\end{array}$ & $\begin{array}{l}0 \\
0 \\
0 \\
0 \\
0 \\
0 \\
0 \\
5 \\
0 \\
0 \\
0\end{array}$ & 47.8 & & $\begin{array}{l}1.5 \\
1.4 \\
1.4 \\
1.1 \\
1.2 \\
1.2 \\
1.8 \\
1.0 \\
1.6 \\
2.4 \\
2.7\end{array}$ & $\begin{array}{r}9.4 \\
.0 \\
9.4 \\
2.4 \\
.0 \\
.0 \\
.0 \\
.0 \\
2.4 \\
.0 \\
.0\end{array}$ \\
\hline 27 MAR 85 & $\begin{array}{r}2 \\
8 \\
8 \\
10 \\
12 \\
14 \\
14 \\
16 \\
16 \\
18\end{array}$ & $\begin{array}{l}0 \\
0 \\
8 \\
0 \\
0 \\
0 \\
3.3 \\
0 \\
2 \\
0\end{array}$ & $\begin{array}{r}23.7 \\
17.9 \\
5.9 \\
24.6 \\
18.9 \\
15.1 \\
13.2 \\
30.1 \\
4.3 \\
8.9\end{array}$ & 42 & $\begin{array}{l}1.3 \\
1.2 \\
2.2 \\
1.5 \\
2.1 \\
2.3 \\
2.1 \\
3.5 \\
1.7 \\
3.4\end{array}$ & $\begin{array}{r}4.7 \\
.0 \\
4.7 \\
.0 \\
2.4 \\
.0 \\
.0 \\
.0 \\
.0 \\
2.4\end{array}$ \\
\hline 8 APR 85 & $\begin{array}{r}0 \\
2 \\
4 \\
6 \\
8 \\
8 \\
10 \\
12 \\
12 \\
14 \\
16 \\
18\end{array}$ & $\begin{array}{r}0 \\
0 \\
0 \\
0 \\
0 \\
5.5 \\
0 \\
0 \\
5 \\
0 \\
0 \\
0\end{array}$ & $\begin{array}{r}161.5 \\
124.0 \\
127.5 \\
95.9\end{array}$ & $\begin{array}{r}70 \\
\\
54 \\
48.4 \\
36.5\end{array}$ & $\begin{array}{r}3.0 \\
2.9 \\
3.4 \\
4.8 \\
18.2 \\
2.8 \\
4.8 \\
6.1 \\
4.6 \\
6.0 \\
6.2 \\
5.3\end{array}$ & $\begin{array}{r}9.0 \\
12.5 \\
3.9 \\
4.7 \\
.0 \\
7.4 \\
.0 \\
2.4 \\
2.4 \\
.0 \\
.0 \\
.0\end{array}$ \\
\hline 17 APR 85 & $\begin{array}{r}0 \\
4 \\
6 \\
8 \\
8 \\
14 \\
14 \\
18\end{array}$ & $\begin{array}{l}0 \\
0 \\
0 \\
0 \\
5 \\
0 \\
4 \\
0\end{array}$ & $\begin{array}{r}112.0 \\
106.4 \\
71.6 \\
37.5 \\
22.6 \\
18.2 \\
13.5 \\
34.2\end{array}$ & & & \\
\hline
\end{tabular}




\section{BACTERIA ABUNDANCE AND PRODUCTIVITY}

\begin{tabular}{|c|c|c|c|c|c|c|}
\hline DATE & STA & $\underset{\mathrm{m}}{\text { DEPTH }}$ & $\begin{array}{l}\text { THYMIDINE } \\
\text { UPTAKE } \\
\text { P Mole } / \mathrm{h}\end{array}$ & $\begin{array}{c}\text { LABEL IN } \\
\text { DNA + RNA } \\
t\end{array}$ & $\begin{array}{l}\text { BACTERIA } \\
\text { DENSITY } \\
10^{\circ} 6 / \mathrm{mL}\end{array}$ & $\begin{array}{l}\text { BLUE-GREEN } \\
\text { DENSITY } \\
10^{\circ} 5 / \mathrm{mL}\end{array}$ \\
\hline 17 MAY 85 & $\begin{array}{r}0 \\
2 \\
4 \\
6 \\
8 \\
8 \\
8 \\
12 \\
16 \\
18\end{array}$ & $\begin{array}{c}0 \\
0 \\
0 \\
0 \\
0 \\
7.5 \\
0 \\
0 \\
0\end{array}$ & $\begin{array}{l}8.2 \\
9.8\end{array}$ & $\begin{array}{l}83 \\
83\end{array}$ & $\begin{array}{r}2.9 \\
5.6 \\
2.2 \\
5.9 \\
7.0 \\
4.8 \\
11.6 \\
7.6 \\
9.2\end{array}$ & \\
\hline 11 JUN 85 & $\begin{array}{r}0 \\
8 \\
8 \\
12 \\
12 \\
14 \\
18\end{array}$ & $\begin{array}{l}0 \\
0 \\
6 \\
0 \\
5 \\
0 \\
0\end{array}$ & $\begin{array}{r}88.6 \\
63.0 \\
2.0 \\
74.7 \\
4.0 \\
42.9 \\
41.8\end{array}$ & $\begin{array}{r}95 \\
91 \\
94 \\
94 \\
114 \\
88 \\
88\end{array}$ & & \\
\hline 16 JUL 85 & $\begin{array}{r}0 \\
6 \\
8 \\
8 \\
10 \\
10 \\
12 \\
12 \\
14 \\
14 \\
18\end{array}$ & $\begin{array}{l}0 \\
0 \\
0 \\
6 \\
0 \\
6 \\
0 \\
6 \\
0 \\
4 \\
0\end{array}$ & $\begin{array}{r}119.0 \\
122.0 \\
121.0 \\
19.0 \\
97.0 \\
35.0 \\
117.0 \\
37.0 \\
152.0 \\
31.0 \\
131.0\end{array}$ & $\begin{array}{l}91 \\
85 \\
94 \\
96 \\
84 \\
93 \\
88 \\
92 \\
85 \\
85\end{array}$ & & \\
\hline 21 AUG 85 & $\begin{array}{r}2 \\
8 \\
12 \\
12 \\
14 \\
16\end{array}$ & $\begin{array}{r}0 \\
0 \\
0 \\
5.5 \\
0 \\
0\end{array}$ & $\begin{array}{r}91.6 \\
134.0 \\
60.2 \\
85.7 \\
151.0 \\
86.0\end{array}$ & $\begin{array}{r}92 \\
102 \\
96 \\
99 \\
91 \\
87\end{array}$ & & \\
\hline
\end{tabular}


BACTERIA ABUNDANCE AND PRODUCTIVITY

\begin{tabular}{|c|c|c|c|c|c|c|}
\hline DATE & STA & $\begin{array}{c}\text { DEPTH } \\
\text { m }\end{array}$ & $\begin{array}{l}\text { THYMIDINE } \\
\text { UPTAKE } \\
\text { P Mole/h }\end{array}$ & $\begin{array}{c}\text { LABEL IN } \\
\text { DNA + RNA } \\
t\end{array}$ & $\begin{array}{l}\text { BACTERIA } \\
\text { DENSITY } \\
10^{\circ} 6 / \mathrm{mL}\end{array}$ & $\begin{array}{l}\text { STANDARD } \\
\text { ERROR } \\
(n=3)\end{array}$ \\
\hline 3 OCT 85 & $\begin{array}{r}0 \\
2 \\
4 \\
6 \\
8 \\
10 \\
12 \\
14 \\
16 \\
18\end{array}$ & $\begin{array}{l}0 \\
0 \\
0 \\
0 \\
0 \\
0 \\
0 \\
0 \\
0 \\
0\end{array}$ & $\begin{array}{l}46.0 \\
60.0 \\
59.0 \\
62.0 \\
51.0 \\
50.0 \\
58.0 \\
64.0 \\
58.0 \\
74.0\end{array}$ & $\begin{array}{l}95 \\
95 \\
95 \\
94 \\
94 \\
91 \\
93 \\
93 \\
93 \\
93\end{array}$ & $\begin{array}{l}1.3 \\
1.6 \\
2.2 \\
2.3 \\
3.3 \\
5.6 \\
5.3 \\
6.2 \\
8.5 \\
7.0\end{array}$ & $\begin{array}{l}.055 \\
.046 \\
.091 \\
.080 \\
.104 \\
.084 \\
.213 \\
.23 \\
.38 \\
.38\end{array}$ \\
\hline $4 \mathrm{DEC} 85$ & $\begin{array}{r}0 \\
2 \\
4 \\
6 \\
8 \\
8 \\
10 \\
12 \\
12 \\
14 \\
16 \\
18\end{array}$ & $\begin{array}{l}0 \\
0 \\
0 \\
0 \\
0 \\
0 \\
0 \\
0 \\
0 \\
8 \\
0\end{array}$ & $\begin{array}{l}44.3 \\
45.5 \\
54.1 \\
50.3 \\
51.8 \\
35.0 \\
48.2 \\
42.6 \\
32.1 \\
37.6 \\
34.4 \\
56.8\end{array}$ & $\begin{array}{l}66 \\
59 \\
64 \\
66 \\
61 \\
63 \\
64 \\
63 \\
63 \\
64 \\
63 \\
72\end{array}$ & & \\
\hline
\end{tabular}




\section{BACTERIA PRODUCTIVITY}

\begin{tabular}{ccccr} 
DATE & STA & $\begin{array}{c}\text { DEPTH } \\
\text { m }\end{array}$ & $\begin{array}{c}\text { THYMIDINE } \\
\text { UPTAIE } \\
\text { p Mole/h }\end{array}$ & $\begin{array}{c}\text { STANDARD } \\
\text { ERROR } \\
\text { (n }=3\end{array}$ \\
\hline 19 MAR 86 & 0 & 0 & 112.0 & 2.7 \\
& 2 & 0 & 161.0 & 2.3 \\
& 4 & 0 & 159.0 & 1.6 \\
& 6 & 0 & 138.0 & 1.2 \\
& 8 & 0 & 130.0 & 5.6 \\
& 10 & 0 & 138.0 & 7.8 \\
& 10 & 6 & 7.2 & .3 \\
& 12 & 0 & 153.0 & 2.5 \\
& 14 & 0 & 124.0 & 1.5 \\
& 14 & 4 & 76.0 & 10.1 \\
& 16 & 0 & 89.0 & 2.6 \\
18 & 0 & 59.1 & 1.9
\end{tabular}

16 APR 86

$\begin{array}{rrrr}0 & 0 & 64.7 & 7.5 \\ 2 & 0 & 71.3 & 1.2 \\ 4 & 0 & 79.7 & 3.1 \\ 6 & 0 & 63.3 & 2.9 \\ 8 & 0 & 69.0 & 1.7 \\ 10 & 0 & 53.3 & .6 \\ 10 & 6 & 50.0 & 3.6 \\ 12 & 0 & 56.0 & 5.2 \\ 14 & 0 & 55.0 & 1.7 \\ 14 & 3.5 & 52.0 & 2.0 \\ 16 & 0 & 60.0 & 1.0 \\ 18 & 0 & 84.3 & 2.1\end{array}$

